Nuclear Engineering

Division

Nuclear Engineering

Division

Nuclear Engineering

Division

Nuclear Engineering

Division

Nuclear Engineering Division

Nuclear Engineering Division

Nuclear Engineering

Division

Nuclear Engineering

by

Division

Nuclear Engineering

\title{
APPLICATION OF HIGH POWERED LASERS TO DRILLING AND COMPLETING DEEP WELLS
}

C.B. Reed, Z. Xu, R.A. Parker, B.C. Gahan, S. Batarseh

R.M. Graves, H. Figueroa, W. Deeg

Nuclear Engineering Division

Nuclear Engineering

Division

Nuclear Engineering

Division

Nuclear Engineering

Division

Nuclear Engineering

Division

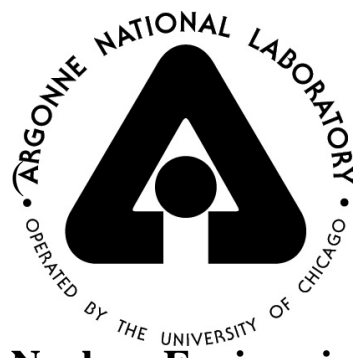

Argonne National Laboratory, Argonne, Illinois 60439

Operated by The University of Chicago for the

United States Department of Energy under Contracts W-31-109-Eng-38

Nuclear Engineering

Division

Nuclear Engineering

Division

Nuclear Engineering

Division

Nuclear Engineering

Division

Nuclear Engineering

Division

Nuclear Engineering

Division

Nuclear Engineering

Division

Nuclear Engineering 


\title{
APPLICATION OF HIGH POWERED LASERS TO DRILLING AND COMPLETING DEEP WELLS
}

\author{
C. B. Reed and Z. Xu \\ Nuclear Engineering Division, Argonne National Laboratory \\ R. A. Parker \\ Parker Geoscience Consulting, LLC \\ B. C. Gahan, and S. Batarseh \\ Gas Technology Institute, Des Plaines, IL 60018, \\ R. M. Graves \\ Department of Petroleum Engineering, Colorado School of Mines, Golden, \\ Colorado 80401. \\ H. Figueroa \\ Petroleos de Venezuela INTEVEP, S.A., Caracas 1070A, Venezuela \\ W. Deeg \\ Halliburton Energy Service
}

JUNE, 2003 
Argonne National Laboratory, with facilities in the states of Illinois and Idaho, is owned by the United States Government and operated by The University of Chicago under the provisions of a contract with the Department of Energy.

\section{DISCLAIMER}

This report was prepared as an account of work sponsored by an agency of the United States Government. Neither the United States Government nor any agency thereof, nor The University of Chicago, nor any of their employees or officers, makes any warranty, express or implied, or assumes any legal liability or responsibility for the accuracy, completeness, or usefulness of any information, apparatus, product, or process disclosed, or represents that its use would not infringe privately owned rights. Reference herein to any specific commercial product, process, or service by trade name, trademark, manufacturer, or otherwise, does not necessarily constitute or imply its endorsement, recommendation, or favoring by the United States Government or any agency thereof. The views and opinions of document authors expressed herein do not necessarily state or reflect those of the United States Government or any agency thereof, Argonne National Laboratory, or The University of Chicago.

Available electronically at http://www.doe.gov/bridge

Available for a processing fee to U.S. Department of Energy and its contractors, in paper, from:

U.S. Department of Energy

Office of Scientific and Technical Information

P.O. Box 62

Oak Ridge, TN 37831-0062

phone: (865) 576-8401

fax: (865) 576-5728

email: reports@adonis.osti.gov 


\section{Table of Contents}

\begin{tabular}{|c|c|}
\hline Executive Summary & \\
\hline Introduction & 1.1 \\
\hline GRI/CSM 1997-2001. & 1.1 \\
\hline GTI/DOE, 2001 . & 1.1 \\
\hline Current Studies & 1.1 \\
\hline Goals and Objectives for 2002 .. & 1.1 \\
\hline Multiple Spot hole. & 1.1 \\
\hline Test Goals . & 1.2 \\
\hline Pertinent Questions .... & 1.2 \\
\hline Lasing Under Water........... & 1.2 \\
\hline Test Goal........................ & 1.2 \\
\hline Pertinent Questions ........ & 1.2 \\
\hline Perforation Simulation.... & 1.2 \\
\hline Test Goal................ & 1.2 \\
\hline Pertinent Questions ......... & 1.3 \\
\hline 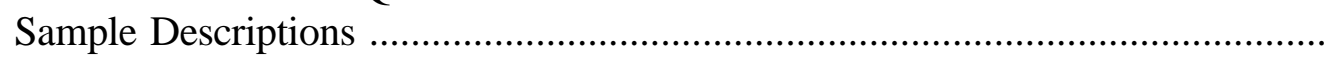 & 1.3 \\
\hline Representative Lithologies........... & 1.3 \\
\hline Sample Preparation... & 1.3 \\
\hline Lasers used in Tests .......... & 1.3 \\
\hline 1.6kW Pulsed Nd:YAG Laser.... & 1.3 \\
\hline The $\mathrm{CO}_{2}$ Laser.............................. & 1.4 \\
\hline Mechanical Sample Stages ........................ & 1.4 \\
\hline Test Plans & 1.5 \\
\hline 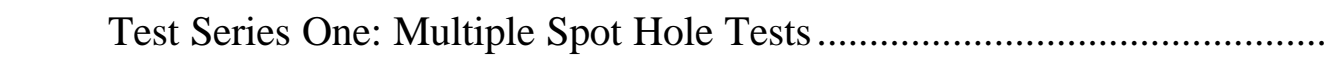 & 1.5 \\
\hline Test Series Two: Laser Testing of Rock Samples in Liquid ...................... & 1.7 \\
\hline Test Series Three: Demonstrating the Possibilities for Perforating ............ & 1.8 \\
\hline Test Series Four: Wavelength Comparisons within the Infrared Spectrum & 1.8 \\
\hline 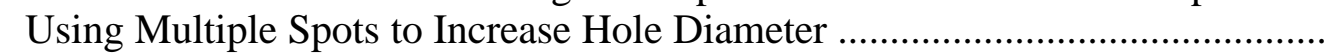 & 2.1 \\
\hline 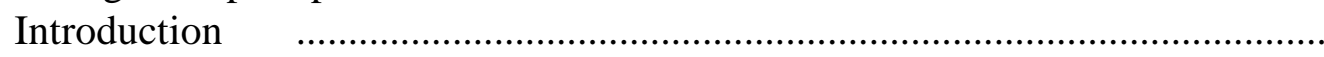 & 2.1 \\
\hline Goals & 2.1 \\
\hline Equipment Setup .... & 2.1 \\
\hline Data Reporting ........ & 2.3 \\
\hline One Spot Repeated Tests & 2.3 \\
\hline Goal................... & 2.3 \\
\hline Test Procedure-Nd:YAG..... & 2.3 \\
\hline 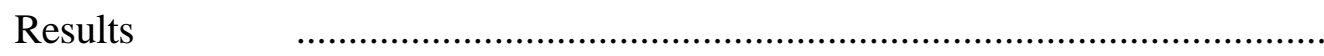 & 2.3 \\
\hline Sandstone & 2.3 \\
\hline 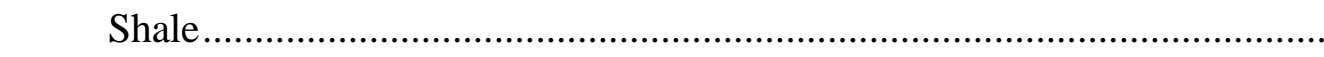 & 2.6 \\
\hline Limestone............................. & 2.6 \\
\hline Multiple Spot Repeated Tests .. & 2.7 \\
\hline 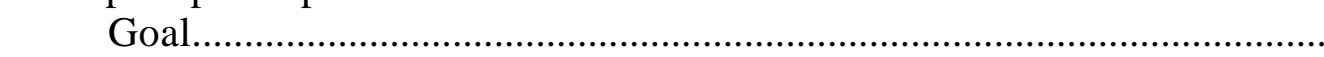 & 2.7 \\
\hline . & 2.8 \\
\hline Qualitative Observations during Testing ......... & 2.8 \\
\hline
\end{tabular}




\begin{tabular}{|c|c|}
\hline \multicolumn{2}{|l|}{ Rest } \\
\hline \multicolumn{2}{|r|}{2.8} \\
\hline Sandsto & 2.8 \\
\hline Shale. & 2.9 \\
\hline Limestone... & 2.10 \\
\hline $\mathrm{CO}_{2} \ldots \ldots \ldots \ldots$ & 2.10 \\
\hline Sandstone & 2.10 \\
\hline Limestone. & 2.11 \\
\hline Conclusions \& Recommendations ............ & 2.12 \\
\hline 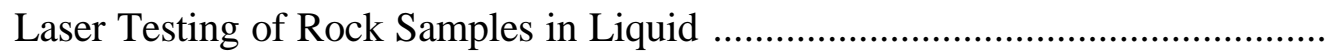 & 3.1 \\
\hline Introduction & 3.1 \\
\hline quipment Setup .. & 3.1 \\
\hline Test Procedures & 3.1 \\
\hline Free water above submerged rock ....... & 3.1 \\
\hline Cross w & 3.3 \\
\hline 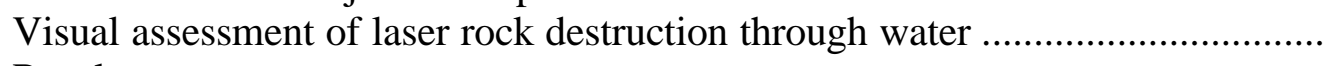 & 3.3 \\
\hline Results & \\
\hline 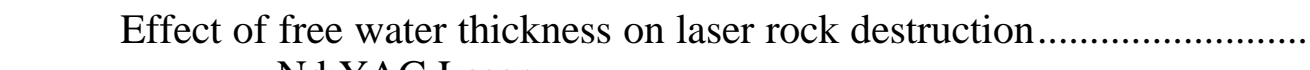 & 3.4 \\
\hline 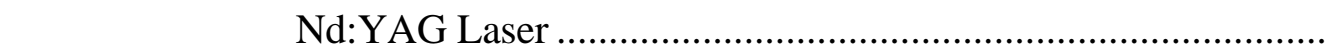 & 3.4 \\
\hline $\mathrm{CO}_{2}$ laser & 3.5 \\
\hline Effect of flowing water over rock surface on laser rock destruction......... & 3.6 \\
\hline Nd:YAG Laser .. & 3.6 \\
\hline $\mathrm{CO}_{2}$ Laser ..................... & 3.6 \\
\hline Attenuation of Laser Energy & 3.9 \\
\hline 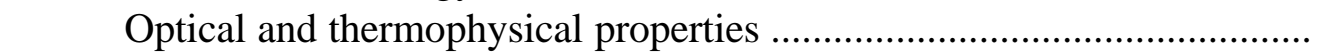 & 3.9 \\
\hline 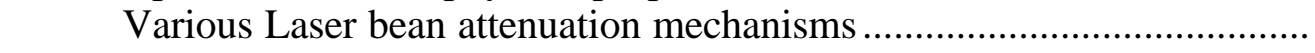 & 3.10 \\
\hline 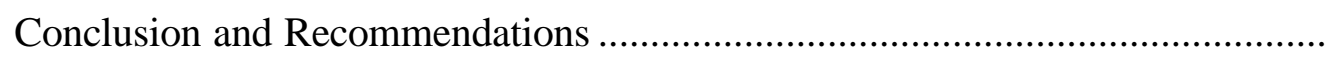 & 3.10 \\
\hline Applications of High Power Lasers to Perforated Completions ................................ & 4.1 \\
\hline Introduction & 4.1 \\
\hline \multirow{2}{*}{$\begin{array}{l}\text { Test Results } \\
\text { Method One: Fixed Beam }\end{array}$} & 4.1 \\
\hline & 4.1 \\
\hline $\begin{array}{l}\text { Method One: Fixed Beam } \\
\text { Several Lessons }\end{array}$ & 4.2 \\
\hline Method Two: Circular Motion beam …………………………….... & 4.3 \\
\hline 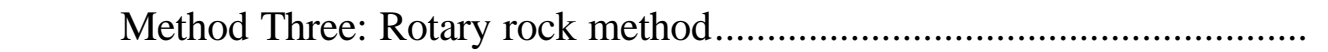 & 4.4 \\
\hline 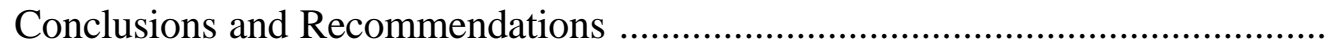 & 4.6 \\
\hline 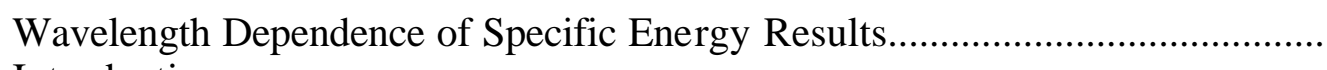 & 5.1 \\
\hline Introduction & 5.1 \\
\hline 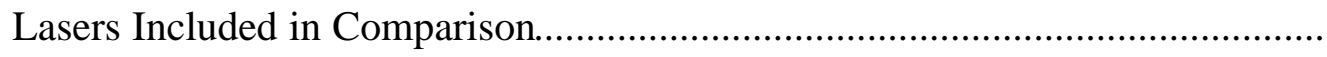 & 5.1 \\
\hline 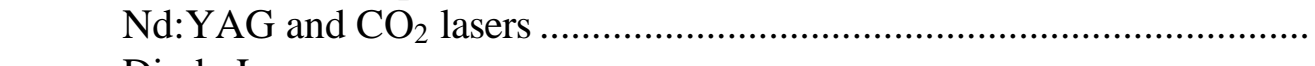 & 5.1 \\
\hline \multirow{2}{*}{ 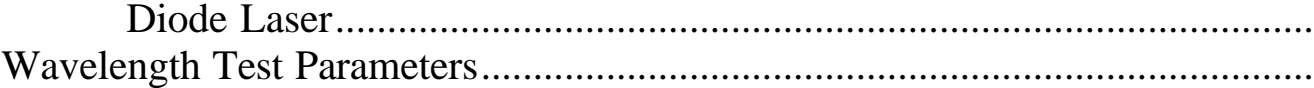 } & 5.1 \\
\hline & 5.1 \\
\hline Equipment Setup & 5.1 \\
\hline Results & 5.2 \\
\hline Sand & 5.2 \\
\hline Limestone & 5.2 \\
\hline & 5.2 \\
\hline
\end{tabular}


Conclusions and Recommendations ............................................................. 5.2

Converting Fundamental Data to Rates of Penetration....................................... 6.1

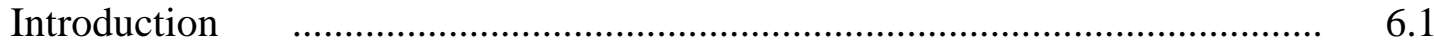

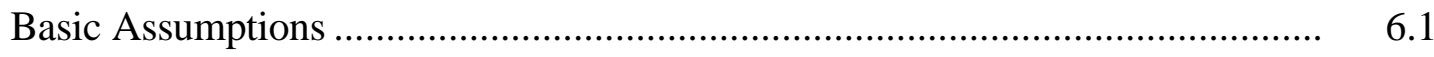

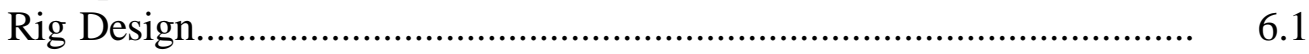

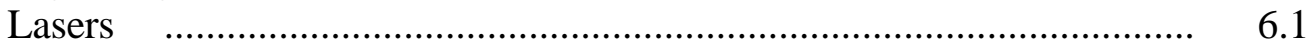

Optical Fibers ................................................................................... 6.1

Rock Characteristics ........................................................................... 6.2

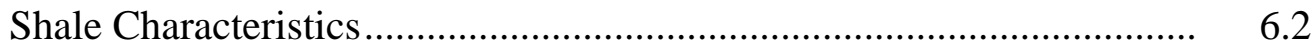

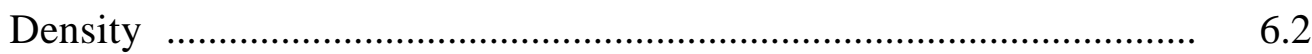

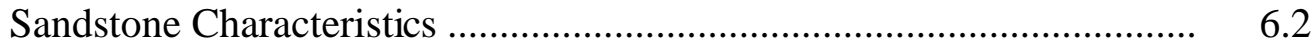

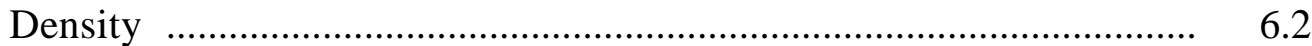

Limestone Characteristics .................................................................... 6.3

Density .................................................................................. 6.3

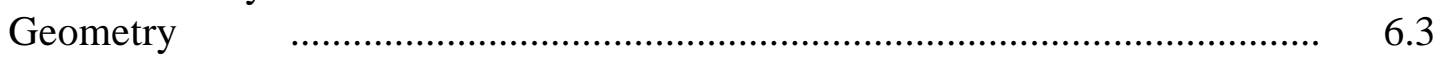

Specific Energy Values ............................................................................. 6.4

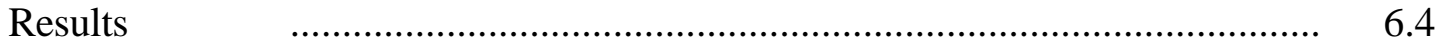

Best Case Scenario............................................................................... 6.5

Most Likely Case ……………………............................................ 6.5

Worst Case Scenario ............................................................................ 6.5

Conclusions and Recommendations ............................................................ 6.6

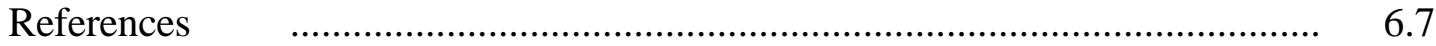

Appendix A: Data Tables......................................................................... A.1

Appendix B: Analyzing the data ................................................................... B. B.

Laser Parameters .................................................................................... B. B.

Rock Characteristics ............................................................................... B.1

Expriment Design ………….................................................................. B. B

Expriment Environnent …………………………….............................. B. B

Non-quantitative Observations ....................................................................... B. B.1

Quantitative Observations .......................................................................... B. B.

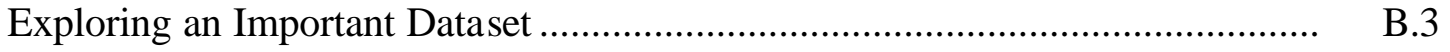

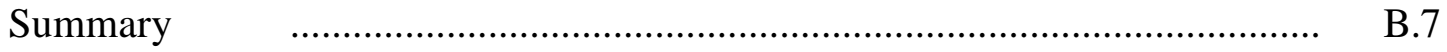




\section{List of Figures}

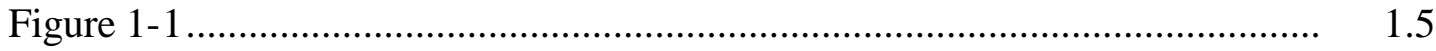

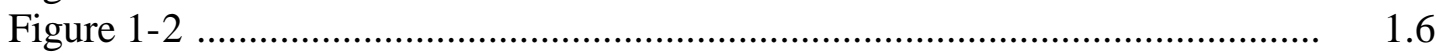

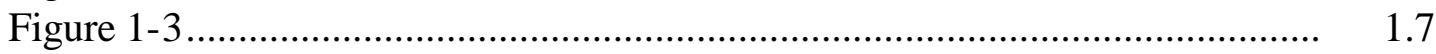

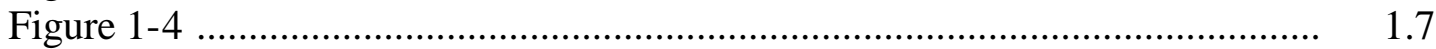

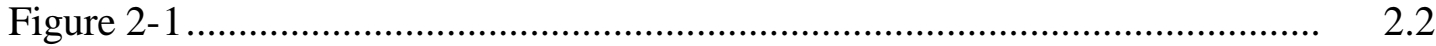

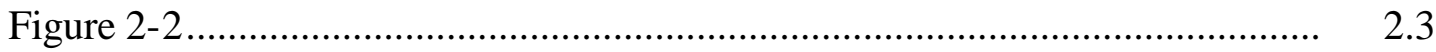

Figure 2-3

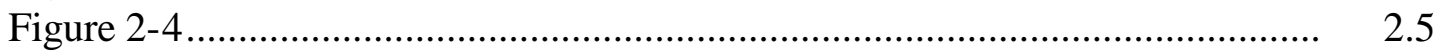

Figure 2-5

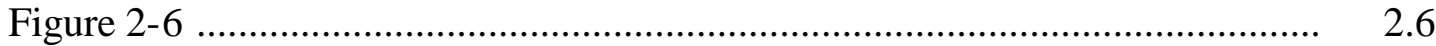

Figure 2-7

Figure 2-8

Figure 2-9

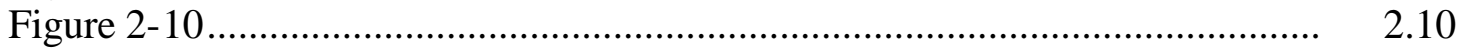

Figure 2-11 ........................................................................ 2.10

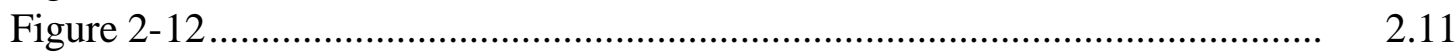

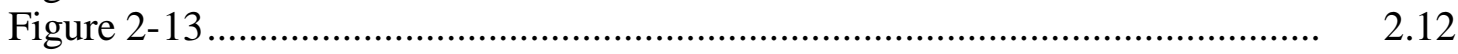

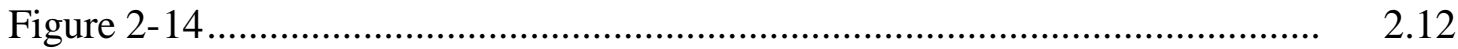

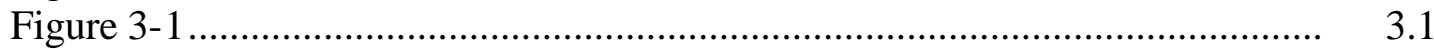

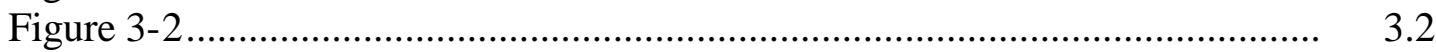

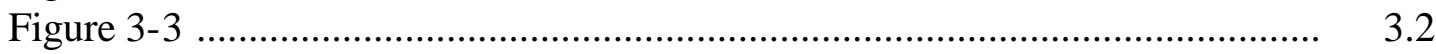

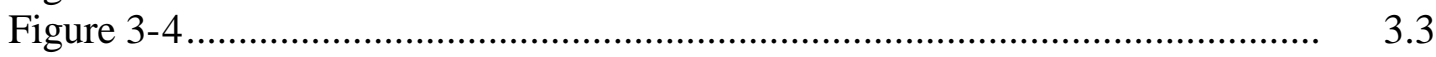

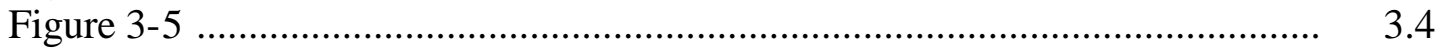

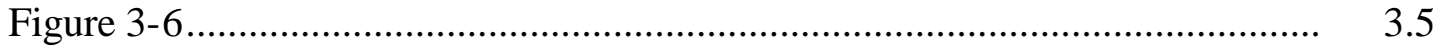

Figure $3-7$.................................................................................... 3.6

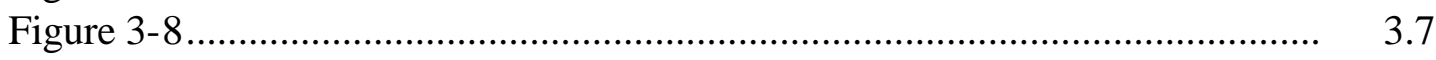

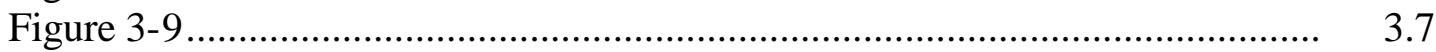

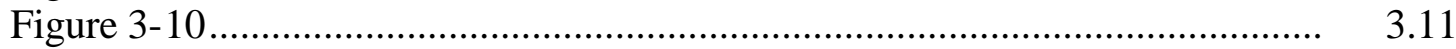

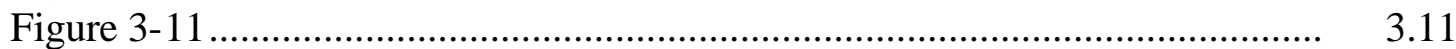

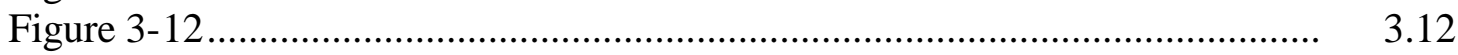

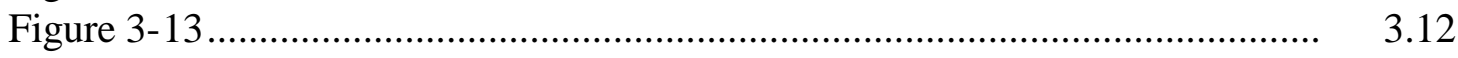

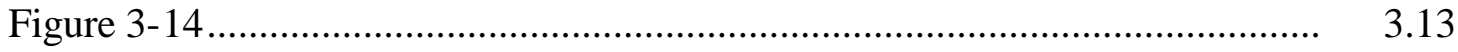

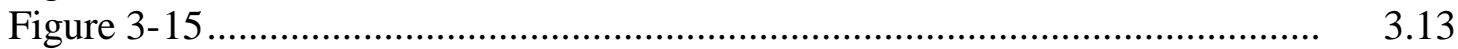

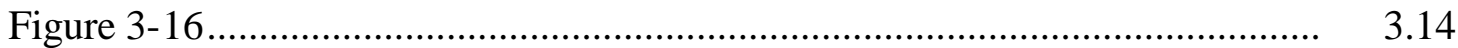

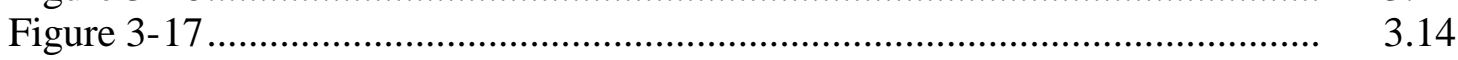

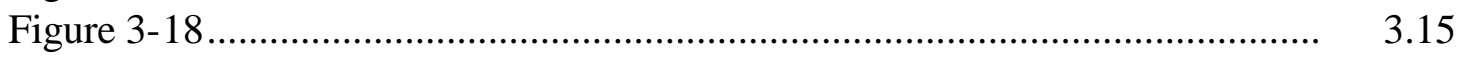

Figure $4-1$...................................................................................

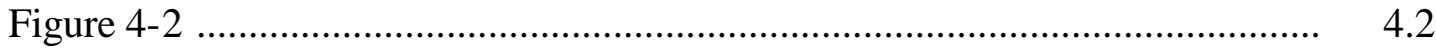

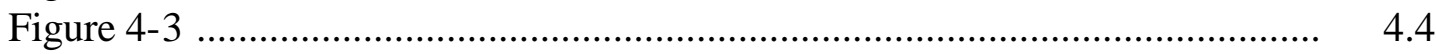

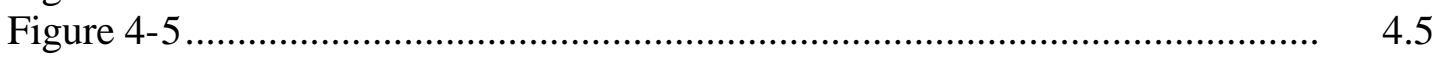

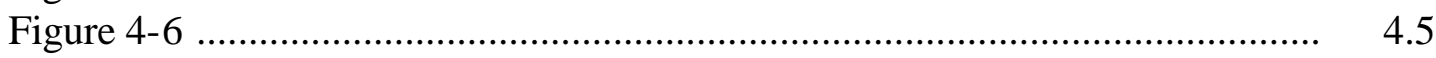

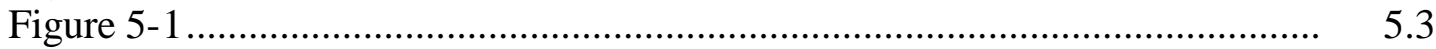




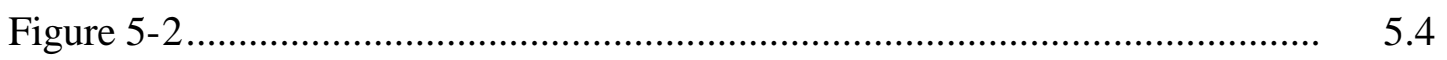

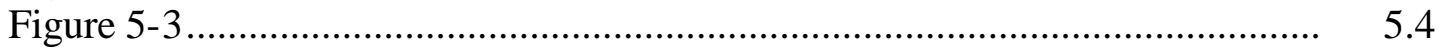

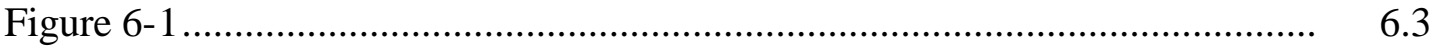

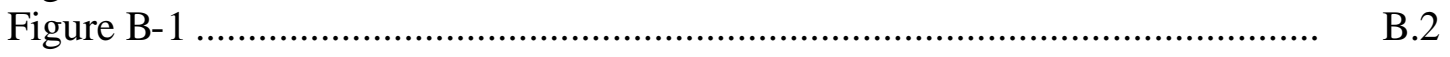

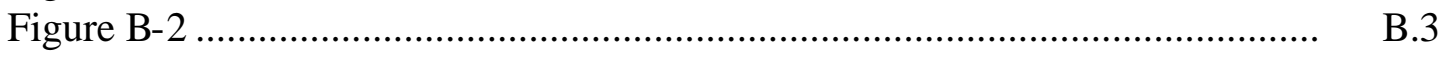

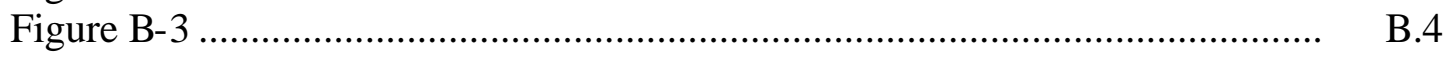

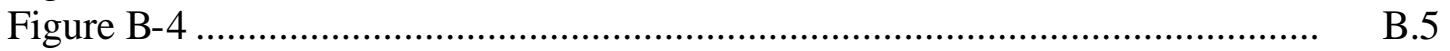

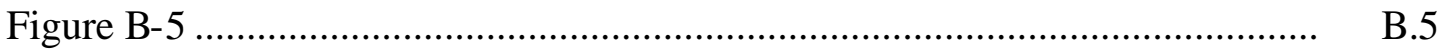

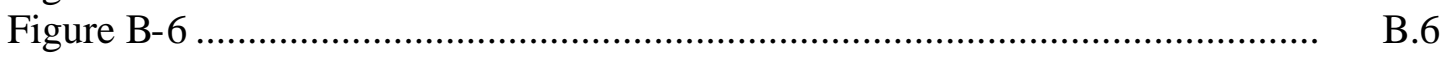

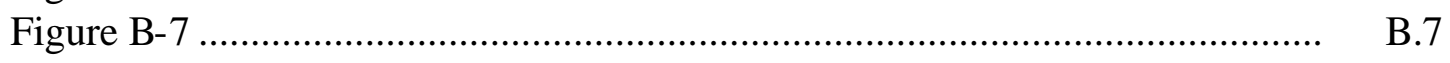




\section{List of Tables}

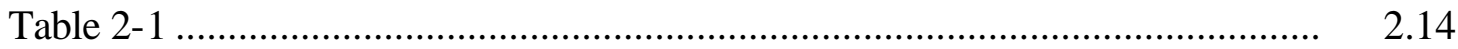

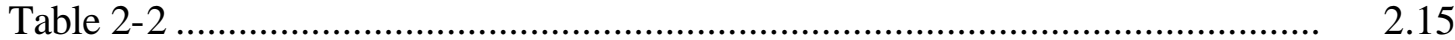

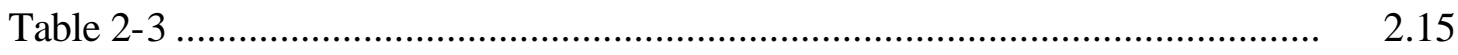

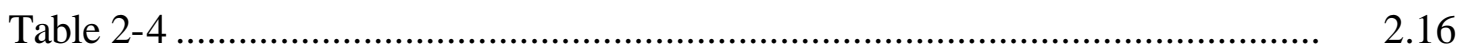

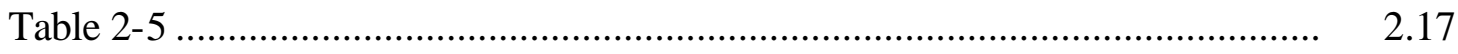

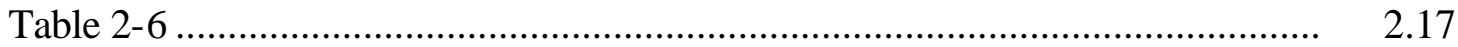

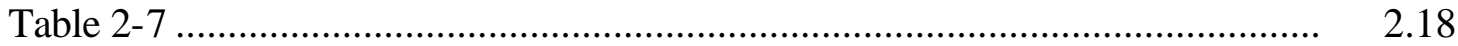

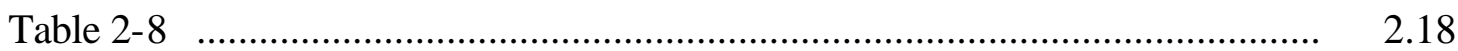

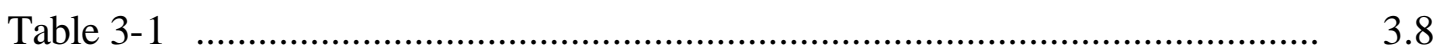

Table $5-1$................................................................................... 5.5

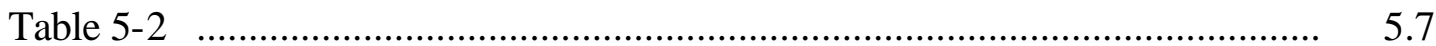

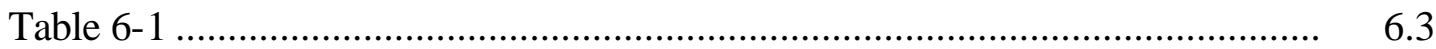

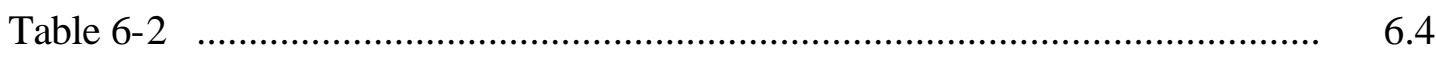

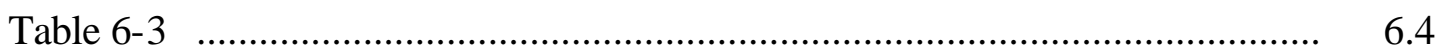

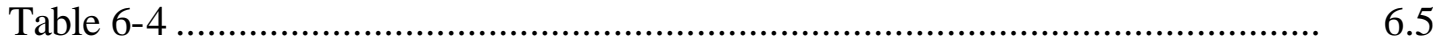

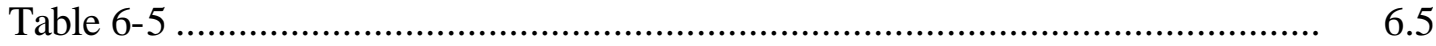

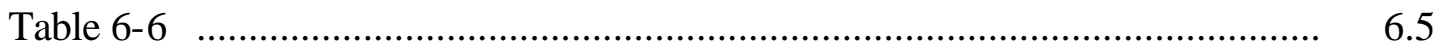

Table A-1: One Spot Repeated Bursts ........................................................... A. A

Table A-2: Multiple Spots, Repeated Bursts-Nd:YAG laser ............................ A. A

Table A-3: $\mathrm{CO}_{2}$ Multiple Spot Tests............................................................ A.4

Table A-4: Perforation Simulation Tests ...................................................... A.7

Table A-5: Wavelength Tests ..................................................................... A. A 


\section{EXECUTIVE SUMMARY}

High powered laser rock drilling was studied as a revolutionary method for drilling and completing deep gas and oil wells (Refs. 1-12). The objectives of this 2002 to 2003 fiscal year research were to study the concept that large diameter holes can be created by multiple overlapping small beam spots, to determine the ability of lasers to drill rock submerged to some depth in water, to demonstrate the possibilities of lasers for perforating application, and to determine the wavelength effects on rock removal. Laser technology applied to well drilling and completion operations is attractive because it has the potential to reduce drilling time, create a ceramic lining that may eliminate the need for steel casing, provide additional monitor-on-drilling laser sensors and improve well performance through improved perforation. The results from this research will help engineering design on a laser-based well drilling system.

Our multi overlapping spot tests showed that large diameter holes can be created efficiently by using a pattern of overlapped small laser spots. The geometric combination of many small spots will create a larger hole while avoiding the development of large amounts of energy-robbing melt. The tests also showed that the laser power levels needed to drill rock efficiently and quickly in multi overlapping spot mode are in the range that optical fiber cables are capable of delivering. This is very supportive of the concept of using optical fiber cables to send the necessary laser energy downhole and has taken the research team much closer to realizing the goal of developing a laser drilling system.

The study on laser-water-rock interaction showed that both $\mathrm{Nd}: \mathrm{YAG}$ and $\mathrm{CO}_{2}$ laser beams can penetrate free water of certain thicknesses above the rock and cause rock destruction. But the degree of destruction was reduced significantly as water became thicker compared to dry sample

data. Because of the great difference in absorption coefficients in water, each of the two wavelength beams travels a unique path to the rock through water. The $1.06 \mu \mathrm{m} \mathrm{Nd:YAG}$ wavelength beam, with small water bsorption coefficient, is mostly transmitted through the shallow water and reaches the rock for destruction. On the other hand, the $10.6 \mu \mathrm{m} \mathrm{CO}_{2}$ wavelength beam, having a large water absorption coefficient must vaporize the water in the path and create a stable vapor tunnel first, then it can reach to rock for destruction. The Nd:YAG laser beam also worked well with the cross over water jet. But with the $\mathrm{CO}_{2}$ laser lasing rock through flowing water became difficult because the cross water jet continuously brought fresh water to the laser beam and destroyed the stable water vapor tunnel condition. Various beam attenuation sources were observed and recorded during the laser water rock tests. Non rock drilling laser energy losses during laser-water-rock interaction were identified as reflection by water and rock surface, absorption by water, blocking by water plasma, and blocking by an upstream cloud of steam, water spatter, rock dust and particles. A better understanding the sources of energy losses will greatly help the engineering design of laser rock drilling test equipments.

Laser perforating tests showed that high power lasers have the ability of drilling good clean holes to a certain depth, at which point melting occurs and a layer of glassy phase forms. Additional laser energy either did little or created fractures due to a combination of the effects of reflection loss from the glassy surface, heat release from the bottom edge, and poor purging. Hole tapering was also observed in all beam-purge-rock configurations as the hole became deeper. With the help of an integral beam/purge system that is angled properly and capable of purging materials out of the way rapidly and efficiently, the benefits of laser perforation (the potential of perforating fast, the flexibility of controlling the size and shape of the holes for optimal production, and the ability of increasing the permeability and porosity of the formation) can be realized. 
The head-to-head wavelength comparison test data with sandstone, limestone and shale samples between the $\mathrm{CO}_{2}$ and $\mathrm{Nd}$ :YAG lasers showed that there is not a great difference in rock volume removed per total energy density between the lasers. The Nd:YAG laser is recommended for future tests due to its optical fiber deliverable capacity and smaller energy loss in water. The $\mathrm{CO}_{2}$ laser will continue to be used in tests in which high laser average power is needed.

The rate of penetration calculations based on the test data showed that the fairly hard rocks tested can be penetrate $d$ at rates the drilling industry deals with everyday. 


\section{INTRODUCTION}

\section{PReVious STUdies}

\section{GRI/CSM, 1997-2001}

This NGOTP project is a continuation of two previous studies. The first, "Determining the Benefits of StarWars Laser Technology for Drilling and Completing Natural Gas Wells", funded by GRI, started by using the military's high-powered lasers:

1) The U.S. Army's 1.6 megawatt Mid-Infrared Advanced Chemical Laser (MIRACL) at the HELSTF facility in White Sands, New Mexico

2) The U.S. Air Force's 7 kilowatt (kW)Chemical Oxygen-Iodine Laser (COIL) at the Directed Energy Weapon facility at Kirtland AFB in Albuquerque, New Mexico,

3) The U.S. Air Force's 50 and $150 \mathrm{~kW} \mathrm{CO}$ lasers at the Metal Hardening facility at Wright-Patterson AFB in Dayton, Ohio.

The feasibility study showed that today's lasers could cut all rock types, and that super-high power (such as the MIRACL) is not necessary to spall (cut), melt and vaporize natural rock materials, including sandstone, limestone, shale, granite, concrete and salt.

\section{GTI/DOE , 2001}

The second laser drilling study, funded by the National Energy Technology Laboratory (NETL) under DOE Cooperative Agreement No. DE-FC26-00NT40917, used the two lasers available at the Laser Applications facility at Argonne National Lab, a $1.6 \mathrm{~kW}$ pulsed Nd:YAG and a $6 \mathrm{~kW} \mathrm{CO}$. In addition, a $4 \mathrm{~kW}$ diode laser at NATech, in Golden, Colorado was used for some comparison studies. This study provided quantitatively the minimum amount of energy required to cut and melt rock and indicated the laser parameters that would cut most efficiently for each lithology tested: sandstone, shale and limestone.

\section{CURRENT STUdY}

The NGOTP funding received for 2002 was used to advance the development of a drilling system that has the potential to revolutionize the drilling industry. This technology can provide a drilling system that is lighter, with a smaller footprint that uses less toxic materials. It may be able to do this while creating a hole in one pass, from surface to target depth and position, without having to pull out to change bits or install steel casing, and then complete the well at the producing horizon(s).

\section{Goals and Objectives For 2002 Multiple Spot Holes:}

The current thinking is that the laser energy will need to be sent downhole by a means similar to optical fibers. The downhole assembly will have to reassemble the beams into one working area, probably by lenses imbedded in a composite matrix bit. The arrangement and spacing of these lenses has yet to be determined. 


\section{Test Goals}

1. Test concept that large holes can be created by placing small holes adjacent to each other, with enough overlap to prevent intervening ridges from forming.

2. Establish that a larger hole can be made efficiently if the overlapping small holes are made in sequence, not all at the same time or each continuously.

\section{Pertinent Questions}

We know that pulsed lasers will begin to melt the rock at any power density setting that is over $700 \mathrm{w} / \mathrm{cm}^{2}$ if the beam duration is long enough. It can be assumed that having some relaxation time between shots would allow the rock to cool enough that melting would not start immediately. How fast can we repeat shots to the same spot before SE increases significantly?

1. Put another way, what is the repeat rate (as opposed to $R$, the repetition rate) that results in the slowest increase of SE?

2. What happens when we overlap the holes to create a smooth surface?

\section{Lasing Under Water}

Conventional drilling usually involves the use of drilling fluids to lubricate and cool moving parts. Often weighting material is added to the fluid to control excessive pore pressures and to prevent catastrophic blowouts.

\section{Test Goal}

Determine the ability of lasers to cut rock that is submerged to some depth in water.

\section{Pertinent Questions}

In 2001, the experiments showed that rocks saturated with water cut as well or better than dry rock. This did not answer the question of whether or not lasers can cut as well with a layer of water above the rock.

1. What is the maximum water depth that can be penetrated by laser beams with enough power to create a hole?

2, What happens to S.E., beam size and spalling vs. melting?

\section{Perforation Simulation:}

\section{Test Goal}

Drill a hole in a rock sample as deep as possible using a series of laser bursts 


\section{Pertinent Questions}

a. Can we get far enough out through use of strong, concentrated purge?

b. Are we going to have to move a tube/fiber out as the hole deepens?

c. What is a sufficient distance?

i. First goal, to get outside the zone of "skin" the zone damaged by drilling activities, a few inches

ii. Second goal, get as far as we can.

\section{Sample Descriptions \\ Representative Lithologies}

After the initial GTI/CSM study, where representative samples from many lithologies were tested, it was decided to focus on the types of rock that are most likely to be encountered in oil and gas drilling. The sandstone, Berea Gray, was chosen for it's ready availability and consistent properties of mineralogy, porosity and permeability. The limestone and shale were more difficult, as the variability of both, even within close proximity, is large, but it was attempted to keep them as close to consistent as possible. For 2002, a source of quarry limestone in the Chicago area was found that allows much more consistency between samples. Shale is still problematic.

As the tests move forward, samples more representative of reservoir and basinal rocks, with higher degrees of variability of their mineralogy and other properties, have been tested to determine the range of values of drilling efficiency and other behavior under the laser.

\section{Sample Preparation}

All samples were cut into disks about 3" in diameter, except the limestone, which was irregular in shape. The thickness varied from 0.5 " to 2.5 ", depending on sample availability and intended purposes.

All samples were tested for porosity and permeability before and after lasing, unless, as in the case of the Berea Gray, enough samples had been tested that the amount of change is known and small.

\section{Lasers Used In Tests}

The lasers available for this study were located at the Laser Applications Laboratory (LAL) of the Technology Development Division at Argonne National Laboratory (ANL). A $6 \mathrm{~kW}$ carbon dioxide laser capable of continuous wave, electric-chopped pulsed and super-pulsed beams, and a $1.6 \mathrm{~kW}$ neodymium yttrium aluminum garnet (Nd:YAG) solid-state laser capable of a wide range of pulse widths and repetition rates were initially evaluated. The characteristics of the two laser test systems used for laser rock drilling are described in this section.

\section{6 kW Pulsed Nd:YAG Laser}

The Nd:YAG laser is a flash-lamp excited solid state laser. The laser is a multiplex cavity laser utilizing two oscillators and two amplifiers (Figure 1-1). The four stage cavity configuration allows the laser beams from the two oscillators to be combined before launching into the fiber optic cable, therefore laser alignment is simplified and beam mode quality is upgraded. The Nd:YAG laser beam of $1.06 \mu \mathrm{m}$ fundamental wavelength is fiber optic cable deliverable which makes it a superior for drilling wells as deep as 10,000 feet where high power beam is required to be delivered downhole. The key characteristics of the laser are as follows: 
Wavelength, $\lambda$

Maximum average power, $\mathrm{P}_{\mathrm{a}}$

Maximum repetition rate, $\mathrm{R}$

Pulse width, $\mathrm{L}$

Maximum energy per pulse

Maximum peak power, $\mathrm{P}_{\mathrm{p}}$

Maximum energy/millisecond, E
$1.06 \mu \mathrm{m}$

1600 watts

800 shots per second

0.10 - 10 milliseconds

100 joules

32 kilowatts

32 joules per millisecond

The test series would use a collimated beam about $6.5 \mathrm{~mm}$ in diameter. Such small beam collimation was realized by using a $25 \mathrm{~mm}$ focal length gradium lens placed at $25 \mathrm{~mm}$ from the fiber output end. The YAG laser power was controlled by the laser schedule that consists of three pulse variables: energy per millisecond, $\mathrm{E}$, pulse width or laser pulse on time in millisecond, $\mathrm{L}$ and pulse repetition rate in hertz, R. For example, schedule E8L2R100 produces a beam of 8 joules/ms, pulse width $2 \mathrm{~ms}$ and repetition rate $100 \mathrm{~Hz}$. The average output power, $\mathrm{P}_{a}$, is equal to $\mathrm{E} \times \mathrm{L} \times \mathrm{R}$ and the peak power, $\mathrm{P}_{\mathrm{p}}$, equals to $\mathrm{E} \times 1000$. For the above example, $P_{a}=1600$ watts and $P_{p}=8000$ watts.

\section{The $\mathrm{CO}_{2}$ Laser}

The $\mathrm{CO}_{2}$ laser is, in some ways, at the opposite end of the spectrum for infrared lasers. As shown in Figure 12 , it is a radio frequency (RF) excited gas laser, where the $\mathrm{CO}_{2}$ is not used up, as the chemicals are in the COIL and MIRACL, but is replenished only when needed. The $\mathrm{CO}_{2}$ has the longest wavelength of the group studied to date.

$\begin{array}{ll}\text { Wavelength } & 10.6 \mu ? \mathrm{~m} \\ \text { Maximum CW Power } & 6.0 \mathrm{~kW}\left(\mathrm{TEM}_{20}\right)\end{array}$

For the drilling through water tests, a $\mathrm{CW} \mathrm{CO}$ laser beam was used at transverse electron mode, $\mathrm{TEM}_{20}$. The beam was defocused by a 5 inch focal length transmissive lens so that the beam spot size on the rock surface was 0.5 inch in diameter. The average laser output power was set up at $4.0 \mathrm{~kW}$.

\section{Mechanical Sample Stages}

Both the Nd:YAG and the CO2 lasers have five axis mechanical stages. This means that samples can be moved with respect to the laser beam outlet lens in both the $\mathrm{x}$ and $\mathrm{y}$ directions, or rotated in either direction, and the lens can move in the $\mathrm{z}$ direction. The $\mathrm{z}$ control is often used with a defocused beam to control the spot size. With a collimated beam, the $\mathrm{z}$ direction was used in some tests to "follow" the bottom of the hole downward to simulate the movement of the drilling head into the space excavated by the beam, as would happen in a real situation. 


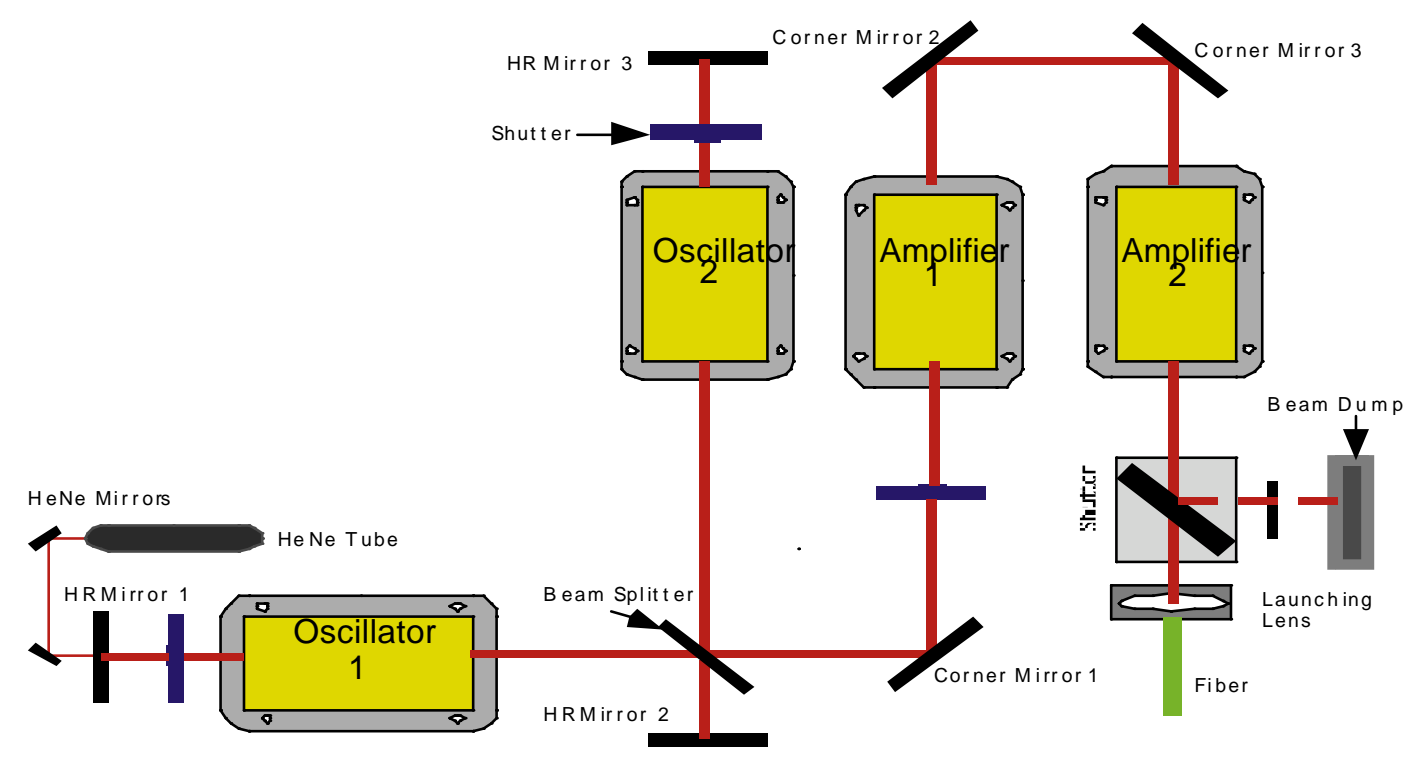

Fig. 1-1: Layout of ANL $1.6 \mathrm{~kW}$ pulsed Nd:YAG laser

\section{Test Plans}

\section{Test Series One, Multiple Spot Hole Tests}

The preliminary work for this test series consisted primarily of programming the mechanical stages to move where and as fast as specified during the planning process. The process makes use of three of the axes of control that the mechanical stages with which both the YAG and $\mathrm{CO}_{2}$ lasers are equipped. The series progressed from repeatedly lasing one spot at varying intervals to two spots and on to three and four. The configurations tested the geometry expected to be used in a bottomhole assembly. 


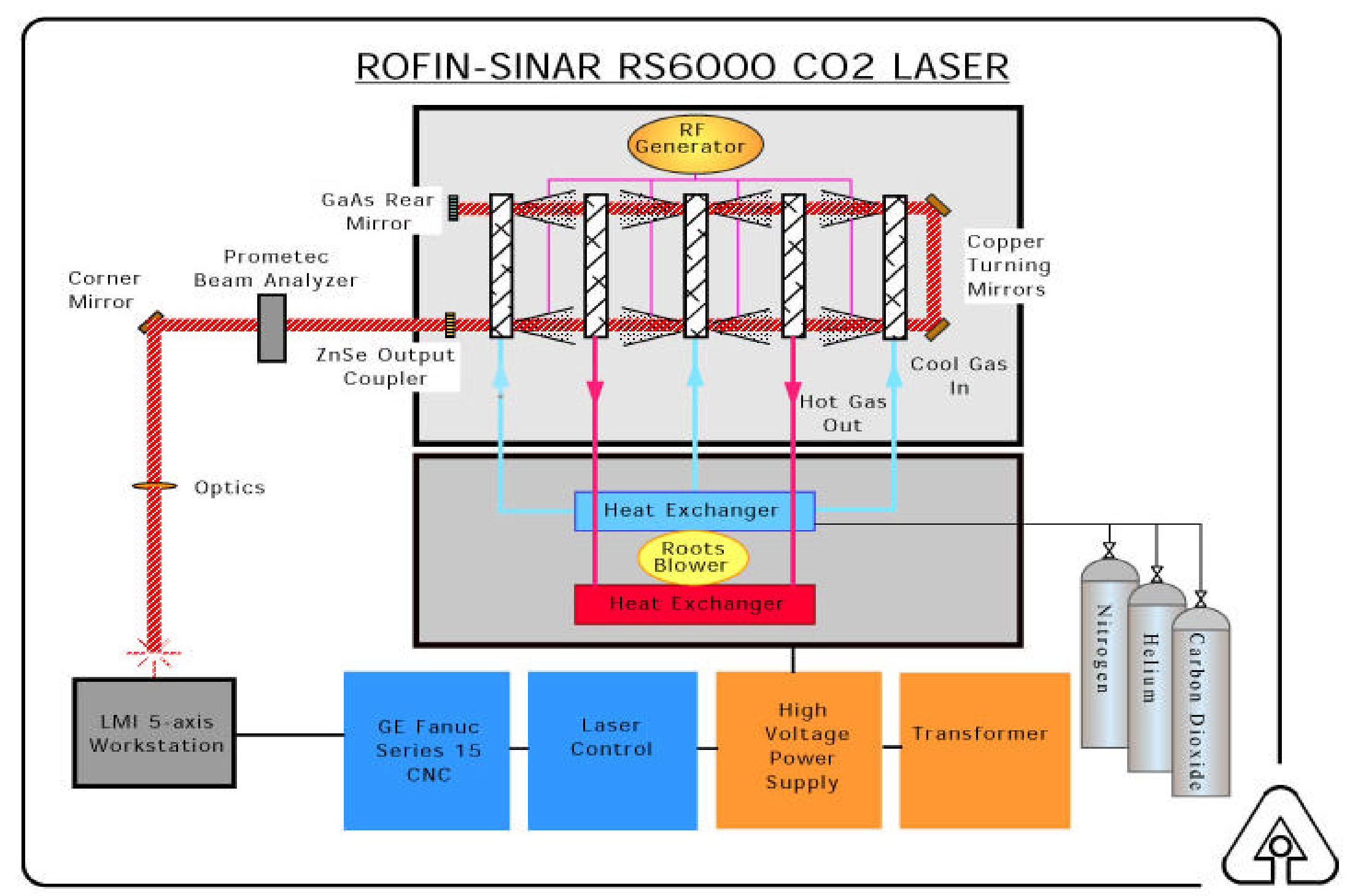

Figure 1-2 Layout of ANL $6 \mathrm{~kW} \mathrm{CO}$ laser 


\section{Test Series Two, Laser Testing Of Rock Samples In Liquid}

\section{Metal Box}

The first preliminary $\mathrm{Nd}: \mathrm{YAG}$ and $\mathrm{CO}_{2}$ laser tests were performed in a metal box with a glass window in an attempt to provide a flat air/glass/water interface to avoid spurious reflections and refractions of the laser beam, with a water jet sweeping across the sample face (Figure 1-3above). The beam, for the first time, was collimated on the YAG laser.

The box, which had been adapted from a project where it had been operated at a slight vacuum, proved unusable at the slight pressure needed to remove air bubbles from inside the glass. The glass leaked around its perimeter and then broke when subjected to a combination of water and clamping pressures. Safety concerns dictated that it not be used as a closed system. It was then used with the lid off as a basin to control water disposal. (Figure 1-3bottom)

\section{Glass Basin}

Next in the preliminary tests was a round, glass basin with a water jet placed into the water at about a 60 degree angle to the sample (Figure 1-4). The water in the basin developed a vortex that disturbed the water surface and scattered the laser beam badly. Samples were lased at water thicknesses from saturated (no free water above the sample surface) to 2 inches.

The samples that were lased during the preliminary tests showed that the laser energy is quickly absorbed in the water system through various mechanisms. The water, which we considered to be fairly transparent to the 1.06 micron wavelength of the Nd:YAG, absorbs $90 \%$ of this energy in $10 \mathrm{~cm}$. The energy that does make it to the surface of the sample heats the rock, but the heat is removed quickly by both
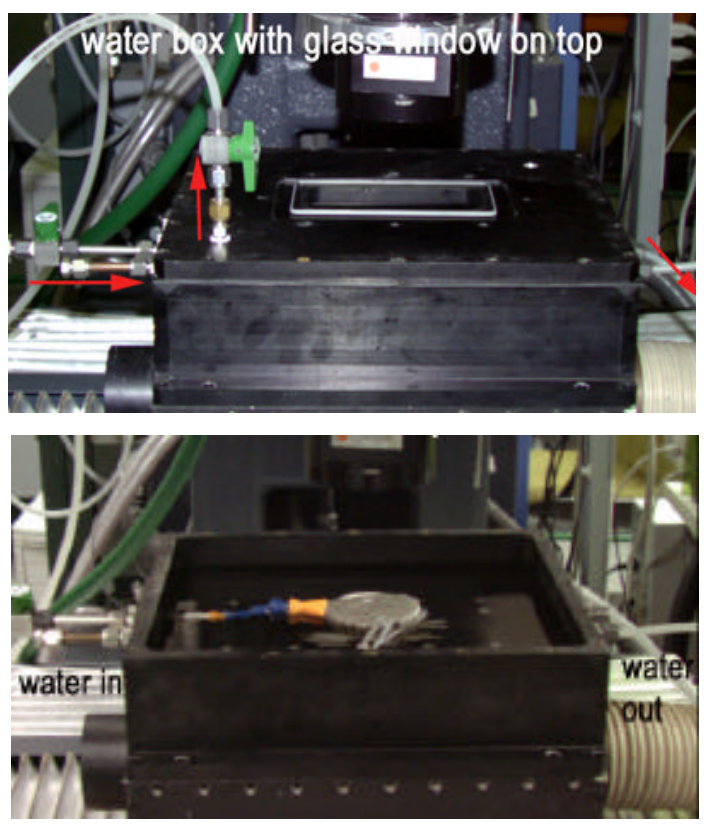

Figure 1-3. Machined metal box used in laser water tests, (above) with lid (note glass window); and (bottom) with the lid off.

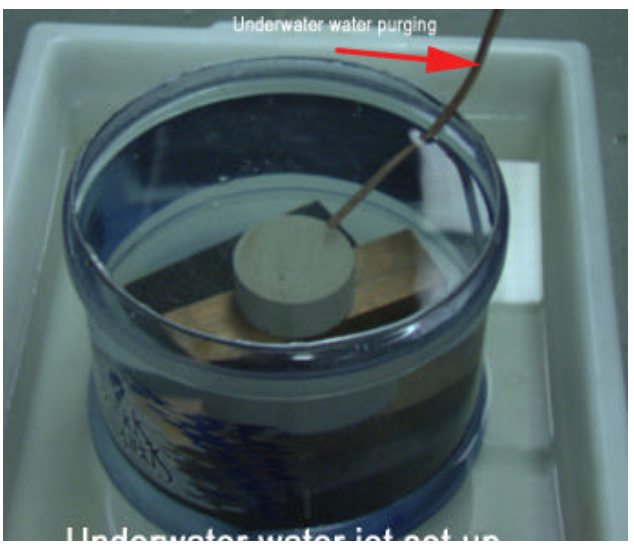

Figure 1-4 Glass basin with a water jet placed into the water convection and conduction behavior of the water. The rock gives off gases and particles, even before the rock starts to visibly destruct, which turbidity further absorbs laser energy. The $\mathrm{CO}_{2}$ wavelength (10.6 microns) energy is absorbed at a much higher rate. The laser literally boils the water, and if the water is too deep (anything over 1 inch by the preliminary tests), the water rushes into the beam at such a rate that the energy never reaches the sample. This is at the $4 \mathrm{~kW}$ $\mathrm{CW}$ power setting. $\mathrm{CO}_{2}$ lasers are capable of over $150 \mathrm{~kW}$, so higher powers could provide longer working distances. 
The samples were affected by both lasers. The pattern for the Nd:YAG is for a cloud of material to be released, the water to start boiling and then the sample to start melting. If the water is too deep $(\sim>8 \mathrm{~mm})$, the sample is not affected. As water depth is increased, the collimated beam (ca $1 / 4$ " on a dry surface) shrinks. It is not clear whether this indicates the water is acting as a lens to concentrate the beam or instead is dispersing the outer fringes of the imperfectly collimated energy.

The jet of water, whether flowing along the sample surface or at an angle to it, could not prevent melted material from adhering to the hole surface. The higher average power of the $\mathrm{CO}_{2}$ allowed melting to occur at larger spot diameters. Water depths up to 1 inch were penetrated and the sample affected, while 2 inches of water totally defeated the beam. Figure 4-3 showed clearly the beam boiling water about half the distance to the sample. Preliminary results made it clear that we would not be able to do a quantitative SE determination as was done for the dry and saturated rocks.

A series of tests was developed that was felt would give a qualitative indication of:

1. Nd:YAG and $\mathrm{CO}_{2}$ working distances through water

2. Provide some indication as to the power levels needed to make significant hole, even if SE would prove to be very high.

\section{Test Series Three: Demonstrating the Possibilities For Perforating}

The GRI/CSM project, "Determining the Feasibility of Drilling and Completion Gas Wells with High Powered Lasers", showed during the Kirtland AFB COIL and Wright Patterson AFB $\mathrm{CO}_{2}$ tests that cutting slows quickly as a narrow hole deepens.

A 0.5 " cw $\mathrm{CO}_{2}$ laser beam at $4 \mathrm{~kW}$ power will be used to drill a hole in 3 or 4 "core rock samples as deep as 6". Three purge gas and beam configurations will be studied.

\section{Test Series Four, Wavelength Comparisons within the Infrared Spectrum}

The field system envisioned by the research team of this project will require a laser that is durable, reliable and efficient. Part of the efficiency has been considered to be the coupling of the laser to the rock, determined by the wavelength. These projects have used lasers with wavelengths ranging from the 0.8 micrometer diode laser to the 10.6 micrometer $\mathrm{CO} 2$ laser. When the data was searched in order to do a comparison of the efficiencies of the various wavelengths, it was found that too many other variables, such as pulse parameters, hole sizes (controlling energy density) or average power, prevented the direct comparison of the results already obtained.

A test series was developed that would compare the results already obtained using the Nd:YAG to new results on the $\mathrm{CO}_{2}$. These tests would cover almost the entire infrared spectrum.

Because of the different capabilities of the $\mathrm{CO} 2$ and $\mathrm{Nd}$ :YAG systems, it was not a trivial procedure to set the $\mathrm{CO}_{2}$ system to have the same pulse height, width, repetition rate and average power. The one set of parameters that were closest to duplicating the YAG capabilities was the schedule E4L1R400.

The test results from the above four test series will be reported in the following chapters. 


\section{USING MULTIPLE SPOTS TO INCREASE HOLE DIAMETER}

\section{Introduction}

The fundamental work done in the previous GTI/ANL/DOE study has shown that keeping the beam on a single spot for too long will cause melting and reduced cutting efficiency. Also, it is difficult to visualize an efficient way to create a six or eight inch hole by sending one beam down hole. One solution that is seen for both of these problems is to use a pattern of multiple beams, not all illuminated at the same time, to create a nearly circular work face. The result is analogous to the diamond compact disks in a matrix drilling bit, i. e., several spiral patterns of cutters that track next to and behind those in the preceding spiral. A way to visualize the result is to think of an old theater marque with the lights chasing around the outside.

If this concept is to be successful, a balance between the number of spots illuminated at once (more being better) and the amount of time that has to pass between illuminations (longer being better) must be reached. The aim is to maximize the amount of material removed at each illumination, without causing the onset of melting.

\section{Goals}

This test series was developed to determine:

1. The effect on cutting efficiency of varying the relaxation time between bursts in the same spot.

2. The relationship between relaxation time and number of bursts to onset of melting in the same spot.

3. The extension of one and two above to multiple spot holes.

4. The amount of spot overlap necessary to prevent a ridge from forming between spots.

\section{Equipment Setup}

The repeated single hole and multiple hole tests were done on both the Nd:YAG and $\mathrm{CO}_{2}$ lasers. The $\mathrm{CO}_{2}$ was particularly useful for the limestone samples as the higher average power available (4.5kW compared to $1.5 \mathrm{~kW}$ for the YAG) allowed larger spot sizes on the limestone while maintaining the power density needed to cut well, which avoided the secondary effect of small holes.

The tests were done on dry samples using the laser parameters (peak power, repetition rate, pulse width, spot diameter and beam duration) that earlier resulted in the best Specific Energy for each lithology. The time the laser was turned on for that duration is termed a burst. For example, for the Berea Gray sandstone, the laser schedule was E8L1R200, the duration was 0.5 second and the spot diameter was $1.27 \mathrm{~cm}$. One burst of 0.5 second would consist of 100 pulses of laser energy (figure 2-1).

The first set of tests, the one spot tests, consisted of multiple bursts at the same location with increasing lengths of time between bursts and increasing numbers of bursts. For the second series of tests in this category, the $\mathrm{x}$ and $\mathrm{y}$ directions of the mechanical stages were programmed to move the sample under the beam in either two spot, three-spot (triangle) or four-spot (parallelogram) patterns (figure 2-2). For some of the multispot tests with larger number of repeats, the laser head was also moved downward to simulate the movement of a drilling head as the working face migrates away from it. 

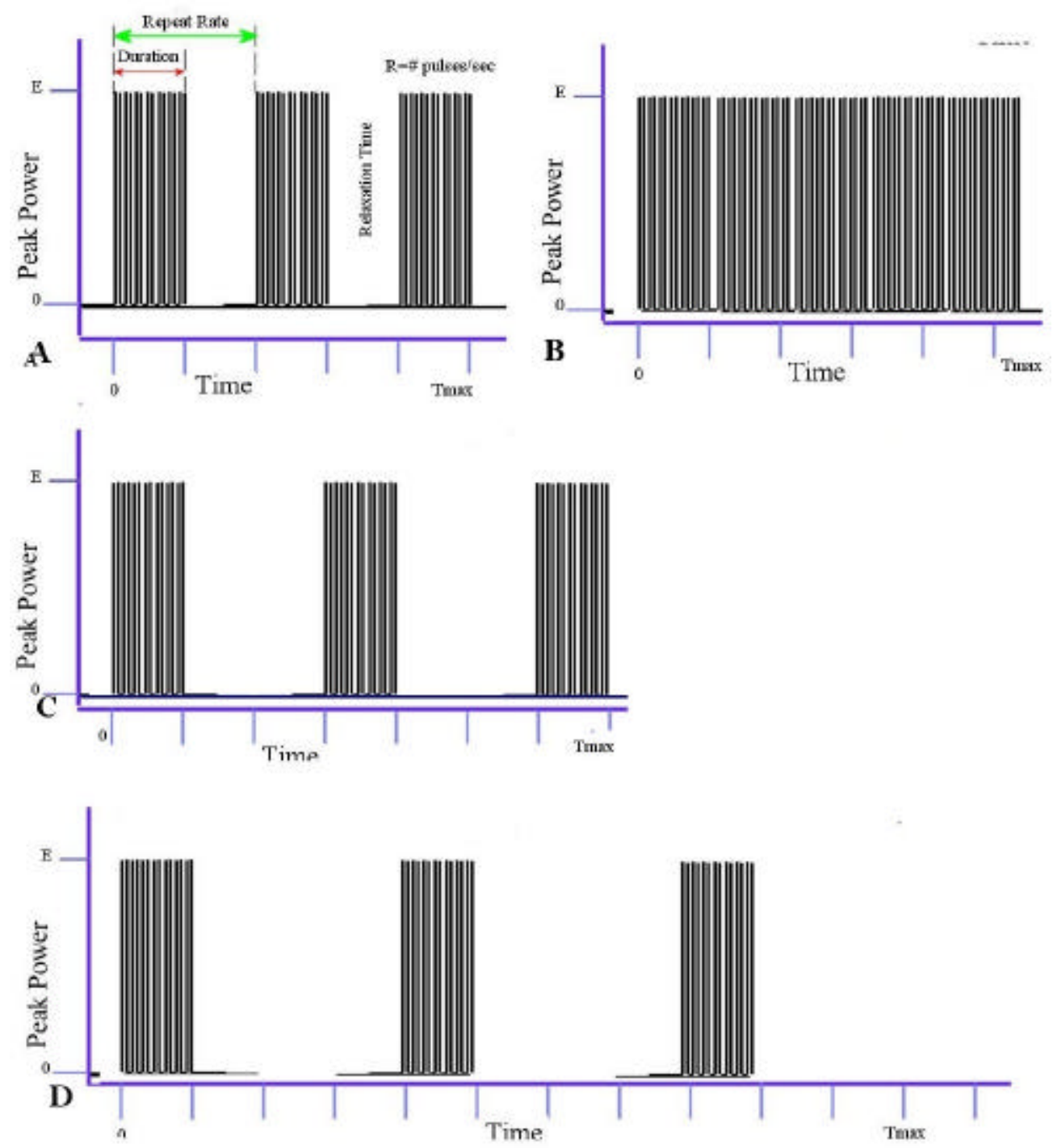

Figure 2-1. Schematic of pulse patterns used for multiple spot tests. A. Each burst (e.g., 0.5 seconds long consisting of 100 pulses) is separated by 0.5 seconds, or one duration relaxation time; B. Five bursts, as defined in A, with no relaxation time; C. Each burst is separated by two durations; D. Each burst is separated by three durations relaxation time.

For the multiple spot tests, the mechanical stage was programmed to allow one laser burst, then move to the next location in $0.5 \mathrm{sec}$, then another burst, then movement, at which time the third burst would either be in the original location (two spot tests) the final point of an equilateral triangle (three spot tests), or the third position of the parallelogram, for which the fourth burst would finish the figure.

At this time the entire program would be repeated. The relaxation time between bursts at a given location depended on how many holes were made. For a two spot test, the minimum relaxation time was 1.5 seconds, including the movement time after the first burst, a burst on the other location and movement time back to the original location. For the three spot series, the relaxation time was 2.5 seconds while for the four spot test, it was 3.5 seconds.

The offsets for the spots were determined by the desired amount of overlap. Some overlap of the spots is thought to be needed to remove the ridge between the spots due to lower intensity at the edges of the beam. Two offsets were tested, $1.1 \mathrm{~cm}(0.433$ ") and $1.0 \mathrm{~cm}(0.4 ")$. The first would result in an overlap of $6 \%$, the 
second of $10 \%$, according to geometrical calculations done during planning. The triangular and parallelogram patterns were chosen based on the opinion that hexagonal closest-packing is going to be the most efficient pattern for a multibeam cutting head.

\section{Data Reporting}

For this section, all data tables are placed at the end of the section. The tables are intended to show pertainent data only to make the point of the discussion. Additional data can be found in the more comprehensive presentation of the data in Appendix A.

\section{One Spot Repeated Tests}

\section{Goal}

The goal of the one spot repeated tests was to investigate the effect of varying the amount of time allowed to elapse between laser bursts on a single location. This will effect the amount of time required to lase an entire working face and the rate of penetration in a full size borehole.

\section{Test Proce dure - Nd:YAG Laser}

All of the one spot tests were done on the ND:YAG laser, using sandstone, shale and limestone. The laser was set at the optimal parameters for each lithology. For the Berea Gray sandstone and the limestone samples, the parameters were E8L1R200, with $1.27 \mathrm{~cm}$ beam diameter at the sample face and 0.5 second burst duration. For the shale the laser was programmed at E8L1R100. The spot size was set at $1.27 \mathrm{~cm}$, using an optically collimated beam for the first time (previous tests were done with a defocused beam). The burst length is called the duration, and relaxation times between bursts was set at multiples of the duration.

A matrix was created wherein spots would be exposed to two bursts, with one, two, and then three durations relaxation. The matrix was repeated with each spot getting three bursts with one, two and three durations relaxation time. Third and fourth matrices were done with four and five bursts on the spot, but with one and three durations relaxation. Gauging tests were done with single bursts equal to one and five durations.

\section{RESULTS}

\section{Sandstone}

The sandstone results are listed in Table 2-1. The calculated Specific Energies were all greater than the single burst gauging tests (BG-A1-7 \& 8), but less than the gauging shot equivalent to five bursts with no relaxation time (BG-A3-8). This is shown in Figure 23, where it can be seen that the SE generally increases with increased repeats at all relaxation times, but longer intervals increase less. 


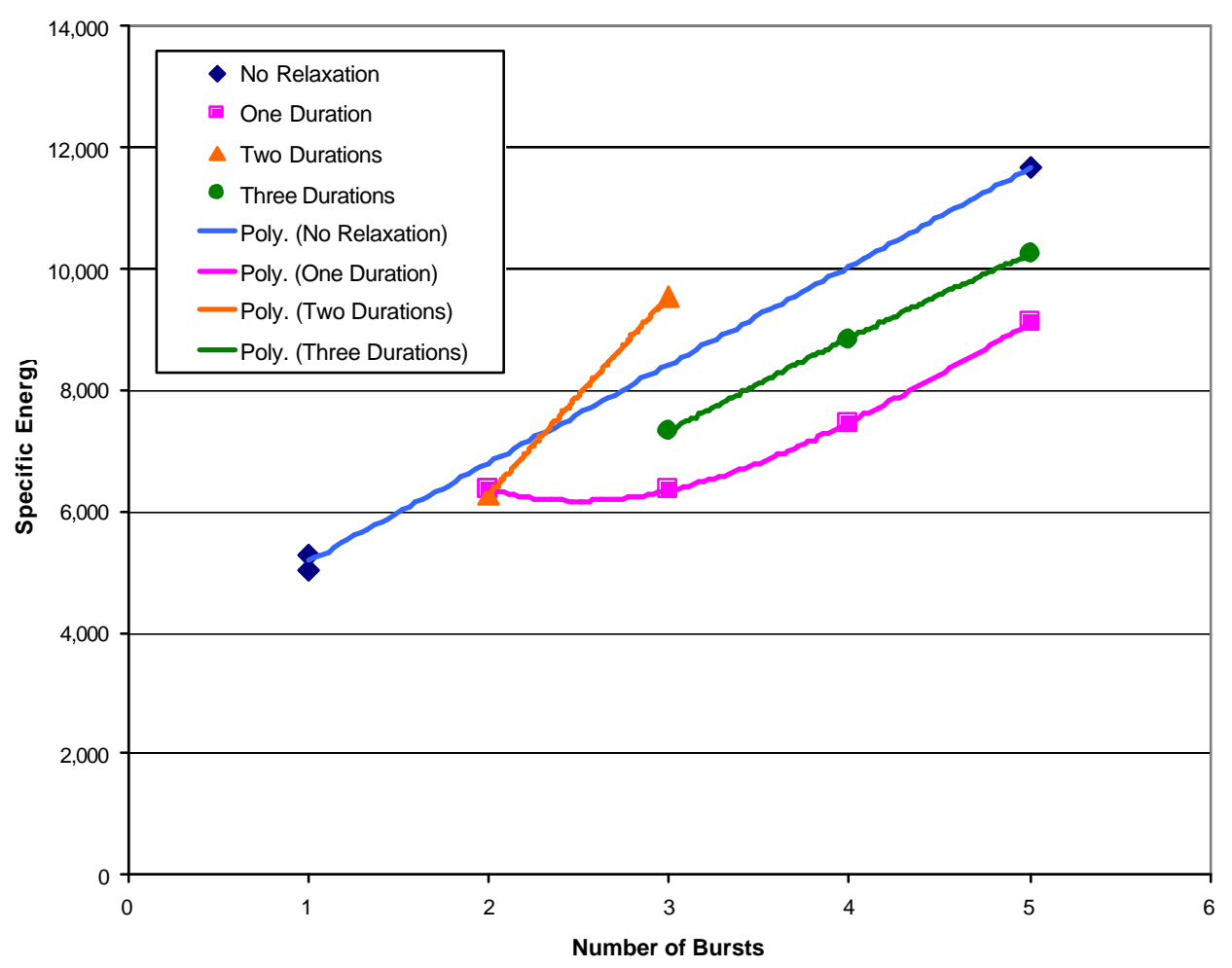

Figure 2-3. Single spot test, sandstone. Laser parameters are: E8L1R200, $1.27 \mathrm{~cm}$ beam diameter, burst time 0.5 second.

Three durations resulted in uniformly higher SE than one duration results, but both were lower than uninterupted lasing. The two durations, three bursts result is inexplicable. It could be that the rock properties (the two, three duration tests were done on different disks) or short-term laser variation.

As seen in Figure 2-4, melting is relatively minor in all the tests. The tests done on sample BG-A4 include the two longer relaxation times, 1.0 and 1.5 seconds. Spots 7, 8 and 9, with 3 repeats and 1.0 second relaxation has a median SE of 9,552 J/cc, while on sample BG-A3, the same spot numbers had the same number of repeats with longer relaxation time, 1.5 seconds and a lower SE. With additional repeats, shown in Figure 2-5, the longer relaxation time continued to result in lower SE values for four repeats, as seen on BGA4-1 \& 2, but with 5 repeats, such as BG-A4-4, $5 \& 6$ the SE values once again increased significantly. 

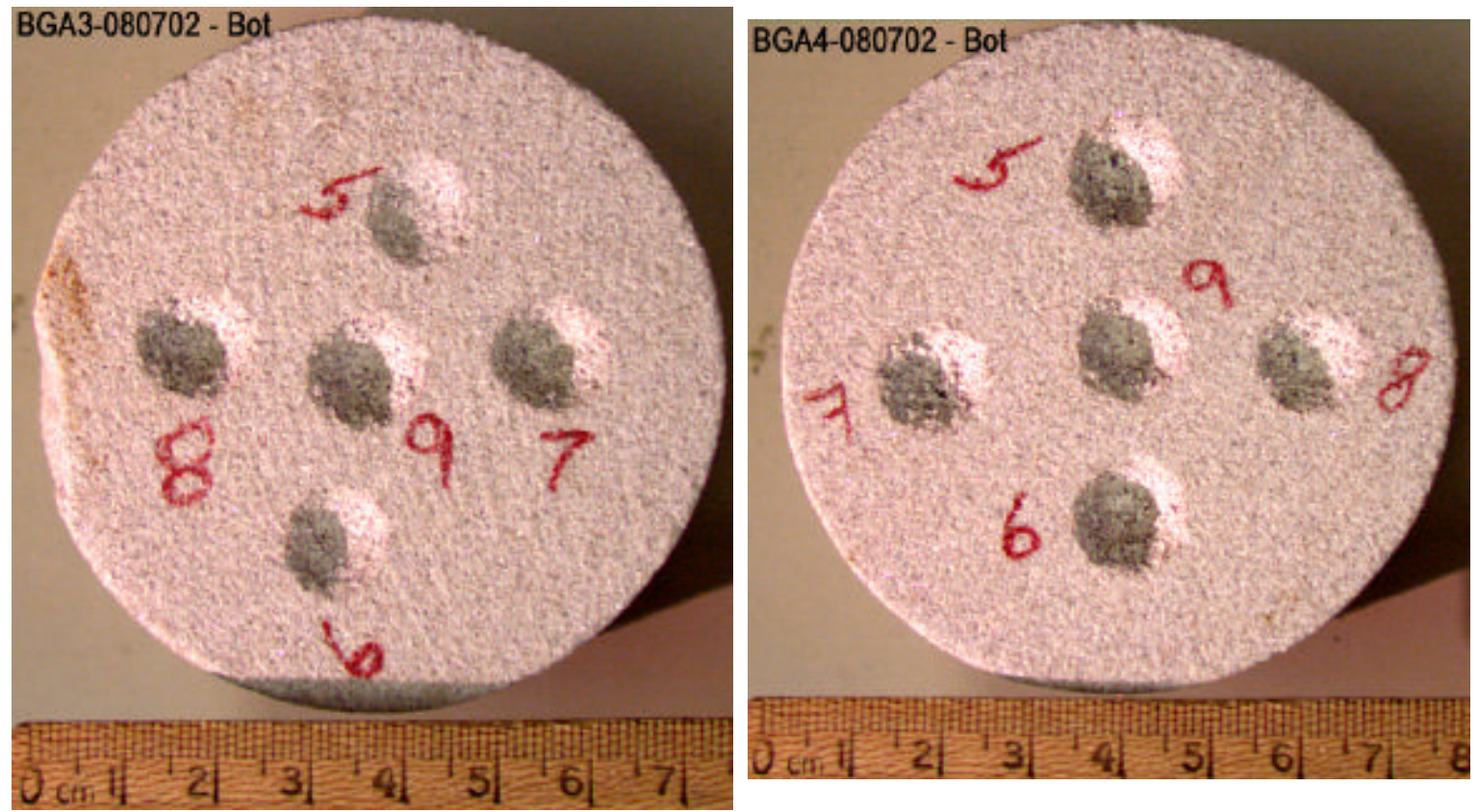

Figure 2-4. Single spot, multiple burst tests on Berea Gray Sandstone. Sample BG-A 3-7, 8 \& 9 has the same number of repeats as BG-A4-7, 8 \& 9, but longer relaxation time and lower SE values. There is a somewhat larger amount of melted material evident in the bottoms of the BG-A4 holes.

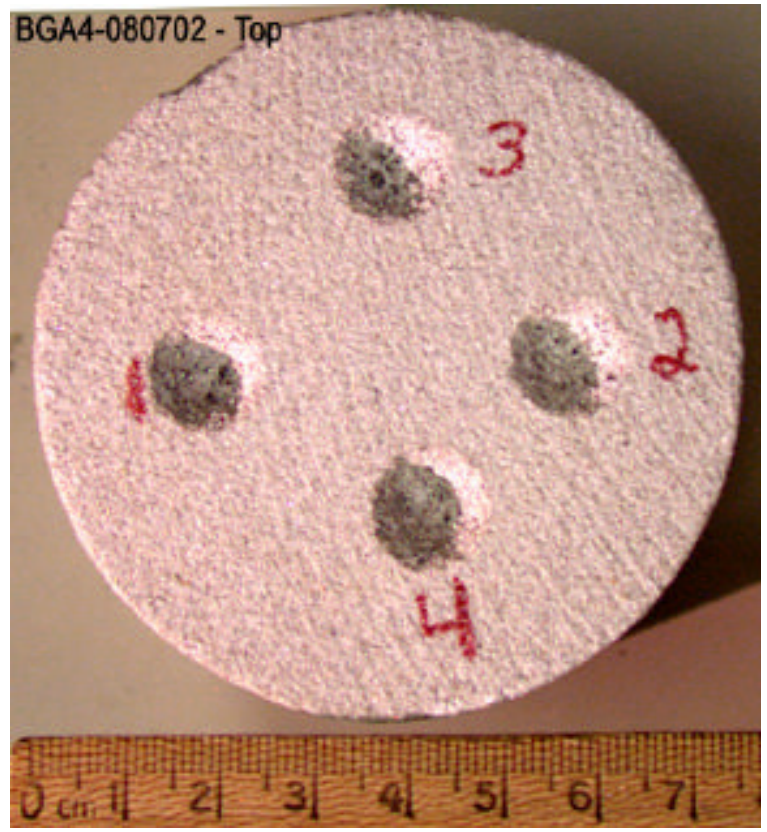

Figure 2-5. Sample BG-A4 Top shows single spot tests with more repeats. Spots $1 \& 2$ have four repeats each, while spot 4 has five. Spot three is an invalid test. 


\section{Shale}

The single hole tests on the shale sample were done on a dark, organic rich clayey shale from a set of samples that had been used in previous tests. Unfortunately, this shale ran out after this set of tests, so a shale was used that is quite different from this, as will be discussed in the multiple spot test paragraphs below.

The shale experienced more melting than the sandstone when subjected to repeated lasing on the same spot (Figure 26). The shale cuts so easily that lower power density might have been better to avoid melting. The SE reported in Table 2-2 indicates that the melting affected the cutting efficiently profoundly. The single spot, single burst tests done in 2001 had a best SE of just over $500 \mathrm{~J} / \mathrm{cc}$, while these tests jumped almost an order of magnitude to over $3500 \mathrm{~J} / \mathrm{cm}^{3}$.

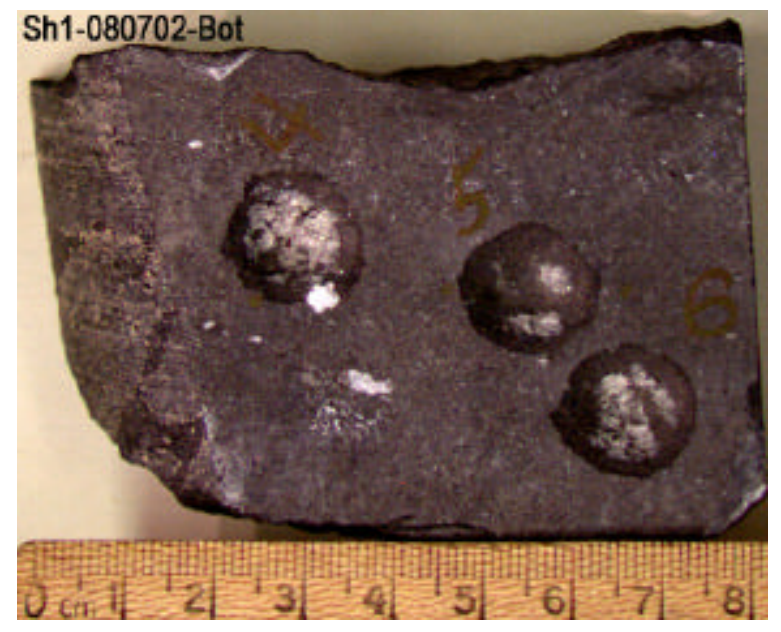

Figure 2-6. Shale sample Sh1, holes 4, 5 and 6. All holes were exposed to 3 bursts with one duration between bursts. Hole 5, with less visible melting, has an SE equal to the lowest in the test.

The parameter that seems to have the most effect on the shale tests is the power density. Figure 2-7 is a graph that shows the single spot shale tests. The one spot tests had power densities nearly the same as the best previous tests, about $500 \mathrm{w} / \mathrm{cm}^{2}$, while the multiple spot tests used power densities the same as the sandstones, about $900 \mathrm{w} / \mathrm{cm}^{2}$.

\section{Limestone}

In order to obtain power densities high enough to reach the threshold level on limestone, the beam diameter during previous Nd:YAG tests had to be reduced to $0.32 \mathrm{~cm}$. This produced a power density high enough to cut the rock, but also resulted in holes so small and deep that secondary effects such as beam absortion and particle re-lasing became important, causing very high SE values. Because the 2002 tests were all related to making multiple spots, the larger $1.27 \mathrm{~cm}$ spot size was used with the power density of about $1 \mathrm{~kW} / \mathrm{cm}^{2}$. This power density was not much more than the threshold value, and the SE values were over $100,000 \mathrm{~J} / \mathrm{cm}^{3}$. The test results are reported in Table 2-3, but the tests on the $\mathrm{CO}_{2}$ laser, reported below, with its higher average power and power densities, are much more valid. 


\section{All Nd:YAG Shale Repeated Tests}

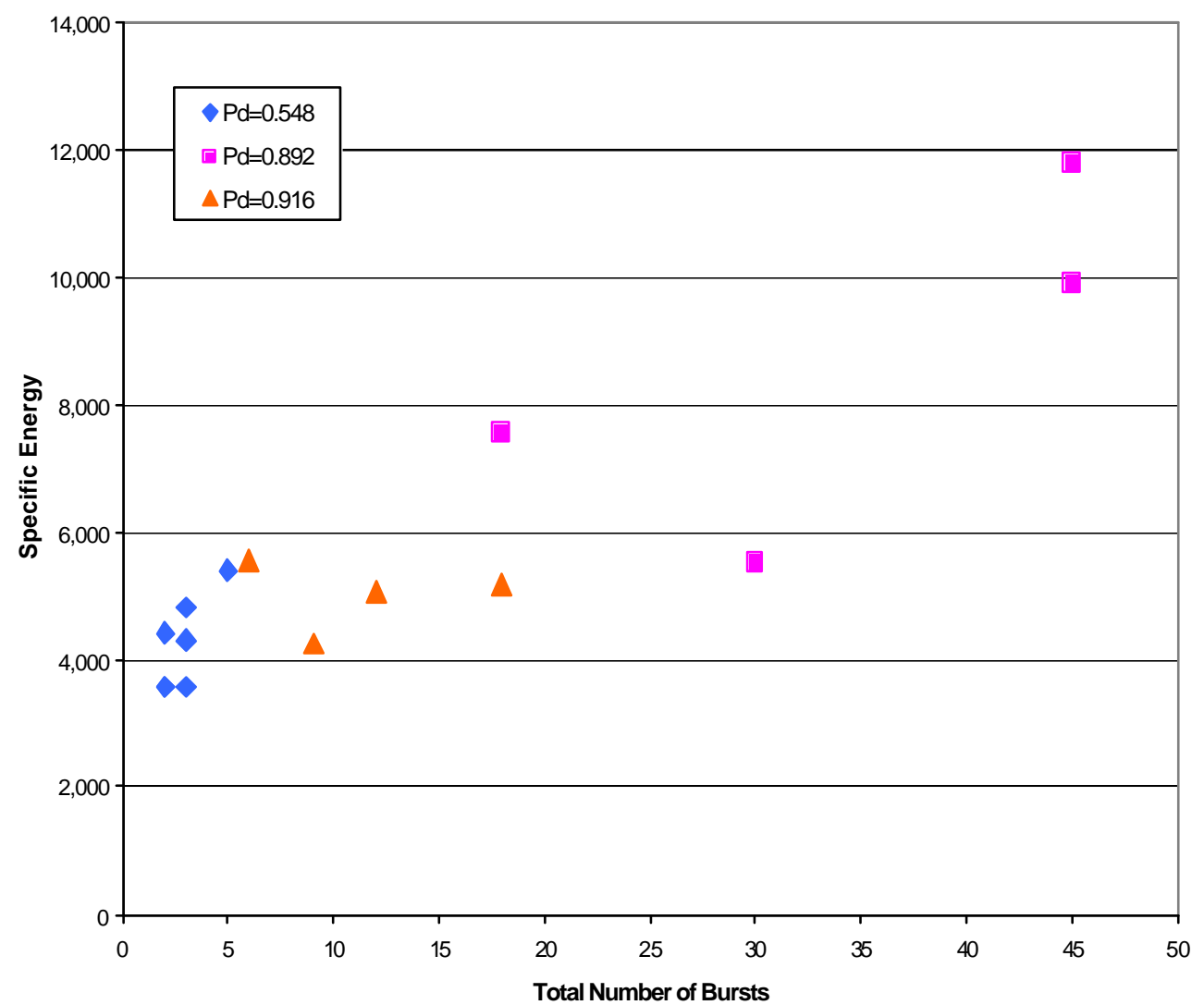

Figure 2-7. All shale tests. The change in power densities does not seem to affect the trend of increasing SE with increasing number of bursts. The reason for median power density having a higher SE at the same number of bursts is not known, and may show a range of values in a single population. All of the $\mathrm{Pd}=0.548 \mathrm{~kW} / \mathrm{cm}^{2}$ points are single spot repeat tests.

\section{Multiple Spot repeated Tests}

\section{Goal}

The two, three and four spot experiment design was intended to be an extension of the single spot tests, with varying relaxation times as well as spacing and number of repeats. However, it was realized that the relaxation times would be longer than the one spot tests due to the nature of the experiment. Therefore, the focus of the test became to vary the number of repeats and the spacing between spots. 


\section{Test Procedure}

The multiple spot test design was executed as discussed in the introduction above. The $1.27 \mathrm{~cm}$ diameter spots were created using varying spacing and numbers of repeats. The two spot tests also varied relaxation times, with a minimum of 1.0 second and a maximum of 1.5 seconds. The relaxation times for the three and four spot tests were not varied, but were determined by the amount of time it took to get back around the figure to a given spot again, 2.5 seconds for the three spot tests and 3.5 seconds for the four spot experiments.

\section{Qualitative Observations During Testing}

1. The samples were clamped into place, but only a moderate amount of force was used on the clamps to avoid cracking the stone. Progression of the tests indicated that the sample was shifting on the stage due to the acceleration and deceleration of the stage while moving the sample under the beam (Fig. 2-8). More clamps were added and the movement was stopped.

2. The holes that were created using additional passes were encouraging in that no melt was created along the walls of the hole, even when they became quite deep. However, the holes became narrower as they grew deeper. The beam was collimated as completely as possible, but the hole looked like one made with a beam focused several inches below the sample surface. There is no obvious answer as to why the hole walls narrow with depth. It is assumed that this problem will disappear when the laser head moves down into the hole so a constant distance to the working face is maintained. A few tests were done to explore this possibility, but the results were not appreciably different from the stationary lens tests.

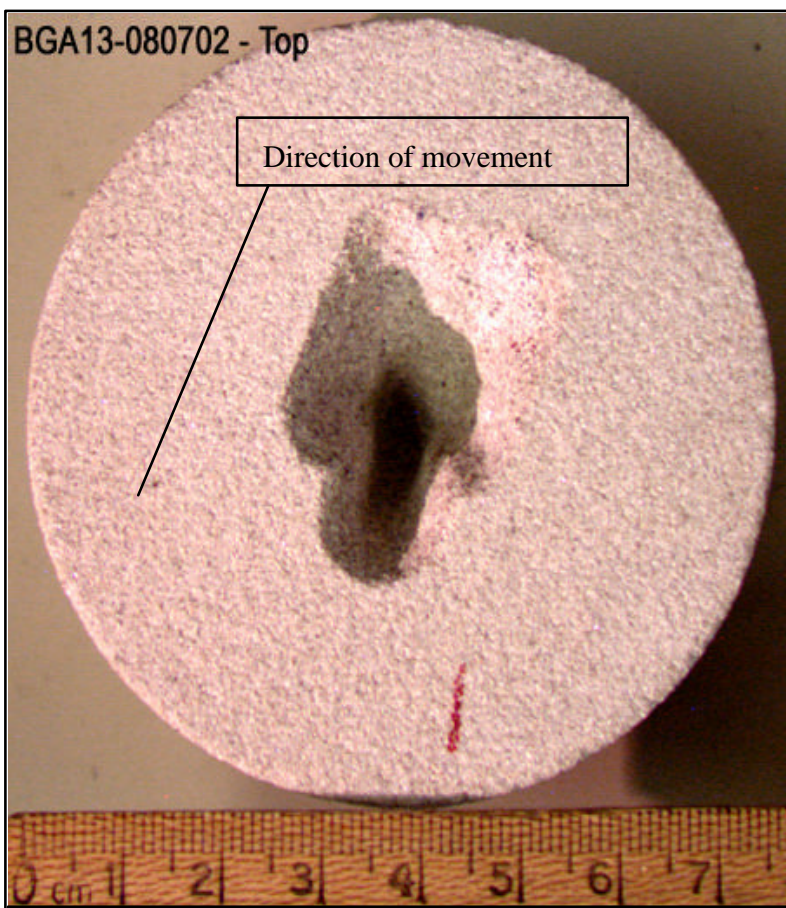

Figure 2-8. The sample shifted as the stage moved, resulting in the pattern observed/

\section{RESULTS}

ND:YAG

\section{Sandstone}

The results of the tests are given in Table 2-4. Tests done on the same disk with the same laser and test parameters have been averaged to reduce the number of points on the graphs.

The reasons for the variability of results with increasing relaxation time is not immediately apparent. The two duration data is particularly confusing but the 3 burst point may be a function of the particular sample, BGA4, which gave low material removal amounts for all tests done on it.

The amount of material removed with each successive burst clearly goes down, but whether the process will level off as relaxation time increases is not clear. The three duration's data indicates that it will, but this needs to be tested further. 


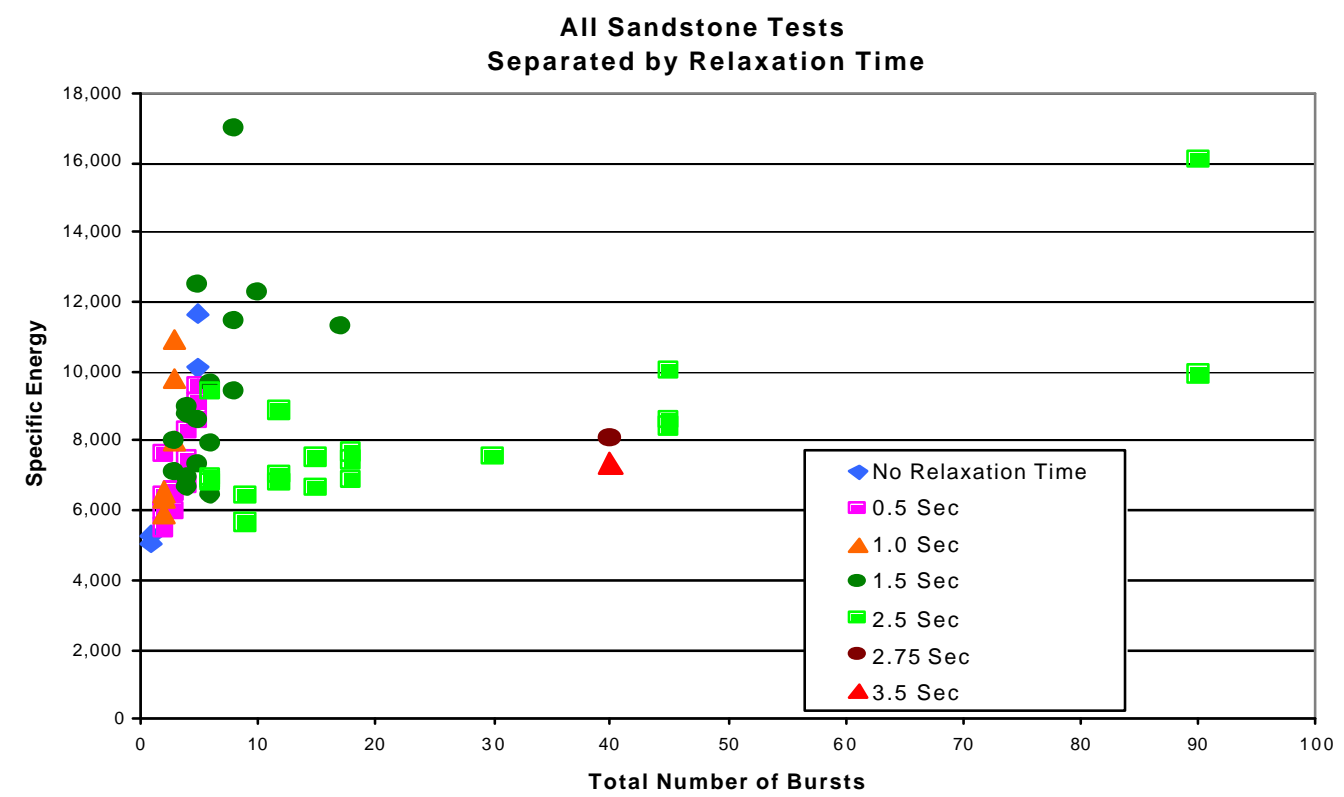

Figure 2-9. All sandstone one, two, three and four spot tests. Highlighting relaxation time shows that above about 20 bursts, the trends separate at between 1.54 seconds and 2.5 seconds relaxation

The results of this test series are encouraging in that both the two and three spot tests indicate that the weight loss levels off as number of bursts per shot increases. The two shot tests indicate a precipitous increase in SE before the leveling occurs, but the three shot tests indicate a very small increase in SE, which seems to be related to the relaxation time. The three spot tests had relaxation times of 2.5 seconds, the four spot tests of 3.5 seconds, while the two spot tests had a maximum relaxation time of 1.5 seconds. (Figure 2-9).

The spacing tests were done most on the sandstone disks. Figure 2-10 shows the two spot tests with $1.27 \mathrm{~cm}$, $1.1 \mathrm{~cm}$ and $1.0 \mathrm{~cm}$ spacing. The three and four spot tests were very encouraging in that there was very little melting evident, even in the tests with 10 or 15 repeats on each spot.

\section{Shale}

The shale tests were done on a different type of shale than the one spot test. The color is much lighter and the rock has the appearance of granularity, much like a quartzose sand or siltstone. The mineralogy is discussed in the chapter on sample properties. The effect of color on SE is one that has been discussed, but a test series has not been developed for the purpose of determining what the effect might be. 

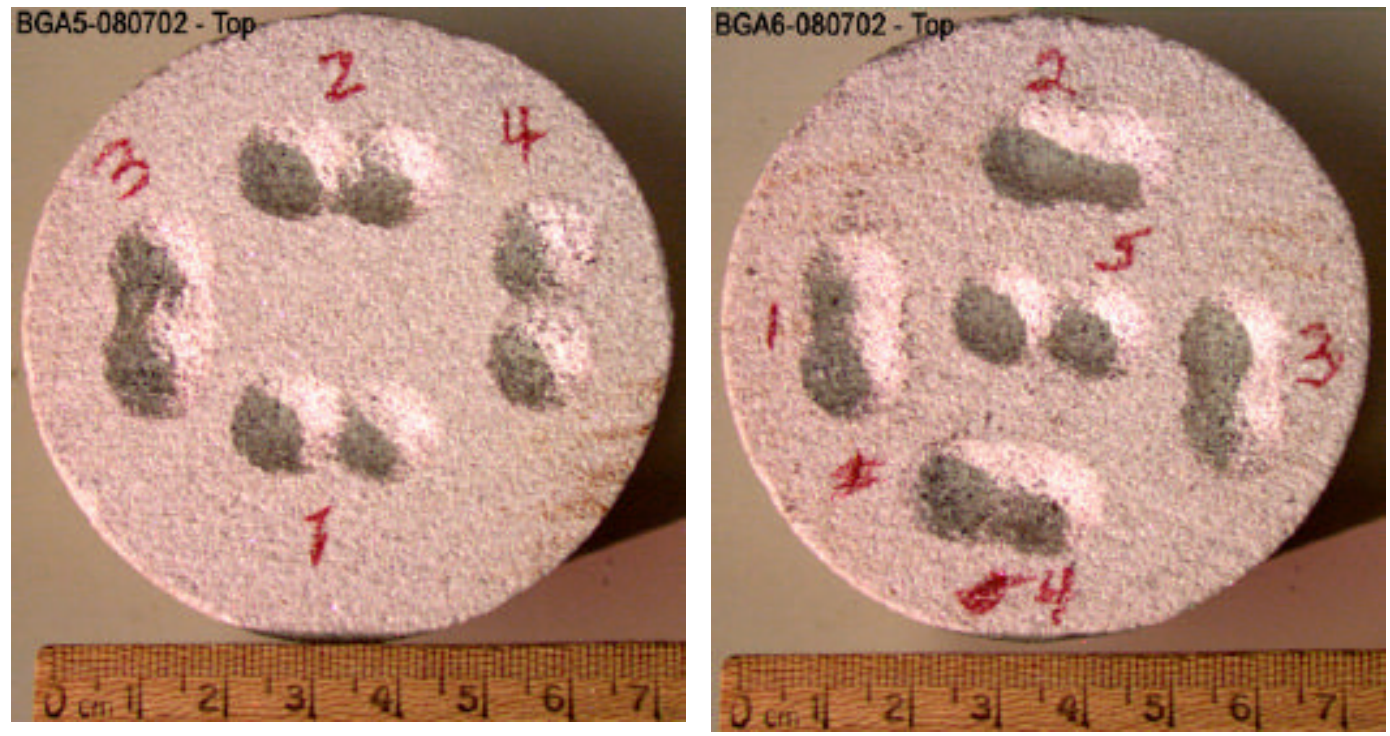

Figure 2-10. Samples BG-A5 and BG-A6 show the effect of varying numbers of bursts and spacing. BG-A5, tests 1 to 3 were done at $1.1 \mathrm{~cm}$ spacing, with 4,6 and 8 total burst respectively. Test 4 was 1.27 $\mathrm{cm}$ spacing, with 8 bursts. Test 3 shows $1.1 \mathrm{~cm}$ spacing can remove the median ridge at higher bursts. Sample BG-A6, tests $1-4$ used $1.0 \mathrm{~cm}$ spacing, showing almost total ridge removal. Test 5 used $1.1 \mathrm{~cm}$ spacing with 6 bursts, and the median ridge is prominent.

Table $2-5$ lists the results of the tests. The rock cut more easily than the limestone or sandstone, but SE values are significantly higher than the optimized single shot single burst tests done in 2001.

The Nd:YAG shale three spot arrangement tests were all with the $1.1 \mathrm{~cm}$ spacing. The relaxation time for all tests was 2.5 seconds. The SE behavior is similar to the sandstone, with higher SE values, in general, than the single spot, single burst tests done previously, by almost an order of magnitude. The SE also increases with increasing numbers of bursts, even though melting is not much more evident in the higher burst number samples.

Figure 2-11 shows samples SH1D-2, the lowest SE result, and SH6D, the highest number of bursts and highest SE result. SH6D has only a slight amount of melt evident. It is not clear why the SH6D SE is so high. The most likely reason is that the hole is getting deep enough that secondary effects, such as exsolving gases absorbing the beam or particles released fro the sample staying in the beam and absorbing energy.

\section{Limestone}

Based on the one spot results on the Nd:YAG, it was decided not to attempt limestone multispot tests except on the $\mathrm{CO}_{2}$ laser. 

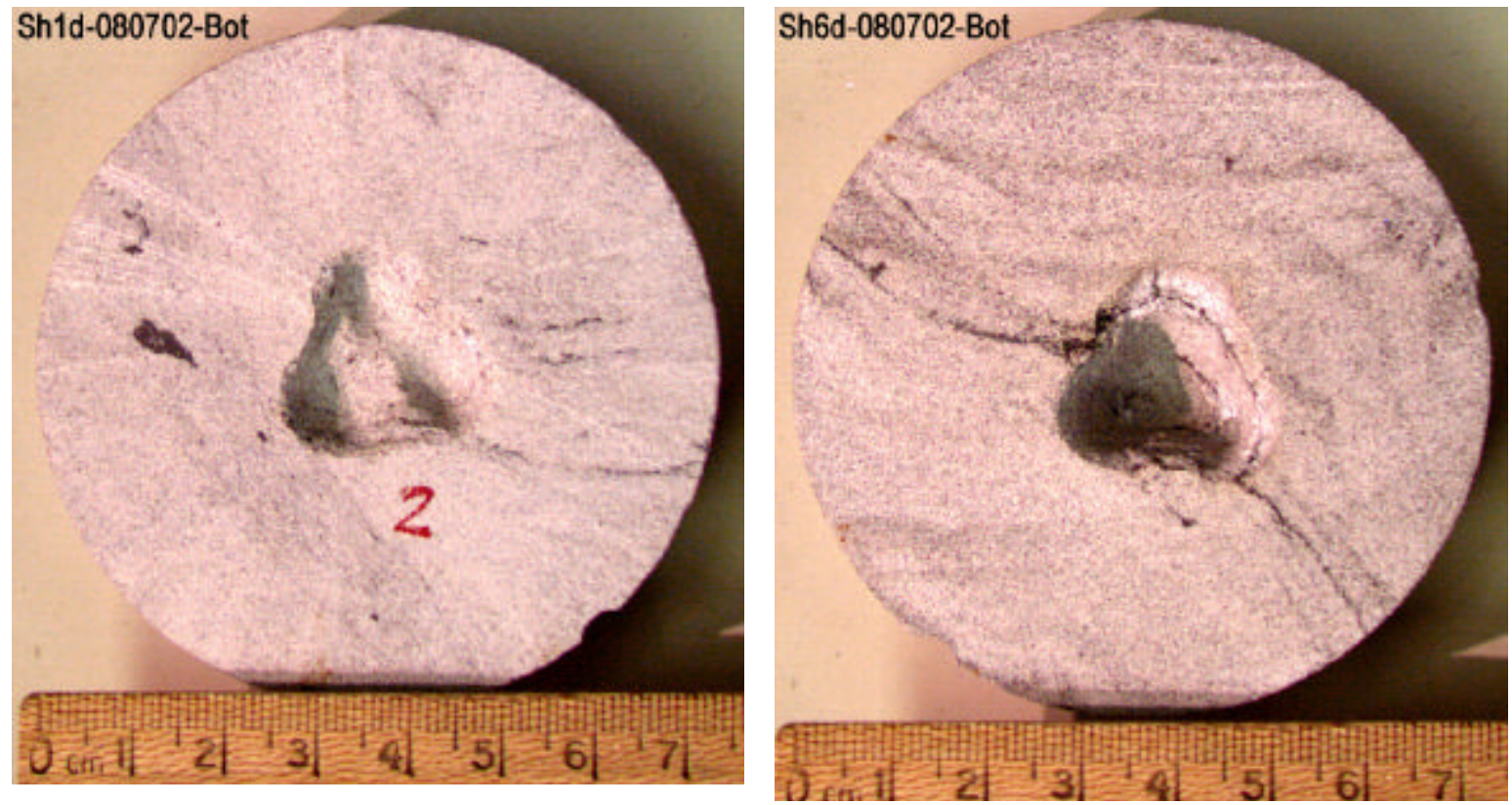

Figure 2-11. Photos of the lowest SE result (SH1D-2, left), and highest SE (SH6D, right). Note the small amount of melt in sample SH6D (white crust inside lip of hole).

\section{$\mathrm{CO}_{2}$}

The equipment setup and procedure were the same for both the Nd:YAG and the $\mathrm{CO}_{2}$ lasers. The higher average power of the $\mathrm{CO}_{2}$ laser allowed higher power densities at the $1.27 \mathrm{~cm}$ beam diameter, which strongly affected the limestone results. The beam characteristics were different between the two lasers. The Nd:YAG beam is strongly gaussian, with higher intensities in the center of the beam, decreasing gradually to the outer edge. The $\mathrm{CO}_{2}$ laser had multiple beam profiles, referred to as $\mathrm{TEM}_{00}$, which can be described as several concentric rings of amplitude creating a square beam with ripples on the top.

\section{Sandstone}

As laser wavelength does not seem to make a difference on Specific Energy for each sample (see Section 7, Wavelength Comparison, this report), the main reason to use the $\mathrm{CO}_{2}$ laser is to evaluate the effect of higher average power and power densities on the SE results. The sandstone tests were done with one setting on the $\mathrm{CO}_{2}, 2210$ watts average power and $1745 \mathrm{w} / \mathrm{cm}^{2}$ power density, compared with between 1210 watts average and $955 \mathrm{w} / \mathrm{cm}^{2}$ power density on the Nd:YAG. Figure 2-12 and Table 2-7 show the results, with the SE values being similar to those obtained with the Nd:YAG for similar test parameters. Figure 2-13 shows photos of representative samples of both sandstone and limestone tests on the $\mathrm{CO}_{2}$ 


\section{Limestone}

Limestone has a high threshold energy compared to sandstone and shale. That is, the amount of energy put that has to be put into the rock before spalling commences is higher than the other lithologies. Also, the energy has to be at a certain density to be effective. In order to reach the threshold energy and power density on the Nd:YAG laser, the spot size must be reduced to the point that it quickly becomes a narrow hole instead of a shallow one, which means that the secondary effects noted in previous narrow hole work become significant.

The liberated material cannot be scavenged and remains in the beam, parasitically absorbing energy Exsolved gasses also cannot be purged and also absorb beam energy that would otherwise be used to spall the rock.

Sandstone CO2 vs Nd:YAG

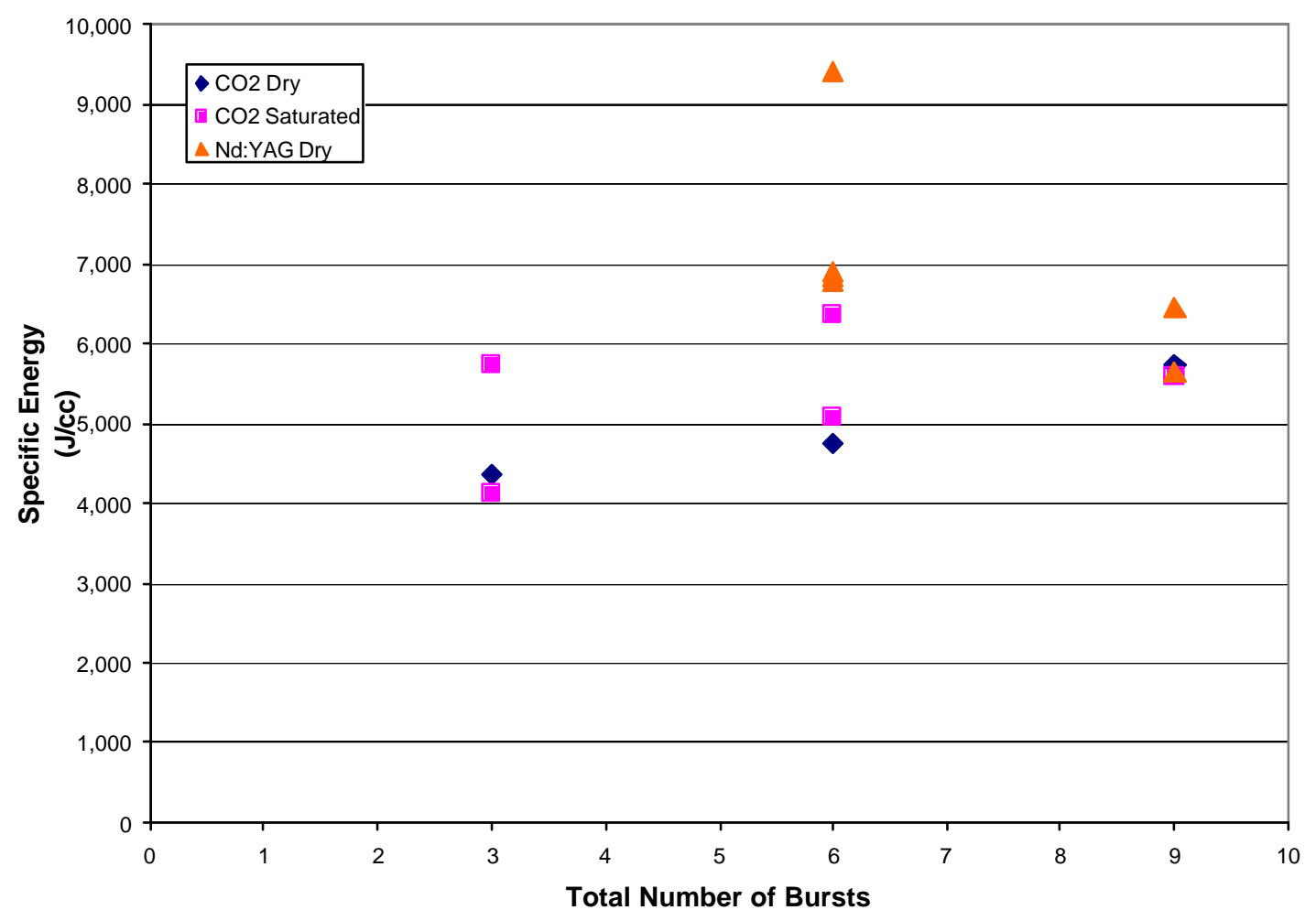

Figure 2-12. Comparison between sandstone results on the $\mathrm{CO} 2$ and Nd:YAG lasers. Spot size $(1.27 \mathrm{~cm})$, burst duration $(0.5 \mathrm{sec})$, number of spots $(3)$ and spot spacing $(1.1 \mathrm{~cm})$ are the same for all tests. Power density of the CO2 laser was $1745 \mathrm{w} / \mathrm{cm} 2$ compared to $955 \mathrm{w} / \mathrm{cm} 2$ for the Nd:YAG. While this difference is important for limestone, it does not seem to be

The higher average power available using the $\mathrm{CO}_{2}$ laser allowed the hole size to be expanded to the "standard" $1.27 \mathrm{~cm}$, while maintaining power densities high enough to get past the threshold. The results of the $\mathrm{CO}_{2}$ tests are shown in Figure 2-13 and tabulated in Table 2-8. In Figure 2-13, average power is used instead of power density, but the relationships are the same, as Pave increased, power density increases. Note that the power limit has not been reached, i.e., higher average power might result in a further reduction of SE values. At all of these values, the SE calculated is significantly lower than tests done on the Nd:YAG, often by an order of magnitude. 

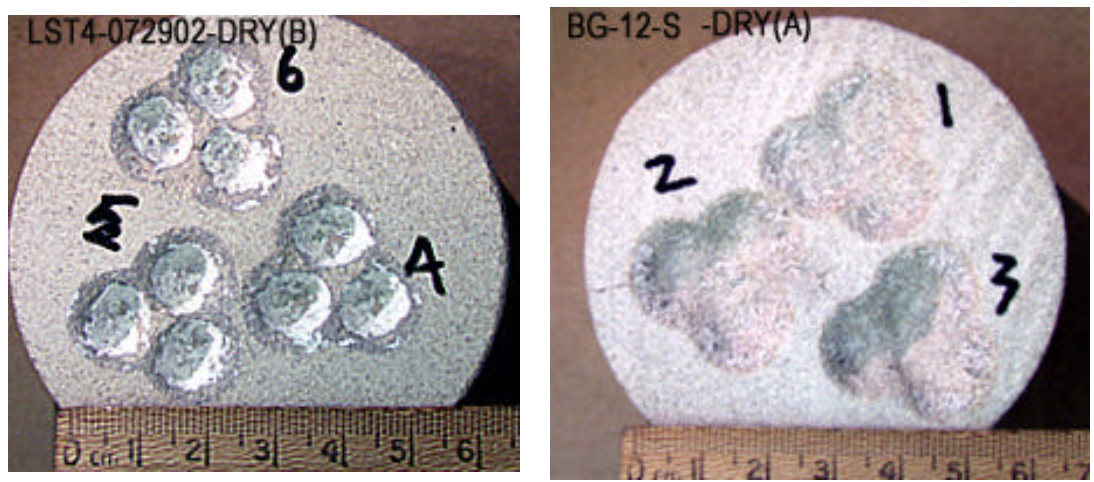

Figure 2-13. Examples of the CO2 laser test results. On left, limestone LST4, with three, three spot tests. SE values from this test are an order of magnitude less than the Nd:YAG tests. On right, sandstone BG-12-S. SE values for this test are in the same range as results of the Nd:YAG tests.

Limestone, Multispot Tests on the $\mathrm{CO} 2$

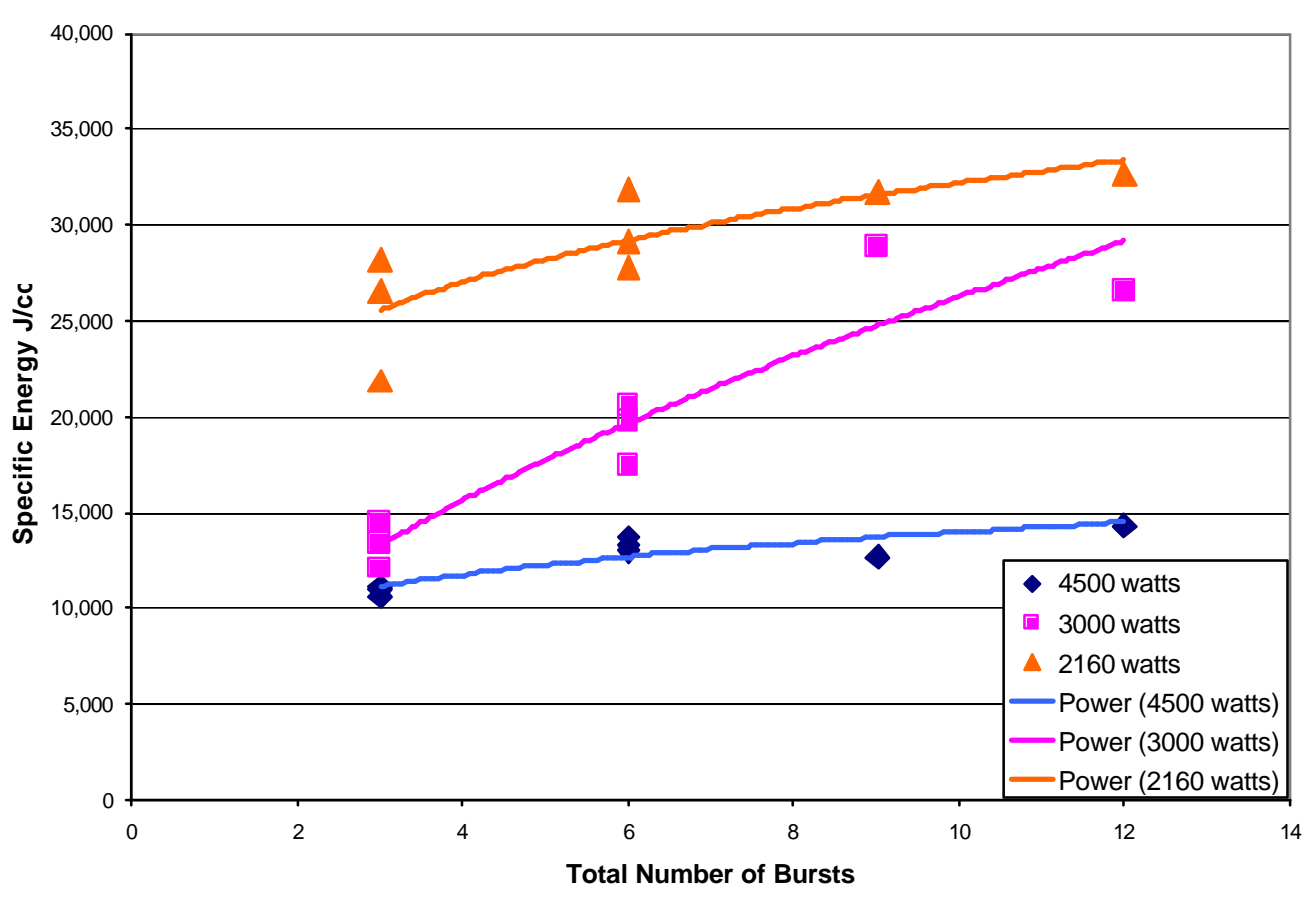

Figure 2-14. Limestone tests done on the $\mathrm{CO} 2$ laser. The physical parameters were the same for all tests, $1.27 \mathrm{~cm}$ spot size, $1.1 \mathrm{~cm}$ spot spacing, three spots for each test.

\section{Conclusions and Recommendations}

The results of the tests reported here do not by any means finish the fundamental work needed to move on to the stage of developing a working bench or field scale prototype of a laser drilling system. They do, however, provide indications of what a drilling system could look like. 


\section{Relaxation Times}

The SE values resulting from these tests are both troubling and encouraging. The sandstone and shale repeated spot and multiple spot tests indicate that SE increases with increasing numbers of repeats. The longer relaxation times resulting from the tests indicate that ROP may be limited by having to wait longer before illuminating the same spot again.

On the other hand, the tests revealed that limestone reacts extremely well to the application of higher power densities, as long as the spot size is kept large compared to the depth of the hole. The Nd:YAG was not able to accomplish this. The power density available at the geometric test spot size was at or below the threshold levels necessary to cut the rock, so SE values sky-rocketted. The $\mathrm{CO}_{2}$ laser, with much higher average power available, was able to increase power densities 2 to 4 times the YAG while keeping the same spot size.

The results from the range of average powers used on the $\mathrm{CO}_{2}$ laser indicate that it would be worthwhile to do further tests with higher average power settings and power densities for all lithologies.

\section{Geometry}

The multiple spot tests are very supportive of the fiber optic method of sending energy downhole. The geometric combination of many small spots will create a larger hole while avoiding the development of large amounts of energy-robbing melt. The investigation done to prepare the accompanying report on fiber optic capabilities (Ref. 3) combined with the work reported in this report indicates that fibers are capable of carrying power levels high enough to allow geometrically placed spot sizes with power densities in the range necessary to cut rock efficiently and quickly.

\section{Recommendations}

\section{Further Testing}

As mentioned above, it could be revealing to perform a series of fundamental tests using higher power densities ( 2 to $4 \mathrm{~kW} / \mathrm{cm}^{2}$, compared to the $1 \mathrm{~kW} / \mathrm{cm}^{2}$ used for most of the tests reported here) and higher numbers of repeats at the different geometries.

Future tests should use equipment that allows movement of the beam rather than the sample. The amount of time required to accelerate and decelerate the sample to a new location cannot be reduced much. If the beam could be switched from fiber to fiber, the time between shots could be reduced to almost instantaneous, which would allow better simulation of a design for a downhole laser head.

\section{Application to Goal}

This series of tests has taken the research team much closer to realizing the goal of developing a laser drilling system. The ideas that have been merely drawings or concepts now can be shown to work at the level they were tested. Now, with some additional fundamental tests to fill in gaps and test related ideas, a system design can go forward toward a bench prototype that can combine the cutting, cooling and solids removal sub-systems needed for such a system. 
Table 2-1. The sandstone samples repeatedly lased in one spot showed a decrease in amount of material removed per shot as the number of repeats increased, with a corresponding increase in Specific Energy. The tests with longer relaxation times decreased less, but it is not clear if the difference is statistically significant. See Figure 2-3.

\begin{tabular}{|c|c|c|c|c|c|c|c|}
\hline Lithology & $\begin{array}{c}\text { Disk } \\
\text { Number }\end{array}$ & $\begin{array}{c}\text { Spot } \\
\text { Number(s) }\end{array}$ & $\begin{array}{c}\text { Number of } \\
\text { Bursts }\end{array}$ & $\begin{array}{c}\text { Time } \\
\text { Between } \\
\text { Bursts (s) }\end{array}$ & $\begin{array}{c}\text { Total } \\
\text { Weight } \\
\text { Lost (g) }\end{array}$ & $\begin{array}{c}\text { Average } \\
\text { Weight } \\
\text { Loss per } \\
\text { Burst (g) }\end{array}$ & $\begin{array}{c}\text { Specific } \\
\text { Energy (J/cc) }\end{array}$ \\
\hline BG & A1 & 7 & 1 & 0 & 0.240 & 0.240 & 5,040 \\
\hline BG & A3 & 5 & 1 & 0 & 0.240 & 0.240 & 5,303 \\
\hline BG & A1 & 8 & 5 & 0 & 0.540 & 0.108 & 11,666 \\
\hline BG & A1 & $1,2 \& 3$ & 2 & 0.5 & 1.210 & 0.202 & 6,371 \\
\hline BG & A3 & 1 & 2 & 0.5 & 0.400 & 0.200 & 6364 \\
\hline BG & A1 & $4,5 \& 6$ & 3 & 0.5 & 1.790 & 0.199 & 6,344 \\
\hline BG & A2 & $1,2 \& 3$ & 4 & 0.5 & 2.040 & 0.170 & 7,464 \\
\hline BG & A2 & $4,5 \& 6$ & 5 & 0.5 & 2.080 & 0.139 & 9,101 \\
\hline BG & A3 & $2,3 \& 4$ & 2 & 1 & 1.220 & 0.203 & 6,270 \\
\hline BG & A4 & $7,8 \& 9$ & 3 & 1 & 1.220 & 0.136 & 9,552 \\
\hline BG & A3 & $7,8 \& 9$ & 3 & 1.5 & 1.570 & 0.174 & 7,323 \\
\hline BG & A4 & $1 \& 2$ & 4 & 1.5 & 1.150 & 0.144 & 8,855 \\
\hline BG & A4 & $4,5 \& 6$ & 5 & 1.5 & 1.910 & 0.127 & 10,240 \\
\hline
\end{tabular}


Table 2-2. Single hole repeated test results for the organic rich clayey shale used in this test series. The Specific Energies are generally higher than for single burst tests, but are still lower than for the sandstone.

\begin{tabular}{|c|c|c|c|c|c|c|c|}
\hline Lithology & $\begin{array}{c}\text { Disk } \\
\text { Number }\end{array}$ & $\begin{array}{c}\text { Spot } \\
\text { Number(s) }\end{array}$ & $\begin{array}{c}\text { Number of } \\
\text { Bursts }\end{array}$ & $\begin{array}{c}\text { Time } \\
\text { Between } \\
\text { Bursts (s) }\end{array}$ & $\begin{array}{c}\text { Total } \\
\text { Weight } \\
\text { Lost (g) }\end{array}$ & $\begin{array}{c}\text { Average } \\
\text { Weight Loss } \\
\text { per Burst (g) }\end{array}$ & $\begin{array}{c}\text { Specific } \\
\text { Energy (J/cc) }\end{array}$ \\
\hline SH & 1 & 1 & 2 & 0.5 & 0.460 & 0.230 & 3,561 \\
\hline SH & 1 & 2 & 2 & 0.5 & 0.460 & 0.230 & 3,561 \\
\hline SH & 1 & 3 & 2 & 0.5 & 0.370 & 0.185 & 4,427 \\
\hline SH & 1 & 4 & 3 & 0.5 & 0.510 & 0.170 & 4,817 \\
\hline SH & 1 & 5 & 3 & 0.5 & 0.690 & 0.230 & 3,561 \\
\hline SH & 1 & 6 & 3 & 0.5 & 0.570 & 0.190 & 4,310 \\
\hline
\end{tabular}

Table 2-3: Single hole repeated test results for the quarry limestone. Because of the small hole size required to have an energy density high enough to cut the limestone, secondary effects seen in the GRI/CSM tests became apparent here, resulting in very high specific energies.

\begin{tabular}{|c|c|c|c|c|c|c|c|c|}
\hline Lithology & $\begin{array}{c}\text { Disk } \\
\text { Number }\end{array}$ & $\begin{array}{c}\text { Spot } \\
\text { Number(s) }\end{array}$ & $\begin{array}{c}\text { Burst } \\
\text { Length } \\
(\mathbf{s})\end{array}$ & $\begin{array}{c}\text { Number of } \\
\text { Bursts }\end{array}$ & $\begin{array}{c}\text { Time } \\
\text { Between } \\
\text { Bursts (s) }\end{array}$ & $\begin{array}{c}\text { Total } \\
\text { Weight } \\
\text { Lost (g) }\end{array}$ & $\begin{array}{c}\text { Average } \\
\text { Weight } \\
\text { Loss per } \\
\text { Burst (g) }\end{array}$ & $\begin{array}{c}\text { Specific } \\
\text { Energy } \\
(\mathbf{J} / \mathbf{c c})\end{array}$ \\
\hline LS & T1 & 3 & 0.5 & 2 & 0.5 & 0.030 & 0.015 & 106,560 \\
\hline LS & T1 & 4 & 0.5 & 5 & 0 & 0.040 & 0.008 & 199,800 \\
\hline LS & T1 & 1 & 0.5 & 2 & 0.5 & 0.010 & 0.005 & 319,680 \\
\hline LS & T1 & 2 & 1 & 2 & 0.5 & 0.010 & 0.005 & 639,360 \\
\hline
\end{tabular}


Table 2-4. Results of two, three and four spot sandstone tests. Note that the two spot tests were done at two spacings, $1.1 \mathrm{~cm}$ and $1.0 \mathrm{~cm}$ separation.

\begin{tabular}{|c|c|c|c|c|c|c|c|c|c|}
\hline Lithology & $\begin{array}{c}\text { Disk } \\
\text { Number }\end{array}$ & Spot(s) & $\begin{array}{c}\text { Number } \\
\text { of Spots }\end{array}$ & $\begin{array}{c}\text { Spot } \\
\text { Spacing } \\
\text { (cm) }\end{array}$ & $\begin{array}{c}\text { Number } \\
\text { of Bursts } \\
\text { per Spot }\end{array}$ & $\begin{array}{c}\text { Weight } \\
\text { Lost (g) }\end{array}$ & $\begin{array}{c}\text { Weight } \\
\text { Lost per } \\
\text { Spot (g) }\end{array}$ & $\begin{array}{c}\text { Weight } \\
\text { Lost per } \\
\text { Spot per } \\
\text { Burst (g) }\end{array}$ & $\begin{array}{c}\text { Specific } \\
\text { Energy } \\
\text { (J/cc) }\end{array}$ \\
\hline BG & A5 & 1 & 2 & 1.1 & 2 & 0.760 & 0.380 & 0.190 & 6,699 \\
\hline BG & A5 & 2 & 2 & 1.1 & 3 & 0.970 & 0.485 & 0.162 & 7,873 \\
\hline BG & A5 & 3 & 2 & 1.1 & 4 & 0.890 & 0.445 & 0.111 & 11,441 \\
\hline BG & A5 & 4 & 2 & 1.27 & 8 & 0.600 & 0.300 & 0.038 & 33,941 \\
\hline BG & A5 & $5,6 \& 7$ & 2 & 1.1 & 5 & 0.723 & 0.362 & 0.072 & 17,875 \\
\hline BG & A5 & 8 & 2 & 1.1 & 10 & 0.470 & 0.235 & 0.024 & 54,162 \\
\hline BG & A6 & 1 & 2 & 1.0 & 2 & 0.710 & 0.355 & 0.177 & 7,328 \\
\hline BG & A6 & 2 & 2 & 1.0 & 3 & 1.210 & 0.605 & 0.202 & 6,450 \\
\hline BG & A6 & 3 & 2 & 1.0 & 4 & 0.850 & 0.425 & 0.106 & 12,242 \\
\hline BG & A6 & 4 & 2 & 1.0 & 5 & 1.150 & 0.575 & 0.115 & 11,311 \\
\hline BG & A6 & 5 & 2 & 1.1 & 3 & 0.830 & 0.415 & 0.138 & 9,403 \\
\hline BG & A6 & $6,7,8 \& 9$ & 3 & 1.1 & 2 & 1.063 & 0.354 & 0.177 & 7,486 \\
\hline BG & A7 & $1 \& 2$ & 3 & 1.1 & 3 & 1.950 & 0.650 & 0.217 & 6,030 \\
\hline BG & A8 & $1,2 \& 3$ & 3 & 1.1 & 4 & 2.093 & 0.698 & 0.174 & 7,562 \\
\hline BG & A8 & $4 \& 5$ & 3 & 1.1 & 5 & 2.770 & 0.923 & 0.185 & 7,070 \\
\hline BG & A9 & $1 \& 2$ & 3 & 1.1 & 6 & 2.575 & 0.858 & 0.143 & 9,587 \\
\hline BG & A10 & 1 & 3 & 1.1 & 6 & 3.400 & 1.133 & 0.189 & 6,886 \\
\hline BG & A11 & 1 & 3 & 1.1 & 10 & 4.970 & 1.657 & 0.166 & 7,527 \\
\hline BG & A11 & 2 & 3 & 1.1 & 15 & 5.620 & 1.873 & 0.125 & 9,985 \\
\hline BG & A12 & 1 & 3 & 1.1 & 15 & 6.520 & 2.173 & 0.145 & 8,607 \\
\hline BG & A14 & 1 & 4 & 1.1 & 10 & 6.780 & 1.695 & 0.169 & 7,357 \\
\hline BG & A14 & 2 & 4 & 1.1 & 10 & 6.160 & 1.540 & 0.154 & 8,097 \\
\hline
\end{tabular}


Table 2-5: Results of the three spot, multiple pass shale tests done on the Nd:YAG laser. The samples were all the same geometry, with $1.1 \mathrm{~cm}$ spot spacing and the same 2.5 second relaxation time, but with increasing numbers of repeats, from 2 to 15.

\begin{tabular}{|l|c|c|c|c|c|c|c|c|c|}
\hline Lithology & $\begin{array}{c}\text { Disk } \\
\text { Label }\end{array}$ & $\begin{array}{c}\text { Test } \\
\text { Number }\end{array}$ & $\begin{array}{c}\text { Number } \\
\text { of Spots }\end{array}$ & $\begin{array}{c}\text { Separation } \\
\text { Between } \\
\text { Spot } \\
\text { Centers } \\
(\mathbf{c m})\end{array}$ & $\begin{array}{c}\text { Number } \\
\text { of Bursts } \\
\text { per Spot }\end{array}$ & $\begin{array}{c}\text { Total } \\
\text { Number } \\
\text { of Bursts }\end{array}$ & $\begin{array}{c}\text { Delta } \\
\text { Weight } \\
\text { (g) }\end{array}$ & $\begin{array}{c}\text { Delta } \\
\text { Weight } \\
\text { per Burst } \\
(\mathbf{g})\end{array}$ & $\begin{array}{c}\text { Specific } \\
\text { energy } \\
(\mathbf{J} / \mathbf{c c})\end{array}$ \\
\hline SH & 1D & 1 & 3 & 1.1 & 2 & 6 & 1.48 & 0.247 & 5,549 \\
\hline SH & 1D & 2 & 3 & 1.1 & 3 & 9 & 2.9 & 0.322 & 4,248 \\
\hline SH & 3D & 1 & 3 & 1.1 & 4 & 12 & 3.24 & 0.270 & 5,070 \\
\hline SH & 3D & 2 & 3 & 1.1 & 6 & 18 & 4.76 & 0.264 & 5,176 \\
\hline SH & 4D & 2 & 3 & 1.1 & 6 & 18 & 3.17 & 0.176 & 7,571 \\
\hline SH & 5D & 1 & 3 & 1.1 & 10 & 30 & 7.23 & 0.241 & 5,533 \\
\hline SH & 6D & 1 & 3 & 1.1 & 15 & 45 & 5.1 & 0.113 & 11,765 \\
\hline SH & 7D & 1 & 3 & 1.1 & 15 & 45 & 6.06 & 0.135 & 9,901 \\
\hline
\end{tabular}

Table 2-6. ND:Yag laser, sandstone tests where the lens assembly was moved downward as the pattern was repeated. One test was two spots, the rest three. BG A13-1\&2 result is average of two tests with identical parameters.

\begin{tabular}{|c|c|c|c|c|c|c|c|l|l|l|}
\hline Lithology & $\begin{array}{l}\text { Disk } \\
\text { Number }\end{array}$ & Test \# & $\begin{array}{l}\text { Number } \\
\text { of Spots }\end{array}$ & $\begin{array}{l}\text { Number } \\
\text { of Bursts } \\
\text { per Spot }\end{array}$ & $\begin{array}{l}\text { Total } \\
\text { Number } \\
\text { of Bursts }\end{array}$ & $\begin{array}{l}\text { Vertical } \\
\text { Lens } \\
\text { Movemen } \\
\text { (mm) }\end{array}$ & $\begin{array}{l}\text { Weigh } \\
\text { t Lost } \\
(\mathbf{g})\end{array}$ & $\begin{array}{l}\text { Weight Weight } \\
\text { Lost } \\
\text { per } \\
\text { Spot } \\
\text { (g) }\end{array}$ & $\begin{array}{l}\text { Specific } \\
\text { Lost per } \\
\text { Spot per } \\
\text { Burst (g) }\end{array}$ & $\begin{array}{l}\text { Energy } \\
(\mathbf{J} / \mathbf{c c})\end{array}$ \\
\hline BG & A6 & 5 & 2 & 3 & 6 & 1.6 & 0.830 & 0.415 & 0.138 & 9,403 \\
\hline BG & A10 & 2 & 3 & 6 & 18 & 1.6 & 3.050 & 1.017 & 0.169 & 7,677 \\
\hline BG & $\mathrm{A} 12$ & 2 & 3 & 15 & 45 & 0.5 & 6.680 & 2.227 & 0.148 & 8,400 \\
\hline BG & A13 & $1 \& 2$ & 3 & 30 & 90 & 0.25 & 9.145 & 3.048 & 0.102 & 13,001 \\
\hline
\end{tabular}


Table 2-7. $\mathrm{CO}_{2}$ laser sandstone tests. BG-12 was dry, BG-11 was saturated, but not submerged. Power density on the $\mathrm{CO}_{2}$ laser was higher than that for the Nd:YAG, at $1745 \mathrm{w} / \mathrm{cm}^{2}$ versus 916 to $955 \mathrm{w} / \mathrm{cm}^{2}$. Physical parameters were set at $1.27 \mathrm{~cm}$ spot size and three spots at $1.1 \mathrm{~cm}$ spacing for all tests.

\begin{tabular}{|c|c|c|c|c|c|c|c|c|}
\hline Lithology & $\begin{array}{c}\text { Disk } \\
\text { Number }\end{array}$ & Test \# & $\begin{array}{c}\text { Number } \\
\text { of Bursts } \\
\text { per spot }\end{array}$ & $\begin{array}{c}\text { Total } \\
\text { Number of } \\
\text { Bursts }\end{array}$ & $\begin{array}{c}\text { Time } \\
\text { Between } \\
\text { Bursts } \\
(\mathbf{s})\end{array}$ & $\begin{array}{c}\text { Time Between } \\
\text { Bursts on } \\
\text { Same Spot }\end{array}$ & $\begin{array}{c}\text { Delta } \\
\text { Weight } \\
(\mathbf{g})\end{array}$ & $\begin{array}{c}\text { Specific } \\
\text { Energy J/cc) }\end{array}$ \\
\hline BG- & $12 \mathrm{~S}$ & 1 & 1 & 3 & 0.5 & 2.5 & 2.060 & 4,345 \\
\hline BG- & $12 \mathrm{~S}$ & 2 & 2 & 6 & 0.5 & 2.5 & 3.760 & 4,761 \\
\hline BG- & $12 \mathrm{~S}$ & 3 & 3 & 9 & 0.5 & 2.5 & 4.700 & 5,713 \\
\hline BG- & $11 \mathrm{~S}, \mathrm{SAT}$ & 1 & 1 & 3 & 0.5 & 2.5 & 2.170 & 4,125 \\
\hline BG- & $11 \mathrm{~S}, \mathrm{SAT}$ & 2 & 2 & 6 & 0.5 & 2.5 & 2.820 & 6,348 \\
\hline BG- & $11 \mathrm{~S}, \mathrm{SAT}$ & 3 & 3 & 9 & 0.5 & 2.5 & 4.810 & 5,582 \\
\hline BG- & $11 \mathrm{~S}, \mathrm{SAT}$ & 4 & 1 & 3 & 0.5 & 2.5 & 1.560 & 5,737 \\
\hline BG- & $11 \mathrm{~S}, \mathrm{SAT}$ & 5 & 2 & 6 & 0.5 & 2.5 & 3.520 & 5,086 \\
\hline
\end{tabular}

Table 2-8. $\mathrm{CO}_{2}$ laser limestone tests. The higher average power available with the $\mathrm{CO}_{2}$ laser allowed the spot size to be increased to $1.27 \mathrm{~cm}$ in diameter while maintaining a power density high enough to exceed the threshold needed for limestone. This combination resulted in Specific Energy values an order of magnitude less than the small hole tests done on the Nd:YAG. Compare with Table 2-3.

\begin{tabular}{|c|c|c|c|c|c|c|c|c|c|}
\hline Lithology & $\begin{array}{c}\text { Disk } \\
\text { Number }\end{array}$ & Test \# & $\begin{array}{c}\text { Power } \\
\text { Density } \\
\left(\mathbf{w} / \mathbf{c m}^{2}\right)\end{array}$ & $\begin{array}{c}\text { Number } \\
\text { of Bursts } \\
\text { per spot }\end{array}$ & $\begin{array}{c}\text { Total } \\
\text { Number of } \\
\text { Bursts }\end{array}$ & $\begin{array}{c}\text { Time } \\
\text { Between } \\
\text { Bursts } \\
\text { (s) }\end{array}$ & $\begin{array}{c}\text { Time Between } \\
\text { Bursts on } \\
\text { Same Spot }\end{array}$ & $\begin{array}{c}\text { Delta } \\
\text { Weight } \\
\text { (g) }\end{array}$ & $\begin{array}{c}\text { Specific } \\
\text { Energy }\end{array}$ \\
\hline LST & 4 & $1,2 \& 3$ & 3552 & 1 & 3 & 0.5 & 2.5 & 1.677 & 10,874 \\
\hline LST & 4 & $4,5 \& 6$ & 3552 & 2 & 6 & 0.5 & 2.5 & 2.737 & 13,325 \\
\hline LST & 5 & 1 & 3552 & 3 & 9 & 0.5 & 2.5 & 4.330 & 12,627 \\
\hline LST & 5 & 2 & 3552 & 4 & 12 & 0.5 & 2.5 & 5.110 & 14,266 \\
\hline LST & 5 & $3,4 \& 5$ & 2368 & 1 & 3 & 0.5 & 2.5 & 0.920 & 13,282 \\
\hline LST & 5 & 6 & 2368 & 2 & 6 & 0.5 & 2.5 & 1.390 & 17,482 \\
\hline LST & 6 & $1 \& 2$ & 2368 & 2 & 6 & 0.5 & 2.5 & 1.205 & 20,175 \\
\hline LST & 6 & 3 & 2368 & 2 & 6 & 0.5 & 2.5 & 1.260 & 28,929 \\
\hline LST & 6 & 4 & 2368 & 3 & 9 & 0.5 & 2.5 & 1.830 & 26,557 \\
\hline LST & 6 & 5 & 1705 & 4 & 12 & 0.5 & 2.5 & 0.330 & 26,509 \\
\hline LST & 6 & 6 & 1705 & 1 & 3 & 0.5 & 2.5 & 0.310 & 28,219 \\
\hline LST & 9 & 1 & 1705 & 1 & 3 & 0.5 & 2.5 & 0.400 & 21,870 \\
\hline LST & 9 & $2,3 \& 4$ & 1705 & 2 & 6 & 0.5 & 2.5 & 0.593 & 29,581 \\
\hline LST & 9 & 5 & 1745 & 3 & 9 & 0.5 & 2.5 & 0.830 & 32,351 \\
\hline LST & 9 & 6 & 1745 & 4 & 12 & 0.5 & 2.5 & 1.070 & 33,460 \\
\hline LST & 7 & 1 & 1705 & 2 & 6 & 0.5 & 2.5 & 0.630 & 27,771 \\
\hline
\end{tabular}




\section{LASER TESTING OF ROCK SAMPLES IN LIQUID}

\section{Introduction}

The laser drilling team, formed by Argonne National Laboratory (ANL), Gas Technology Institute (GTI), Colorado School of Mines (CSM), Parker Geoscience Consulting (PGC), Halliburton Energy Service and PDVSA, processed over 100 dry or water-saturated sandstone, limestone and shale samples in 2001 with modern high powered lasers. The results strongly show that laser technology applied to drilling and completing oil and gas wells has the potential to reduce drilling time and improve well performance through improved perforation operations. To further simulate the real well drilling downhole environment, which involves liquids such as drilling mud, water, oil, the team decides to carry out laser testing of rock samples in liquid to (1) understand laser power attenuation through water and (2) determine the most efficient laser parameters to lase rock through water. This report will present the test results using ANL $6 \mathrm{~kW}$ $\mathrm{CO}_{2}$ laser and $1.6 \mathrm{~kW}$ pulsed $\mathrm{Nd}$ :YAG laser on rocks under two different water configurations: free water above submerged rock samples and across water jet flowing over top rock surface.

\section{Equipment Setup}

The preliminary tests described in INTRODUCTION Chapter indicated that the closed metal box was not usable for the test series. The box was used for a small number of tests to allow the use of the jet across the surface, but the majority of the tests done during the formal test period were done in the glass basin. After the jet speed was reduced and finally removed, the glass basin actually provided much better control of the thickness of the water above the rock sample than the water jet in the metal box. However, the debris cloud formed in the water by the beam action on the rock absorbed the beam energy by an unknown amount. The addition of a funnel in an attempt to isolate and quiet the water surface directly under the beam was partially successful in allowing the debris-clouded water to be swept from under the beam.

\section{Test Procedure}

Tap water of 60psi pressure directly from the water pipe was used for the laser rock drilling through water tests. The water was applied to the rock sample in two configurations.

\section{Free water above submerged rock}

In this water configuration, the rock sample was submerged in the water with free water thickness above the rock adjustable. A few preliminary tests were run to determine the maximum water thickness that could be penetrated by both lasers at specific power settings. It was determined to fire the beam on dry and saturated samples and then on the samples with $2 \mathrm{~mm}, 4 \mathrm{~mm}, 8$ $\mathrm{mm}$ free water.

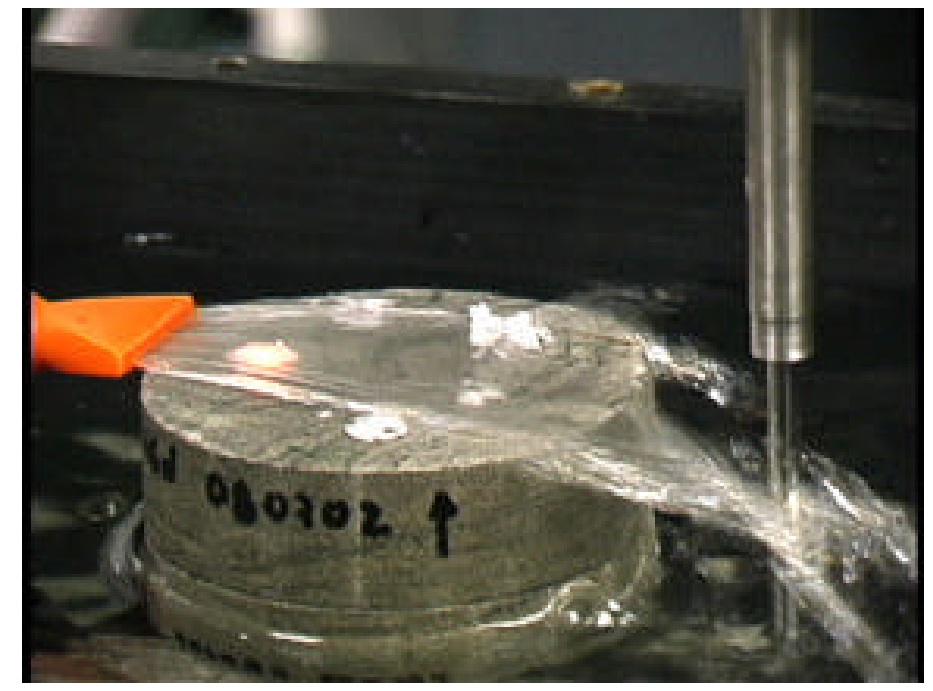

Figure 3-1. Digital picture showing cross water jet setup 


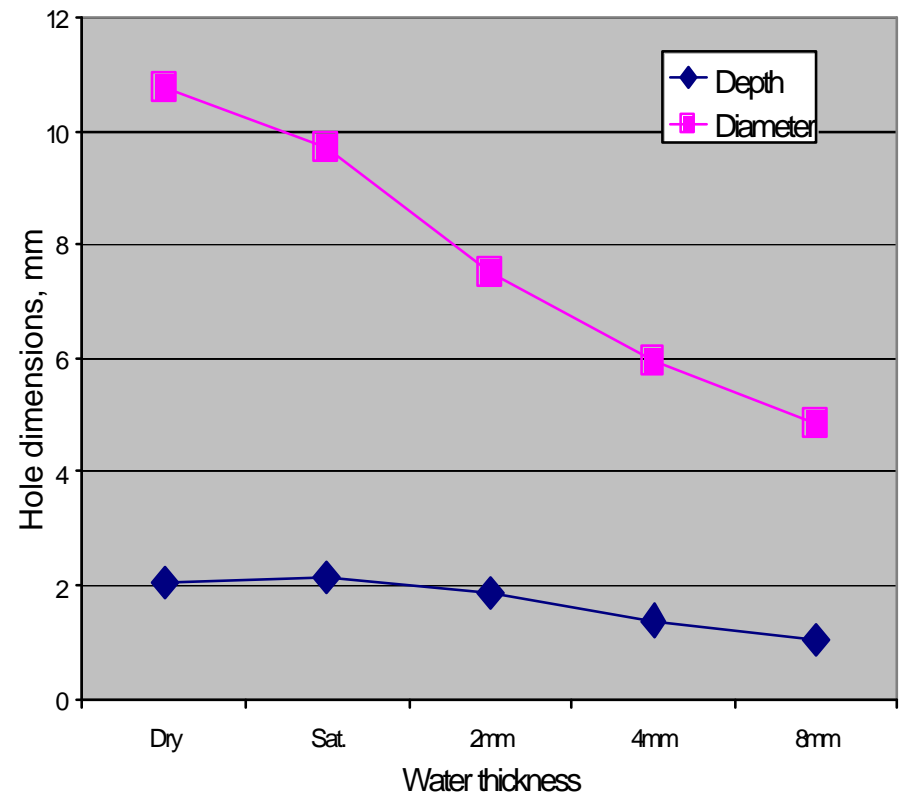

Figure 3-2. Hole dimensions as a function of water thickness on Berea gray sandstone lased by YAG laser at E8L2R100. Also shown at the bottom pictures of the holes with water conditions are from left to right: dry, saturated, $2 \mathrm{~mm}, 4$ $\mathrm{mm}$ and $8 \mathrm{~mm}$.
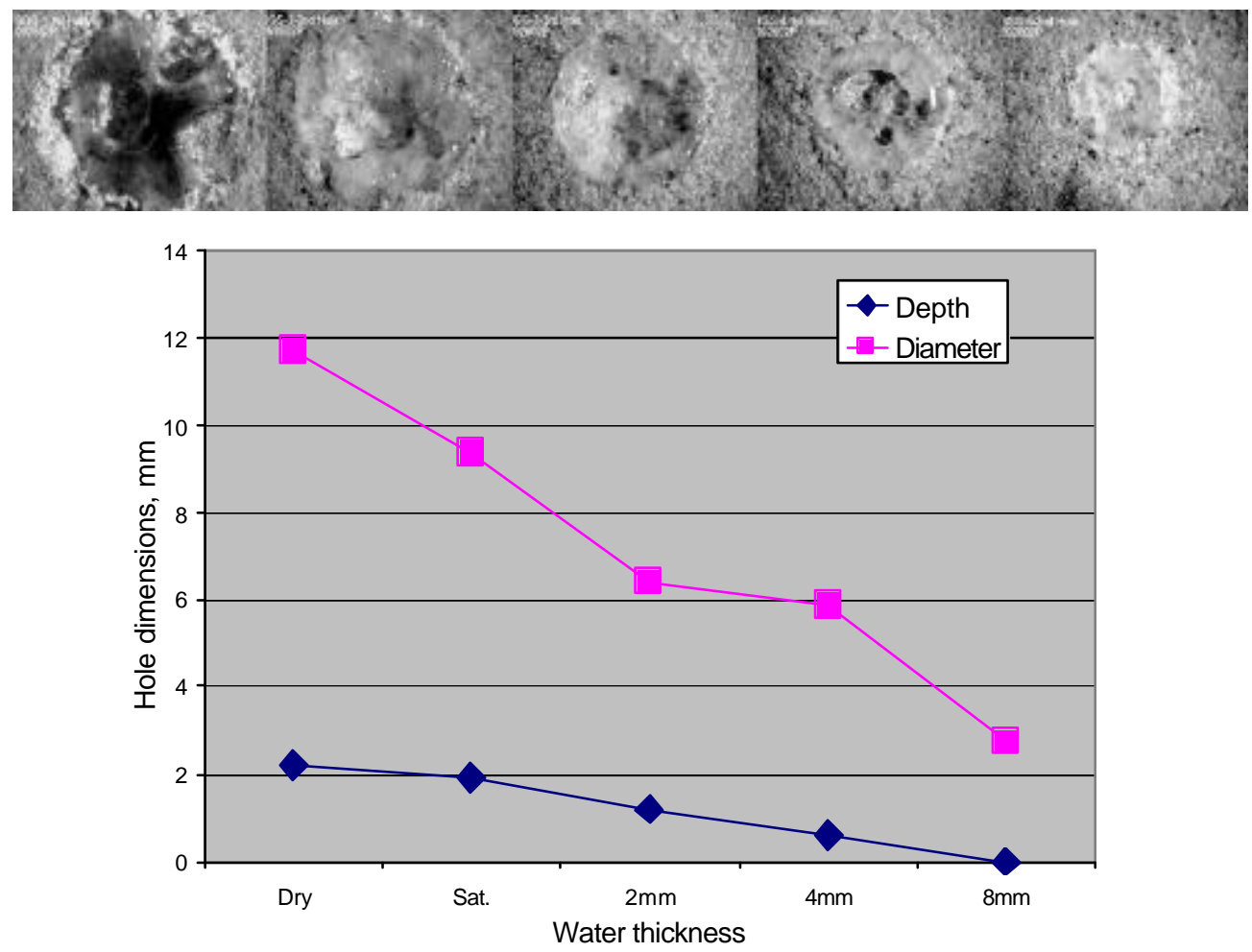

Figure 3-3. Hole dimensions as a function of water thickness on Berea gray sandstone lased by YAG laser at E32L0.5R100 


\section{Cross water jet over top rock surface}

Figure 3-1 shows the test configuration. In this test, the rock sample was placed into a metal box that was stationed on the $\mathrm{CNC}$ table. The tap water jet was then delivered over the top surface of the sample by a flat water nozzle. A vertical laser beam was fired through the water jet and drilled the rock underneath. It was assumed that the stable cross water jet would efficiently remove laser spalled rock chips and dust and create a clean water pass to the incoming laser beam like the purging gas did on the dry rock tests. The rock weights before and after lasing were measured for specific energy assessment.

\section{Visual assessment of laser rock destruction through water}

As the high pressure purging gas jet roiled the water so much in the preliminary tests, it was decided to use no purge at all in the tests of lasing through water. Without the help of the gas jet to remove hser destructed rock material from the hole, the rock was melted and lased material was remained. This made measuring the weight loss for specific energy assessment very difficult. Then the team decided to visually characterize the rock destruction using a stereo-microscope. The dimensions of lased holes, such as average hole diameter and maximum depth, were precisely measured and plotted against laser and water variables. Dry and water-saturated samples were also lased under the same conditions. Their hole dimensions were measured and used as the references.

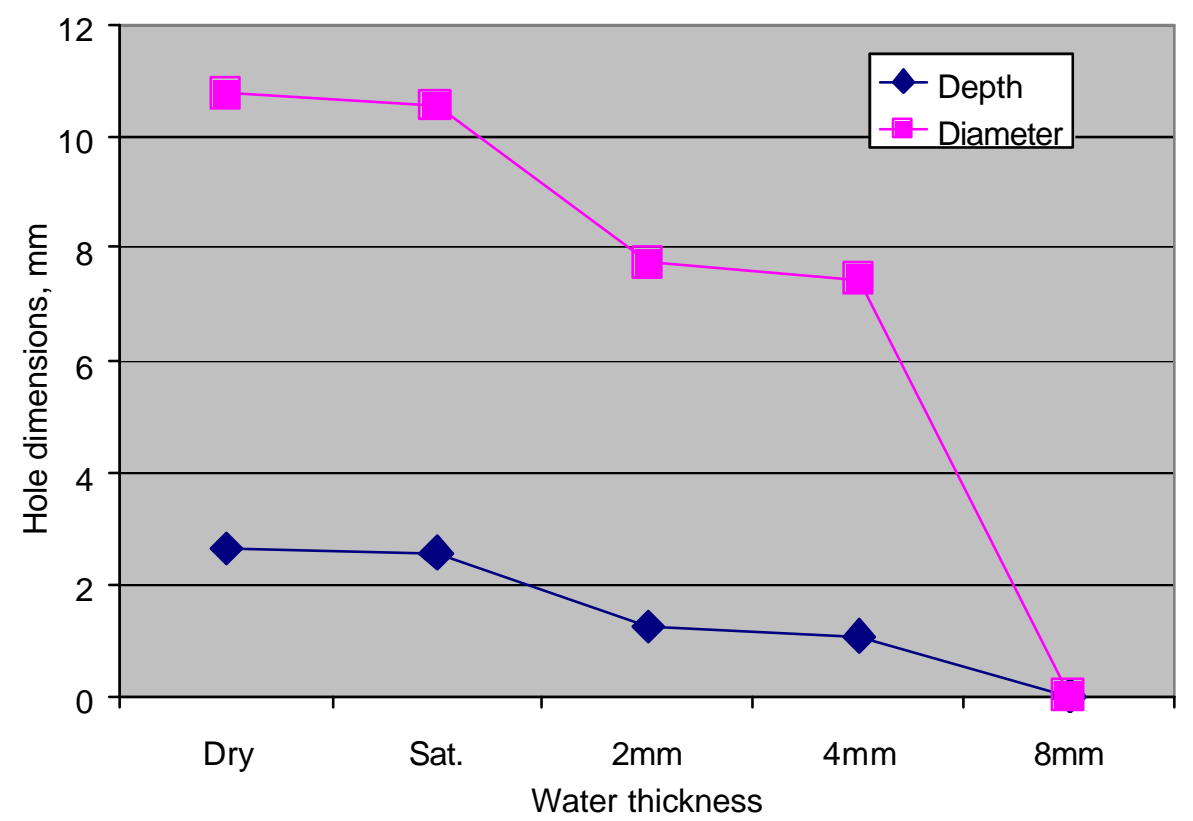

Figure 3-4 Hole Dimensions as a function of water Thickness on Mudstone Lased by Nd:YAG Laser at E32L0.5R100. 


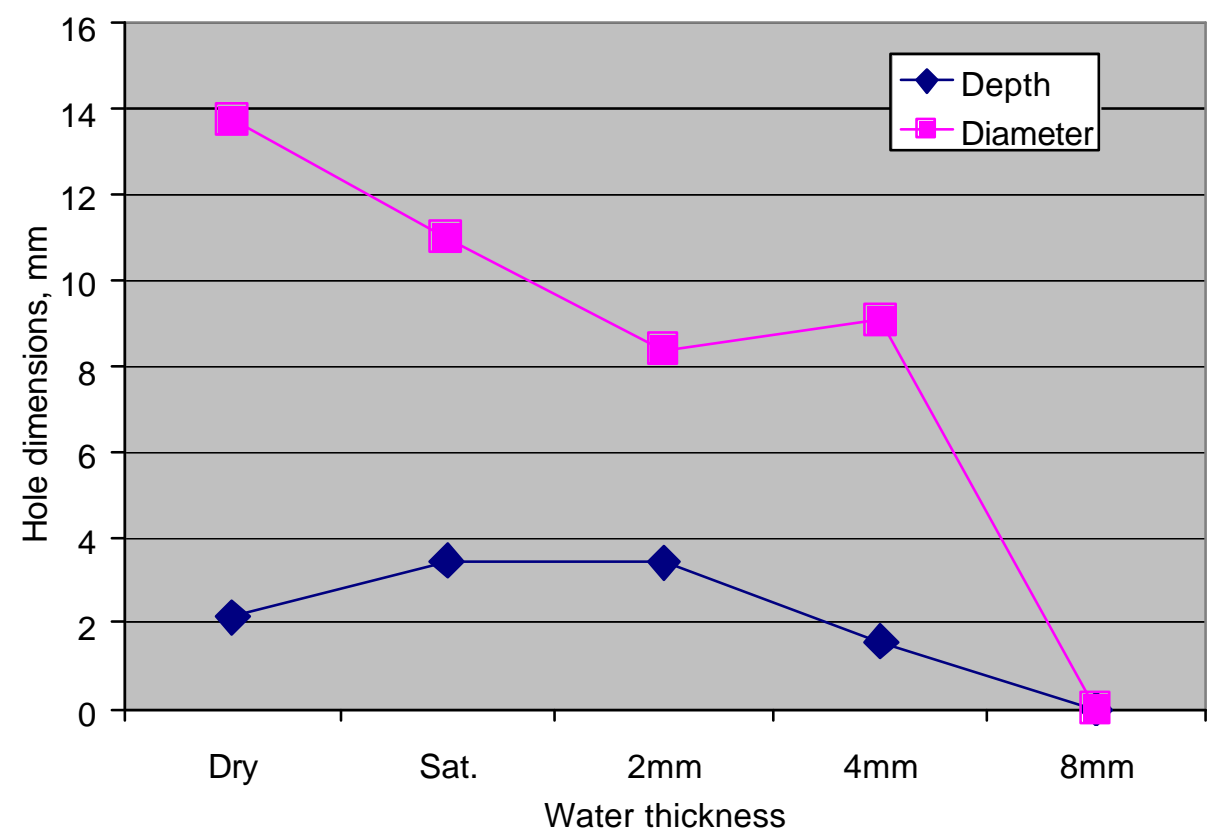

Figure 3.5 Hole dimensions as a function of water thickness on shale lased by Nd:YAG Laser at E32L0.5R100.

\section{Results \\ Effect Of Free Water Thickness On Laser Rock Destruction}

\section{ND:YAG laser}

The test conditions and results of Nd:YAG laser beam on rocks are listed in Table 3-1. Four rock types tested were: Berea gray sandstone, mudstone, shale and limestone. The ranges of water thickness above the sample surface tested were from 0 (dry and saturated) to $8 \mathrm{~mm}$. The measured laser average power of 1522 watts by a laser schedule E32L0.5R100 was used on all rocks. An additional schedule E8L2R100 with measured average power of 1250 watts was also applied to Berea gray sandstone. The lased time on the samples was fixed at one second for most of the tests. The hole dimensions of BG sandstone as a function of water thickness were plotted in Figure 3-2 at E8L2R100 and Figure 3-3 at E32L0.5R100. Also shown at the bottom of Figure 3-2 are pictures of the laser holes at E8L2R100 on BG sandstone with water conditions are from left to right: dry, saturated, $2 \mathrm{~mm}, 4 \mathrm{~mm}$ and $8 \mathrm{~mm}$.

Evidently, the lased hole sizes decreased as the water became deeper. This trend is true also to other rock types shown in Figure 3-4 for mudstone and Figure 3-5 for shale. The reduction of rock destruction through water compared to dry samples with zero water thickness, indicates that more laser energy was consumed through penetrating the water and less laser energy actually reached to the rock as the water became thicker. The incoming laser energy was partially reflected by the water surface, absorbed by the water, absorbed and partially blocked by the plume of a cloud of materials from the lased rock. With no purge, the plume of exsolved bubbles and debris went straight up and remained in the beam, which further reduced the amount of 
energy available to the rock (Figure 3-8). The water was changed often, as it became visibly cloudy after one or two samples (three-six spots each). Boiling and roiling of the water also resulted in splashing water on the protective cover glass on most tests. If slight, the water in the direct path of the beam was evaporated and probably didn't cause too much reduction in beam energy, but many of the tests had a lot of water on the glass.

Laser schedule E32L0.5R100 produces a four times higher peak power than E8L2R100 does. It was noticed during the tests, schedule E32L0.5R100 produced much more severe water splashing on the cover glass than schedule E8L2R100. The contaminated cover glass further reduced the power delivered to the rock. This seems to be the reason why the hole dimensions of submerged BG sandstone lased at E32L0.5R100 with higher measured laser power of 1522 watts are smaller than holes lased at E8L2R100 with lower power of 1250 watts.

YAG laser beam of 1/4 inch in diameter at E32L0.5R100 did not show any significant damages on limestone at any water thickness because of insufficient beam irradiance. Previous study on laser on dry rocks showed limestone required beam irradiance four times higher than sandstone or shale did for an obvious spallation damage.

\section{$\mathrm{CO}_{2}$ laser}

Results of $\mathrm{CO}_{2}$ laser drilling rock through water are shown in Figure 3-6. The CW laser beam of $\mathrm{TEM}_{20}$ mode was fired at $4 \mathrm{~kW}$ for 0.5 second for each hole. The beam spot size on the rock surface was 0.5 inch in diameter. As shown in Figure 3-6, the rock destruction characterized by lased hole diameter shown no big difference between the different lithologies. Again water absorbed laser energy and reduced the amount of rock damage. The average hole diameter was reduced from $14 \mathrm{~mm}$ for dry sample with zero water above the rock, to $10 \mathrm{~mm}$ with $2 \mathrm{~mm}$ thick water, to $9 \mathrm{~mm}$ with $4 \mathrm{~mm}$ thick water, and to $8.5 \mathrm{~mm}$ with $8 \mathrm{~mm}$ thick water. The pictures of lased holes in shale are shown in Figure 3-7.

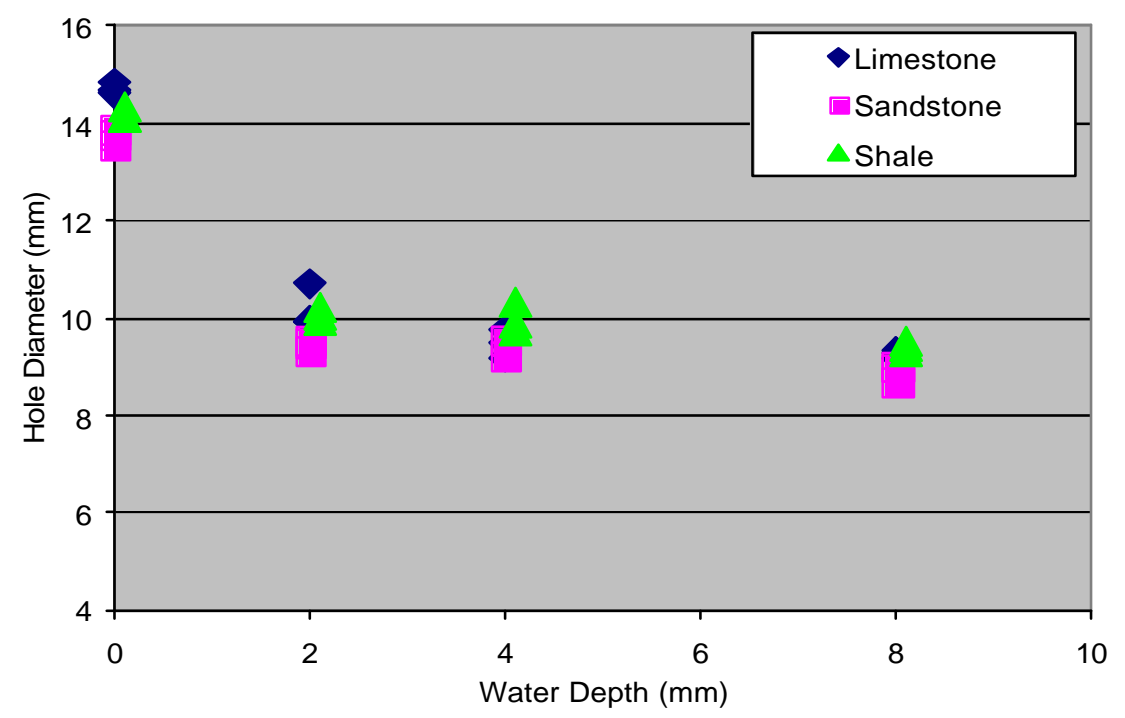

Figure 3-6 Hole diameter as a function of water depth on limestone, sandstone and shale lased by $\mathrm{cw} \mathrm{CO}_{2}$ laser beam at $4 \mathrm{~kW}$ power 


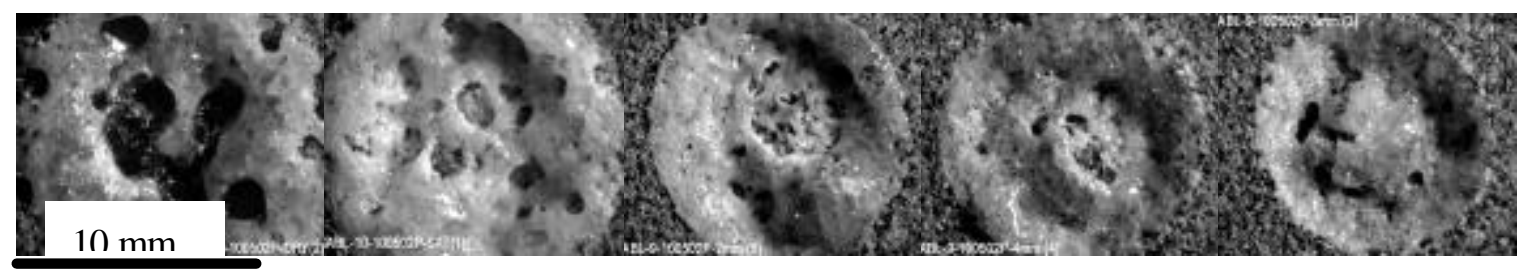

Figure 3-7. Holes lased by a $\mathrm{CW} \mathrm{CO}_{2}$ laser at $4 \mathrm{~kW}$ on shale. Water conditions are from left to right: dry, saturated, $2 \mathrm{~mm}, 4 \mathrm{~mm}$ and $8 \mathrm{~mm}$.

\section{Effect of flowing water over rock surface on laser rock destruction}

\section{Nd:YAG Laser}

As shown in Figure 3-8, a 1/4 inch collimated Nd:YAG beam pulsed at E8L2R100 penetrated through the $2 \mathrm{~mm}$ thick water flowing over rock surface and produced a sallow hole in the rock in one second. Up left picture of Figure 3-8 shows the moment when the beam just reached the water. Up right picture of Figure 3-8 shows the beam reached to the rock and started drilling the hole. As the laser rock interaction started, the rock gives off gases and particles that moving straight up into the incoming beam. Bottom middle picture of Figure 3-8 shows that the laser energy reached to the rock melted rather than spalled the rock and formed a shallow hole on the sample (white spot). The low pressure flowing water could not remove the melted rock material from the hole as it was thought to do. The melted material quickly solidified into a glass phase that consists of most of $\mathrm{SiO}_{2}$. After formation of the glass phase, further increasing laser exposure time at the same spot did not significantly deepen the hole rather than heat up the whole rock sample. From the flowing water tests on YAG laser, we learned that purging while lasing with either gas or water is a must for efficient rock removal under water.

\section{$\mathrm{CO}_{2}$ Laser}

Flowing water over rock tests on $\mathrm{CO}_{2}$ laser at $4 \mathrm{~kW}$ power level is shown in Figure 3-9. Clearly, the $\mathrm{CO}_{2}$ beam generated steam, but did not reached to the rock and caused any damage on it. Water is almost opaque to the $\mathrm{CO}_{2}$ laser beam of $10.6 \mu \mathrm{m}$ wavelength. For the beam to pass through water, it has to vaporize the water first and then the water vapor helps to form a tunnel for the incoming beam. Once the vapor tunnel is stabilized, incoming beam would reach to the rock. But in flowing water tests, the cross over jet continuously brought fresh water to the laser spot and destroyed the tunnel stabilization conditions. Therefore, $\mathrm{CO}_{2}$ laser lasing rock through flowing water became impossible under the current flowing water setup. 

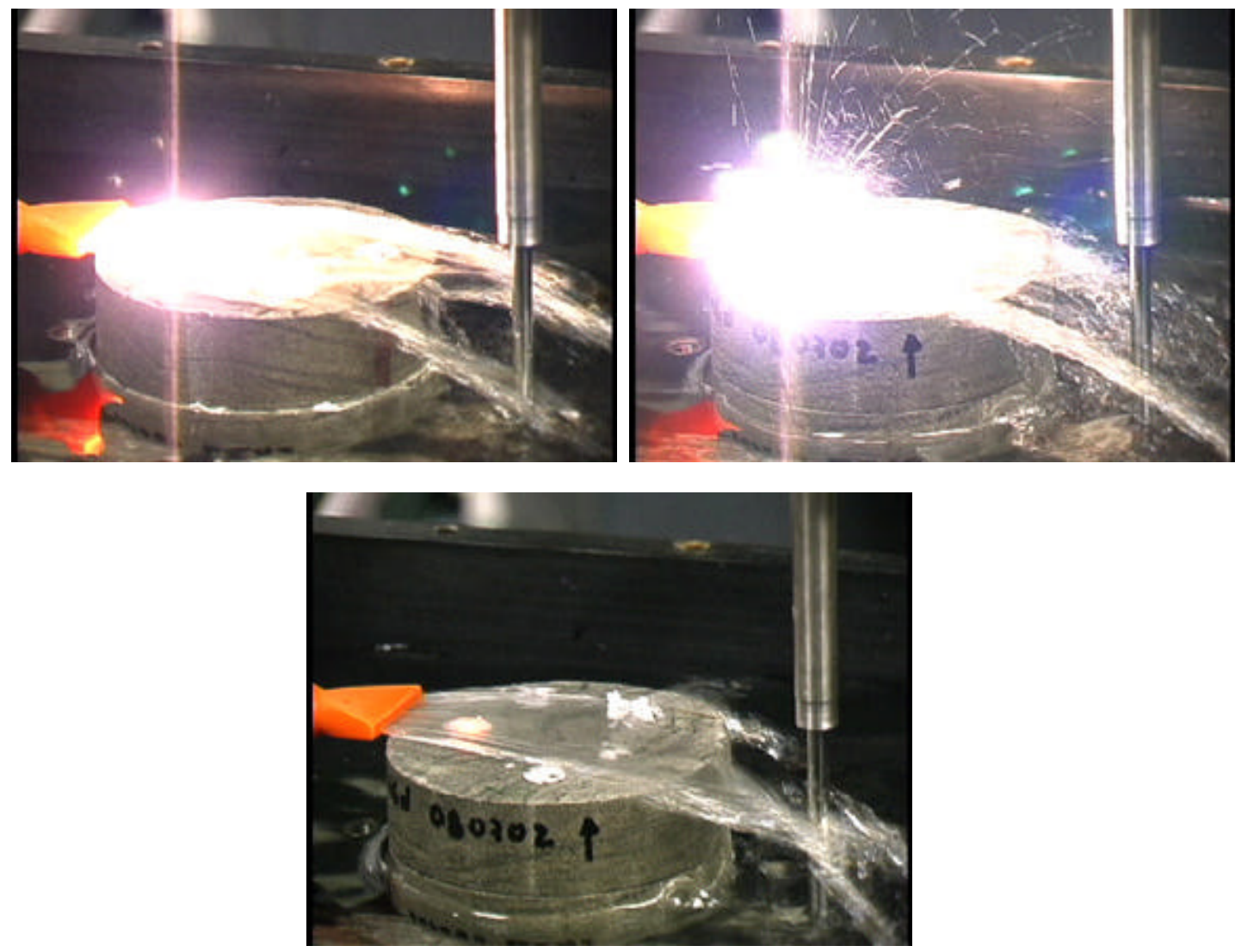

Figure 3-8. YAG laser lasing on shale sample through cross water jet. Up left: laser just reached water, up right: laser energy interacted with water and rock, and bottom middle: laser off and left a hole on the rock (white spot).

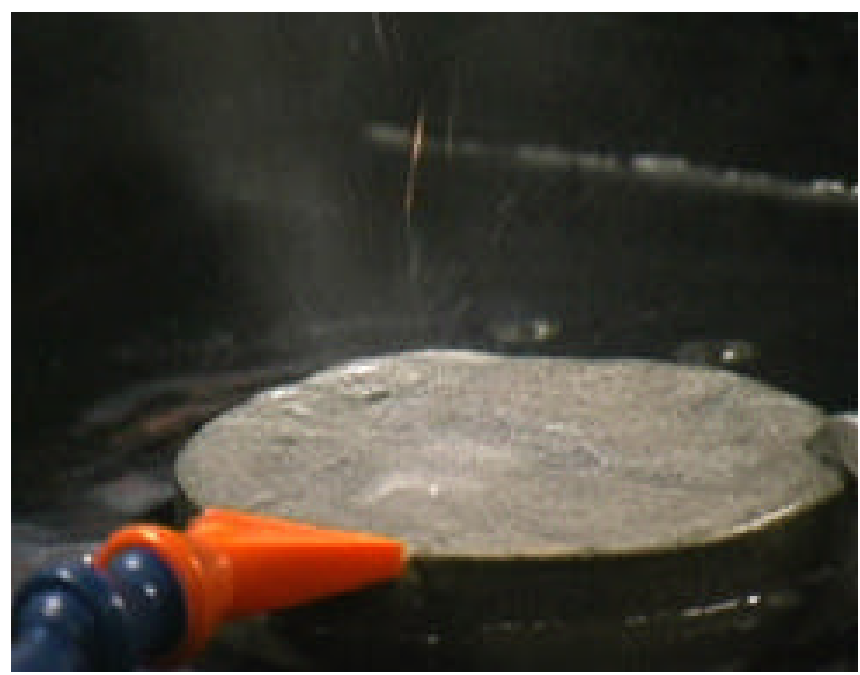

Figure 3-9 A $4 \mathrm{~kW} \mathrm{CO}$ laser beam only steamed the cross over water jet and did not reach the rock. 


\begin{tabular}{|c|c|c|c|c|c|c|c|c|c|}
\hline Test \# & $\begin{array}{c}\text { Spot } \\
\text { size,mm }\end{array}$ & $\begin{array}{c}\text { Laser } \\
\text { schedule }\end{array}$ & $\begin{array}{l}\text { Average } \\
\text { power, w }\end{array}$ & Sample & $\begin{array}{c}\text { \# of } \\
\text { spots }\end{array}$ & $\begin{array}{l}\text { Time } \\
\text { (sec) }\end{array}$ & $\begin{array}{c}\text { Water } \\
\text { thickness }\end{array}$ & $\begin{array}{c}\text { Depth, } \\
\text { mm }\end{array}$ & $\begin{array}{c}\text { Diameter, } \\
\mathbf{m m}\end{array}$ \\
\hline \multicolumn{10}{|l|}{\begin{tabular}{|l|} 
Sandstone \\
\end{tabular}} \\
\hline 1 & 9.2 & E8L2R100 & 1250 & BGG1A & 1 & 1 & DRY & 1.99 & 10.75 \\
\hline 2 & 9.2 & E8L2R100 & 1250 & BGG1A & 1 & 1 & DRY & 2.05 & 10.94 \\
\hline 3 & 9.2 & E8L2R100 & 1250 & BGG1A & 1 & 1 & DRY & 2.15 & 10.32 \\
\hline 4 & 9.2 & E8L2R100 & 1250 & BGG1A & 1 & 0.5 & DRY & 1.22 & 9.71 \\
\hline 1 & 9.2 & E8L2R100 & 1250 & BGG2A & 3 & 1 & SATURATED & 2.12 & 9.72 \\
\hline 1 & 9.2 & E8L2R100 & 1250 & BGG3A & 3 & 1 & $2 \mathrm{MM}$ & 1.87 & 7.48 \\
\hline 1 & 9.2 & E8L2R100 & 1250 & BGG4A & 3 & 1 & $4 \mathrm{MM}$ & 1.39 & 5.93 \\
\hline 1 & 9.2 & E8L2R100 & 1250 & BGG5A & 3 & 1 & $8 \mathrm{MM}$ & 1.02 & 4.84 \\
\hline 1 & 11.02 & E32L0.5R100 & 1522 & BGG8A & 3 & 1 & $8 \mathrm{MM}$ & 0.00 & 2.72 \\
\hline $1-3$ & 11.02 & E32L0.5R100 & 1522 & BGG7A & 3 & 1 & $4 \mathrm{MM}$ & 0.53 & 5.60 \\
\hline $4-6$ & 11.02 & E32L0.5R100 & 1522 & BGG7A & 3 & 1 & $4 \mathrm{MM}$ & 0.65 & 6.14 \\
\hline $1-3$ & 11.02 & E32L0.5R100 & 1522 & BGG6A & 3 & 1 & $2 \mathrm{MM}$ & 1.20 & 6.41 \\
\hline 1 & 11.02 & E32L0.5R100 & 1522 & BGG9A & 3 & 1 & SATURATED & 1.92 & 9.36 \\
\hline 6 & 11.02 & E32L0.5R100 & 1522 & BGG1A & 1 & 1 & DRY & 2.35 & 11.93 \\
\hline 7 & 11.02 & E32L0.5R100 & 1522 & BGG1A & 1 & 1 & DRY & 2.18 & 11.72 \\
\hline 8 & 11.02 & E32L0.5R100 & 1522 & BGG1A & 1 & 1 & DRY & 2.15 & 11.41 \\
\hline \multicolumn{10}{|l|}{\begin{tabular}{|l|} 
Mudstone \\
\end{tabular}} \\
\hline 1 & 11.02 & E32L0.5R100 & 1522 & ANDER WY7 & 1 & 1 & DRY & 2.55 & 11.08 \\
\hline 2 & 11.02 & E32L0.5R100 & 1522 & ANDER WY7 & 1 & 1 & DRY & 2.44 & 10.69 \\
\hline 3 & 11.02 & E32L0.5R100 & 1522 & ANDER WY7 & 1 & 1 & DRY & 2.88 & 10.55 \\
\hline $1-3$ & 11.02 & E32L0.5R100 & 1522 & ANDER WY1 & 3 & 1 & SATURATED & 2.56 & 10.55 \\
\hline $1-3$ & 11.02 & E32L0.5R100 & 1522 & ANDER WY2 & 3 & 1 & $2 \mathrm{MM}$ & 1.23 & 7.73 \\
\hline $1-3$ & 11.02 & E32L0.5R100 & 1522 & ANDER WY3 & 3 & 1 & $4 \mathrm{MM}$ & 1.06 & 7.45 \\
\hline $1-3$ & 11.02 & E32L0.5R100 & 1522 & ANDER WY4 & 3 & 1 & $8 \mathrm{MM}$ & 0.00 & 0.00 \\
\hline \multicolumn{10}{|l|}{ Shale } \\
\hline 1 & 11.02 & E32L0.5R100 & 1522 & NATR4 & 1 & 1 & DRY & 2.03 & 13.74 \\
\hline 2 & 11.02 & E32L0.5R100 & 1522 & NATR4 & 1 & 1 & DRY & 2.27 & 13.85 \\
\hline 3 & 11.02 & E32L0.5R100 & 1522 & NATR4 & 1 & 1 & DRY & 1.84 & 13.57 \\
\hline $4-6$ & 11.02 & E32L0.5R100 & 1522 & BIGH7A & 3 & 1 & SATURATED & 3.44 & 10.97 \\
\hline $1-3$ & 11.02 & E32L0.5R100 & 1522 & BIGH6A & 3 & 1 & $2 \mathrm{MM}$ & 3.41 & 8.36 \\
\hline $1-3$ & 11.02 & E32L0.5R100 & 1522 & BIGH8A & 3 & 1 & $4 \mathrm{MM}$ & 1.56 & 9.06 \\
\hline $1-3$ & 11.02 & E32L0.5R100 & 1522 & BIGH6B & 3 & 1 & $8 \mathrm{MM}$ & 0 & 0 \\
\hline \multicolumn{10}{|c|}{\begin{tabular}{|l|} 
Limestone \\
\end{tabular}} \\
\hline $1-3$ & 11.54 & E32L0.5R100 & 1536 & LSA1Y & 3 & 1 & SATURATED & 1.64 & 8.52 \\
\hline $1-3$ & & E32L0.5R100 & 1536 & LSA2Y & 3 & 1 & $2 \mathrm{MM}$ & no & no \\
\hline 1 & & E32L0.5R100 & 1536 & LSA2Y & 1 & 5 & $2 \mathrm{MM}$ & no & no \\
\hline 1 & & E32L0.5R100 & 1536 & LSA2Y & 1 & 2 & $2 \mathrm{MM}$ & no & no \\
\hline 1 & & E32L0.5R100 & 1536 & LSA2Y & 1 & 2 & $4 \mathrm{MM}$ & NO & \\
\hline 1 & & E32L0.5R100 & 1536 & LSA2Y & 1 & 5 & $4 \mathrm{MM}$ & SLIGHT & \\
\hline 1 & & E32L1R50 & 1660 & LSA2Y & 1 & 10 & $4 \mathrm{MM}$ & SLIGHT & \\
\hline
\end{tabular}




\section{Attenuation Of Laser Energy During Laser-Water-Rock Interaction}

When a high power laser beam is applied to a rock sample through water, the beam interacts with water first; then energy penetrates through the water and interacts with rock. Some of the laser radiant energy is reflected at the water surface and does not enter the water. That which penetrates the water's surface is attenuated by absorption and conversion to other forms of energy, such as heat that warms or evaporates water or drills rock. Laser beam that is not absorbed can be scattered by molecules and rock particles suspended in the water. Scattered beam is deflected into new directional paths and may wander randomly to eventually be either absorbed or directed upward and out of the water. Some of the energy attenuation phenomena occurred during the interactions among laser beam, water and rock were recorded in forms of photographs and will be presented here. The two lasers used in the tests are a $1.6 \mathrm{~kW}$ pulsed Nd:YAG laser $(1.06 \mu \mathrm{m}$ wavelength) with fiberoptic cable beam delivery and a $6 \mathrm{~kW} \mathrm{CO}$ laser $(10.6 \mu \mathrm{m}$ wavelength).

\section{Optical and thermophysical properties of water}

Thermal conductivity
$\lambda, \mathrm{W} / \mathrm{cm} \mathrm{K}$
$5 \times 10^{-3}$

Heat capacity per unit volume

$$
\mathrm{C}, \mathrm{J} / \mathrm{cm} \mathrm{K}
$$

Effective absorption coefficient $(\alpha(1 / \mathrm{cm}))$

\begin{tabular}{ll} 
Wavelength & $\alpha(1 / \mathrm{cm})$ \\
\hline $248 \mathrm{~nm}$ & 0.01 \\
$1.06 \mu \mathrm{m}$ & 0.5 \\
$2.94 \mu \mathrm{m}$ & 12,000 \\
$10.6 \mu \mathrm{m}$ & 800
\end{tabular}

Notice that $\mathrm{CO}_{2}$ laser beam at wavelength $10.6 \mu \mathrm{m}$ is absorbed by water 1600 times greater than $\mathrm{Nd}: \mathrm{YAG}$ laser beam at $1.06 \mu \mathrm{m}$ is.

\section{Various laser beam attenuation mechanisms}

Figure 3-10 shows a $1200 \mathrm{~W}$ pulsed Nd:YAG laser beam with water absorption coefficient 0.5 $1 / \mathrm{cm}$ at wavelength $1.06 \mu \mathrm{m}$ penetrated through the water jet crossover the rock surface, interacted with the rock and created a plume mixture of water plasma, water spatters, steam, rock dusts and particles. On the other hand, as shown in Figure 3-11, a $4 \mathrm{~kW} \mathrm{cw} \mathrm{CO}_{2}$ laser beam with absorption coefficient by water $8001 / \mathrm{cm}$ at wavelength $10.6 \mu \mathrm{m}$ interacted with the same water jet flowing over a sandstone sample and only created water vapor/steam but attenuated fully and failed to reach the rock. In case of free water above the submerged rock, both laser beam can penetrate certain thickness water and reach the rock. Figure $3-12$ shows a $6.5 \mathrm{~mm}$ collimated $\mathrm{Nd}$ :YAG beam at $1200 \mathrm{~W}$ power penetrated the free water above the rock and interacted with the rock. The laser-water-rock interaction created a similar plume as shown in crossover water jet case in Figure 3-10. But only here a cross gas jet was used. The gas jet successfully blown the plume away from the incoming beam at the level where it placed, but failed to remove plume below the jet, clearly indicating the gas jet should be placed as close to the rock surface as 
possible to remove the plume right at where it is created even if the jet has to be placed underwater. $\mathrm{A} \mathrm{cw} 4 \mathrm{~kW} \mathrm{CO}$ beam could penetrate shallow free water and produced hole in the rock, but created much extensive steam (Figure 3-13). Figure 3-14 shows a cross gas jet blowing the plume from the incoming $\mathrm{CO}_{2}$ beam. Again the jet should be lowered close to rock. The laser energy was also attenuated through laser-induced shock waves in the water (Figure 3-15). As the free water gets thicker, it becomes difficult for the $\mathrm{CO}_{2}$ beam to penetrate the water and create damage on the rock. Figure 316 shows a cw $4 \mathrm{~kW}$, half second duration $\mathrm{CO}_{2}$ laser beam interacted with water, and created extensive steam and a dimple in one inch thick water above the rock but did not create any visible damage on rock.

In some cases, water acted like an optic lens and redirected the incoming laser beam. The incident laser beam could be focused, diverged or unchanged by the water surface depending on the shape of the water surface that is convex, concave or flat respectively with respect to the incident beam. As shown in Figure 3-17, an incident collimated Nd:YAG laser beam was focused by the free water above the rock, indicating that water surface was convex shape relative to the incoming beam. Unchanged incoming beam by a flat water surface is shown in Figure 3-18.

In summary, attenuation of laser energy during laser-water-rock interaction could be caused by but not limited to the following sources:

1. Reflection by water and rock surfaces

2. Absorption by water the energy of which is consumed in warming up, boiling and steaming water.

3. Scattering by water molecules and rock particles

4. Blocking by water plasma and cloud of steam, water spatter, rock dust and particles.

For efficient laser rock drilling, all the energy attenuation sources must be minimized or even be eliminated. Maintaining a fat, stable water surface and using gas or water jet close to rock surface to create a clean beam pass were approved to be efficient methods to reduce the beforerock laser energy loss.

\section{CONCLUSIONS AND RECOMMENDATIONS}

\section{Water configuration effects}

Both laser beams can penetrate free water of certain thickness above the rock and cause rock destruction. Hole was made through $2-4 \mathrm{~mm}$ water by $\mathrm{Nd}$ :YAG laser and through $\leq 1$ inch water by $\mathrm{CO}_{2}$ laser. But the degree of destruction was reduced significantly as water became thicker compared to dry sample data. Because of the great difference in absorption coefficients in water, each of the two wavelength beams travels a unique path to the rock through water. The $1.06 \mu \mathrm{m}$ Nd:YAG wavelength beam, with small water absorption coefficient $(0.51 / \mathrm{cm})$, is mostly transmitted through the shallow water and reaches the rock for destruction. On the other hand, the $10.6 \mu \mathrm{m} \mathrm{CO}$ wavelength beam, having a large water absorption coefficient $(8001 / \mathrm{cm})$ must vaporize the water in the path and create a stable vapor tunnel first, then it can reach to rock for destruction. The Nd:YAG laser beam also worked well with the cross over water jet. But with the $\mathrm{CO}_{2}$ laser lasing rock through flowing water became difficult because the cross water jet 
continuously brought fresh water to the laser beam and destroyed the stable water vapor tunnel condition

\section{The laser energy attenuation sources}

Various beam attenuation sources were observed and recorded during the under water laser rock tests. Non-rock drilling laser energy losses during laser-water-rock interaction could be caused by reflection by water and rock surface, absorption by water, blocking by water plasma, and blocking by upstream cloud of steam, water spatter, rock dust and particles. As a positive result of the under water tests, causes of laser energy losses through water are better understood, which would greatly help the engineering design for more efficient laser rock drilling equipments.

\section{Better equipment development for future under water tests}

Tests show that rock melting starts almost immediately when the temperature rise is enough to start affecting rock. A better under water purging system or beam/purge coaxial system has to be designed to remove the molted rock before it accumulates in the hole. Our current simple water container-type set up for under water rock tests did not work well in the sense of providing good beam/purge configurations and a clear beam path through water. Better, wet test equipment needs to be developed. 


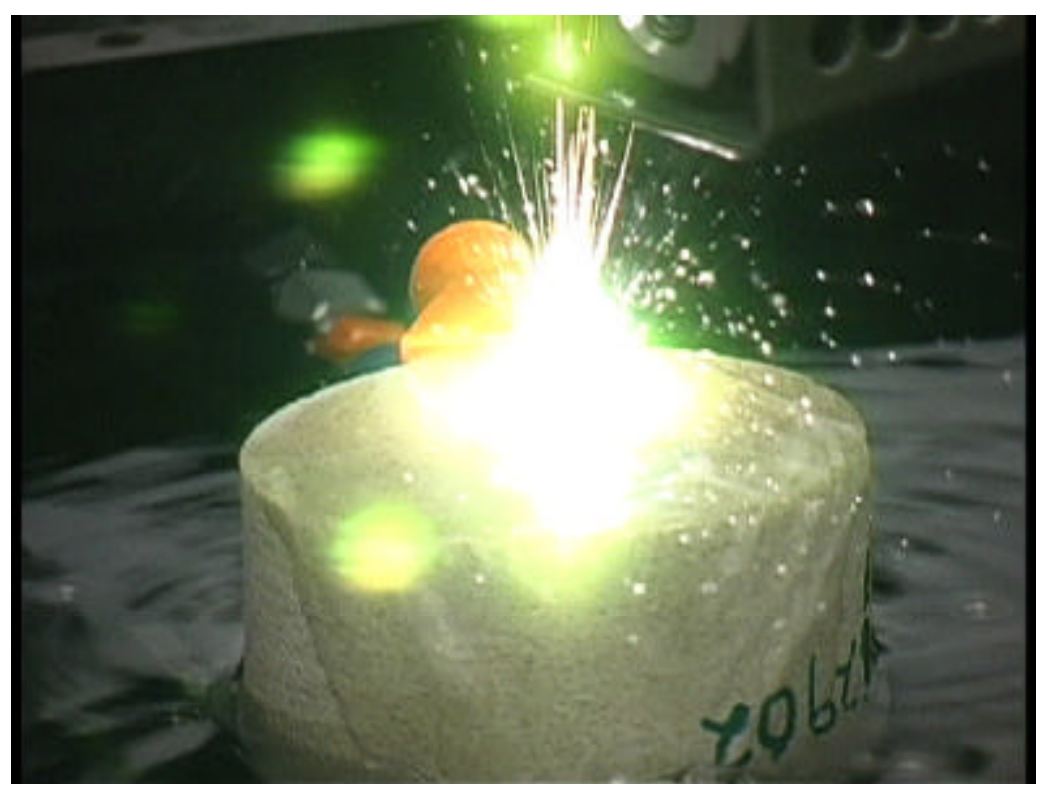

Figure 3-10 A $1200 \mathrm{~W}$ pulsed Nd:YAG laser beam penetrated through water jet crossover the rock surface and interacted with the rock.

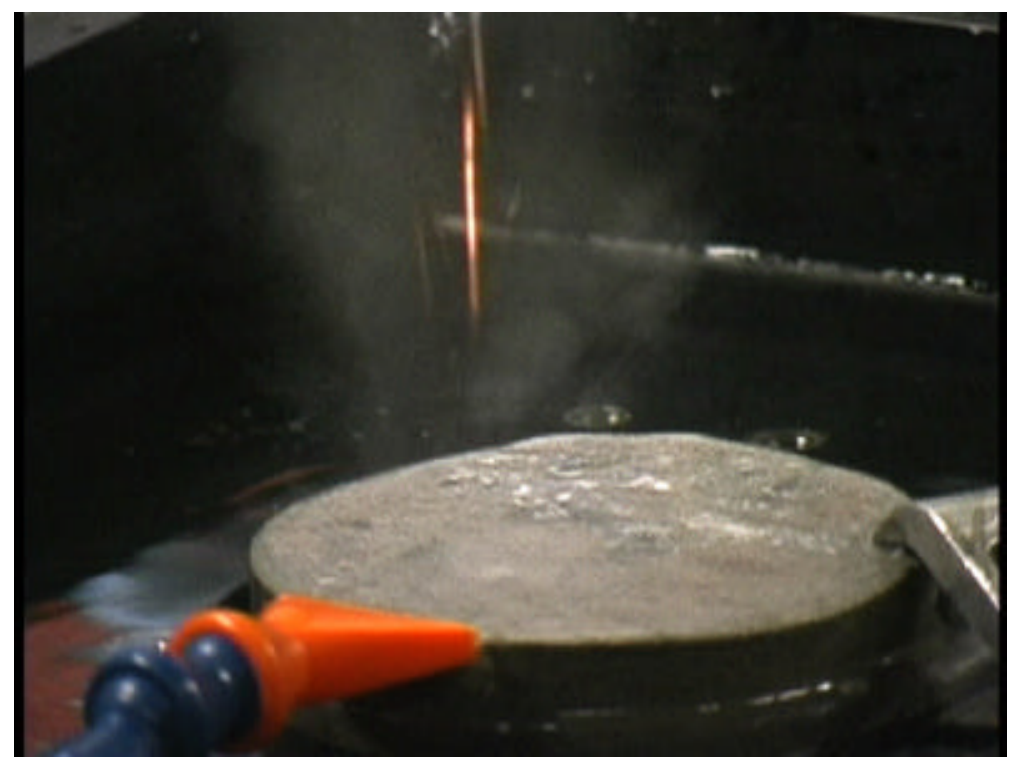

Figure 3-11 A $4 \mathrm{~kW}$ cw CO2 laser beam interacted with a crossover water jet on a rock sample and created water vapor/steam. But it failed to reach the rock. 


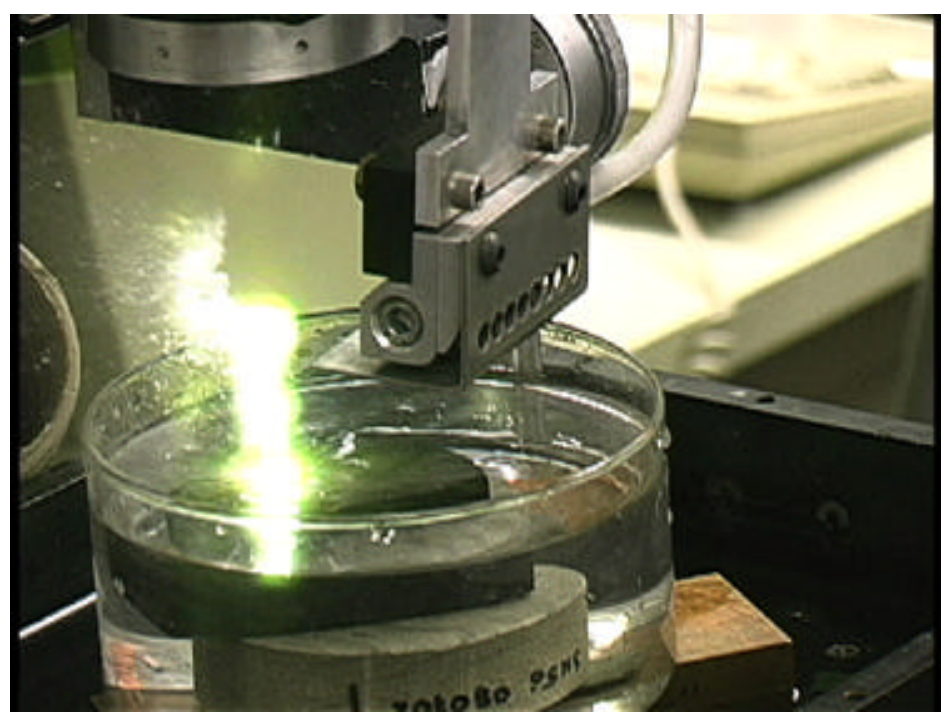

Figure 3-12 A $6.5 \mathrm{~mm}$ collimated Nd:YAG beam penetrated free water above rock and interacted with rock. A cross gas jet used is shown.

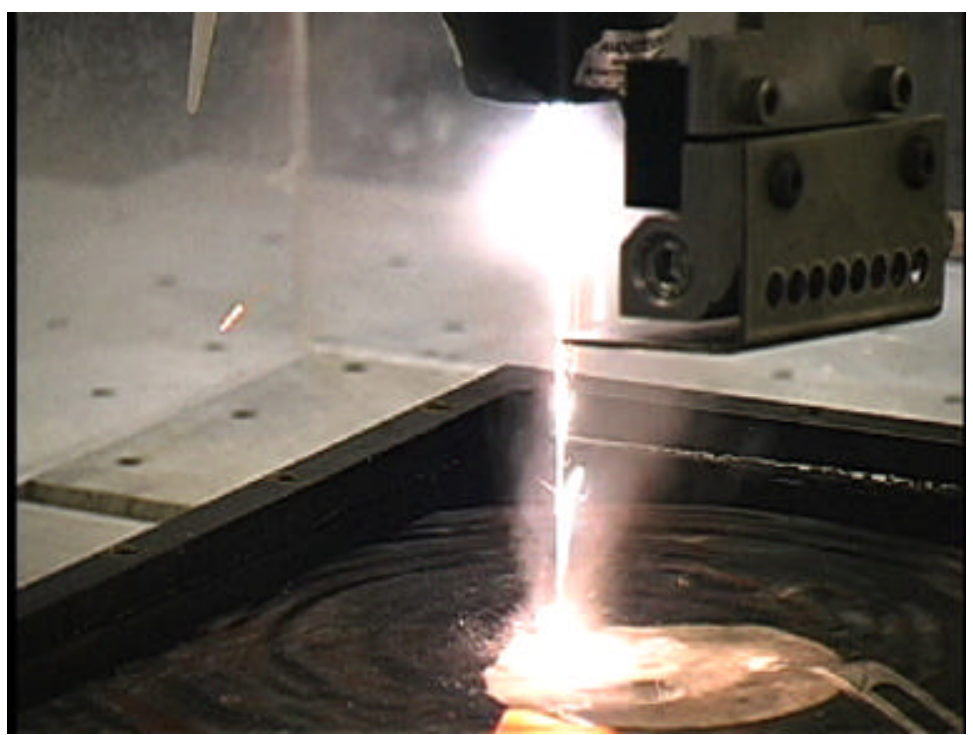

Figure 3-13 A $4 \mathrm{~kW} \mathrm{cw} \mathrm{CO2} \mathrm{laser} \mathrm{beam} \mathrm{drilling} \mathrm{rock} \mathrm{through} \mathrm{shallow} \mathrm{free} \mathrm{water.}$ 


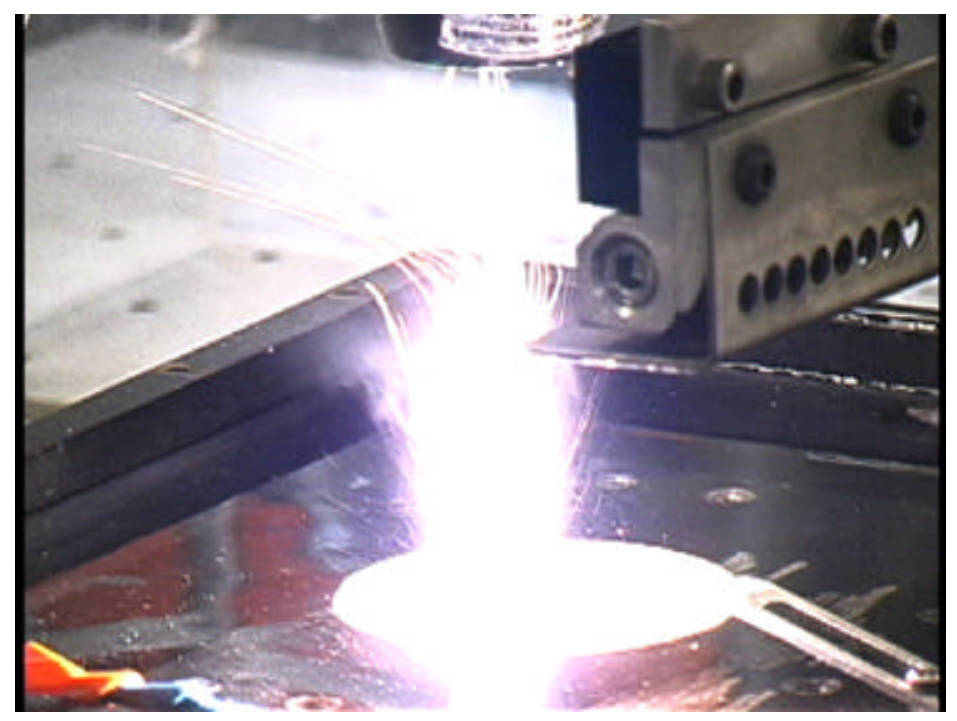

Figure 3-14, A cross gas jet was used and intended to blow the plume away from the incoming $\mathrm{CO}_{2}$ beam.

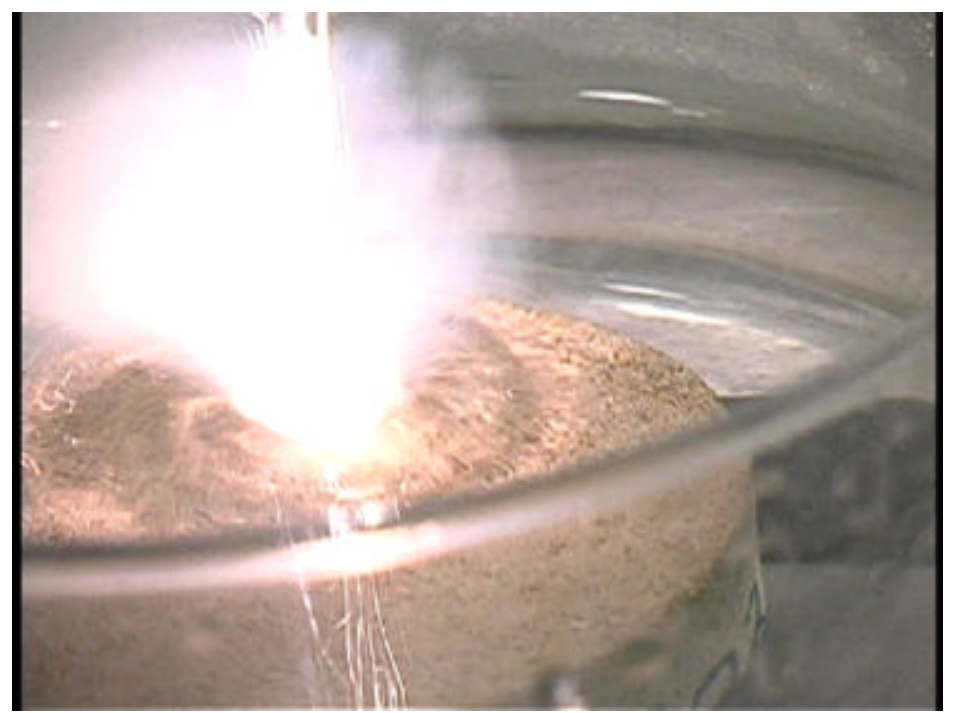

Figure 3-15 Water steam and waves created by laser beam. 


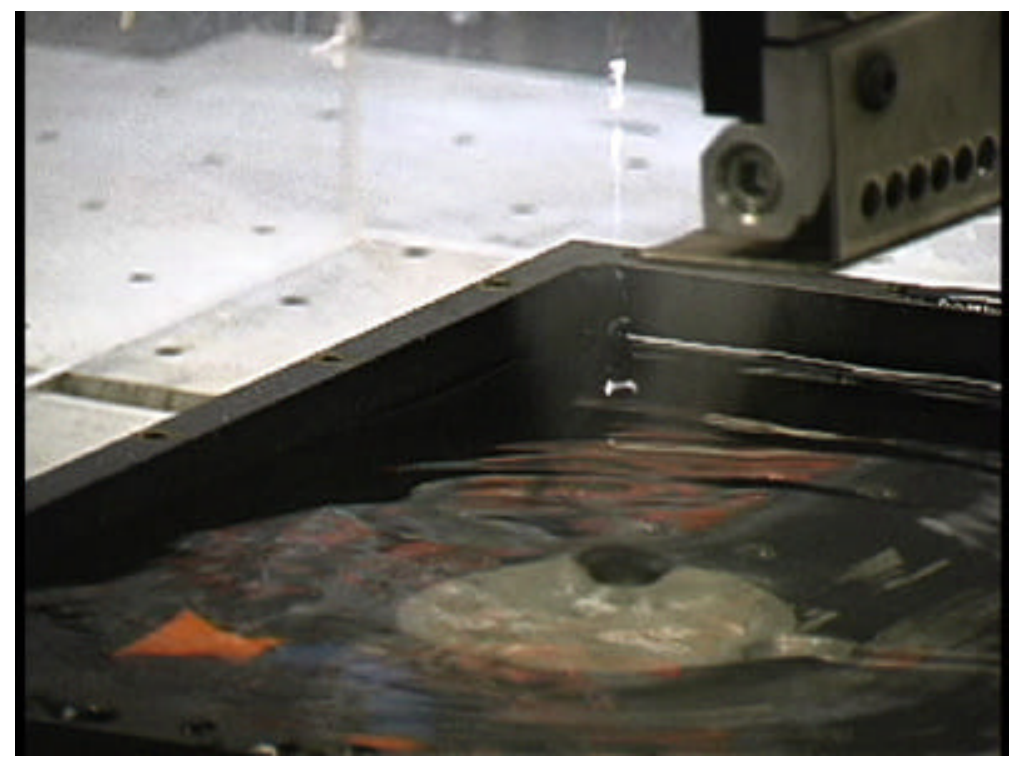

Figure 3- 16 A 4 kW cw, half second duration $\mathrm{CO}_{2}$ laser beam 


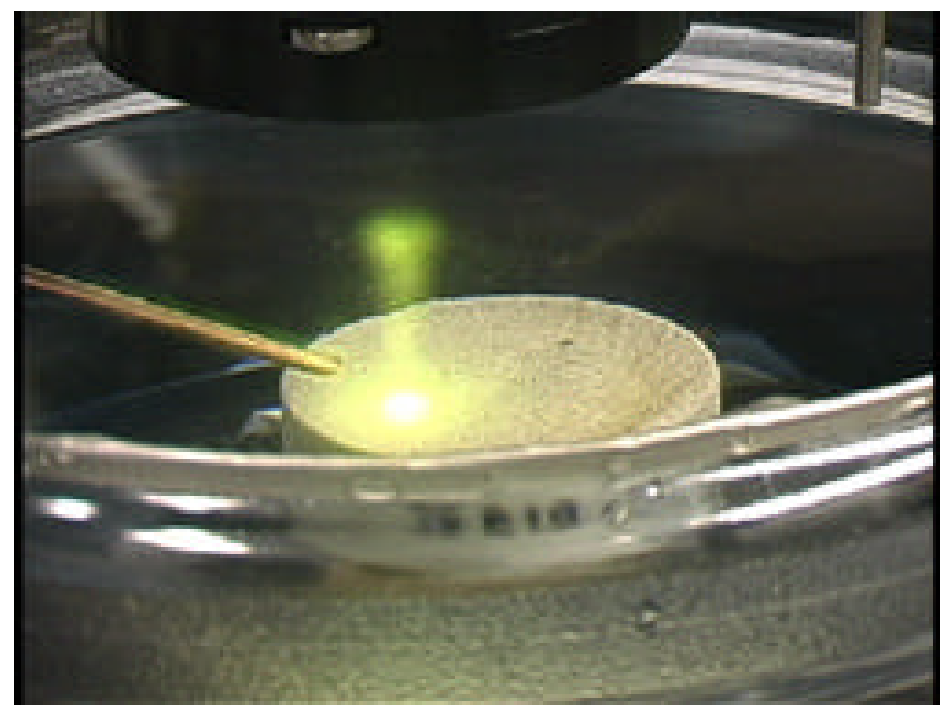

Figure 3-17 The incident collimated laser beam was refocused hv water surface shown hv the orange-colored heam nath.

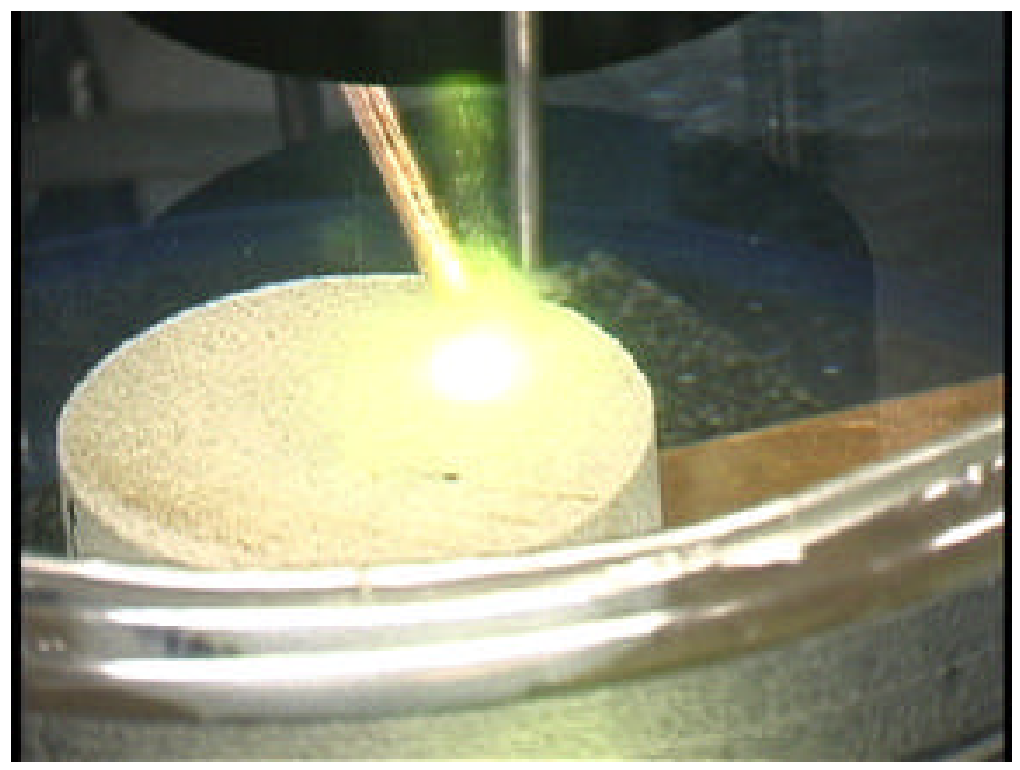

Figure 3-18 Showing here by the orange-colored beam path, the incoming collimated beam size is unchanged when penetrating through water. 


\section{APPLICATION OF HIGH POWER LASERS TO PERFORATED COMPLETIONS}

\section{INTRODUCTION}

In the petroleum industry, perforating is a process of piercing the casing wall and the cement behind it to provide openings through which formation fluids may enter the wellbore. Current technology uses a perforating gun, or perforator to make these openings. The completion crew lowers the long cylindrical gun down the production casing or liner until it is opposite the reservoir zone. The bullets or special explosive charges carried by the perforator are aimed at the walls of the casing and shoot smooth, round holes in the casing and penetrate the rock as well. This available technology has some disadvantages such as (1) lack control of hole size and shape and(2) reduction of permeability of perforated rock. Recent advances in high power laser technology provides a new tool to replace the current perforating gun for creating the holes. The laser perforator has the flexibility of drilling holes with different sizes and shapes. Increase of permeability of laser drilled rock was confirmed in recent laser rock test. This report presents the results from the preliminary study on drilling one inch holes that are $2-5$ inch deep by a continuous wavelength $\mathrm{CO}_{2}$ laser.

\section{Test Results}

Three drilling methods and their experimental results in this preliminary study are presented here. The test condition and perforated hole depths are listed in Table A-4. The goal of experiments was to drill a hole on rock as deep as possible using a serie s of laser bursts.

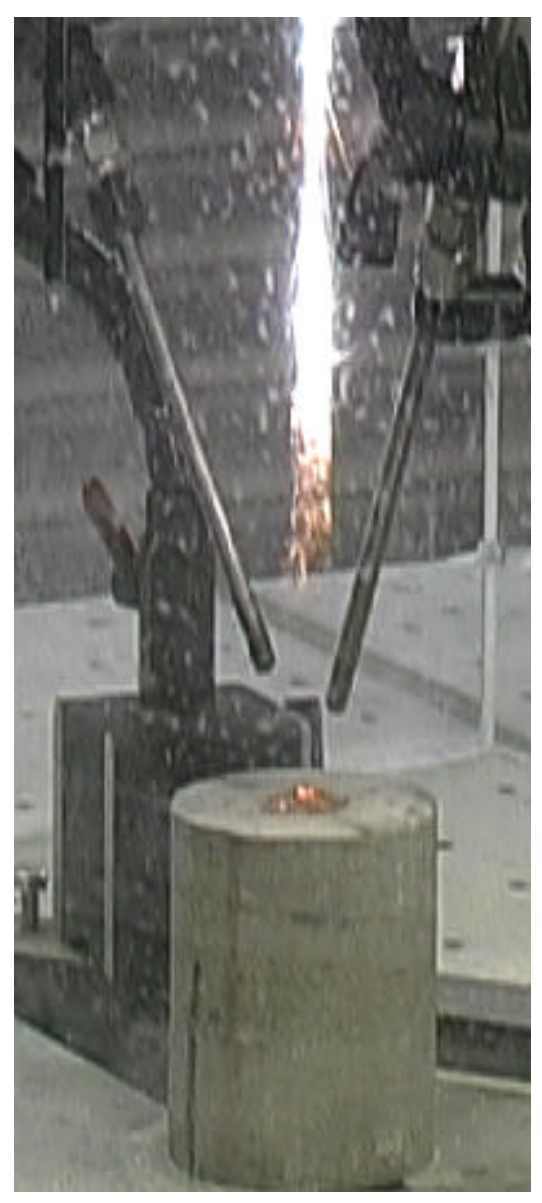

Figure 4-1 Method one setup

\section{Method One: Fixed Beam}

This method is shown in Figure 41. A fixed, defocused beam of one inch in diameter was fired on a rock with two $65^{\circ}$ purging tubes in a symmetrical configuration. The laser head can be lowered down to compensate the beam spot size change at the bottom of the hole as the hole gets deeper, but the available moving distance is limited by the purging tubes first and then the laser head itself.

In the experiment the 1" defocused beam was pointed at a shale sample, 3" thick and $3 "$ in diameter. The $\mathrm{CO}_{2}$ laser power was 4000 watts and nitrogen flow rate from the two $65^{\circ}$ purging tubes were set at 200 cubic foot per hour, cfh, each.

Four laser bursts with duration of 4 seconds each were applied to the center of the circular surface of the sample. The first three bursts drilled a hole 2.9" deep with no traces of melted rock anywhere. The fourth burst was not able to drill any deeper: it only melted the bottom surface of 
the hole, filling a small fraction of the hole depth with melted material. The final hole depth after the fourth burst was $2.8 "$.

Since each burst perforated holes about 0.6" deep, the focusing system was moved 0.5 " down after the first burst and 1" after the third burst, in order to keep the constant beam irradiance near the hole bottom. Severe cracking of rock occurred at the $3^{\text {rd }}$ and $4^{\text {th }}$ bursts. The picture below (Fig. 42) shows the hole drilled after the four bursts

\section{Several Lessons Were Learned From This Experiment}

1. This simple setup works well for shallow holes less than 3 inches deep. The gas pressure used was high enough and efficient enough remove all traces of melted material for the given hole geometry ( 1 " diameter, same as beam spot size), up to a depth of $2.9^{\prime \prime}$.

2. The plume of exsolved debris went straight up, remained in the beam, and reduce the laser energy reached to the rock. In worst case, upstream rock debris reached to the focusing lens and caused lens damage.

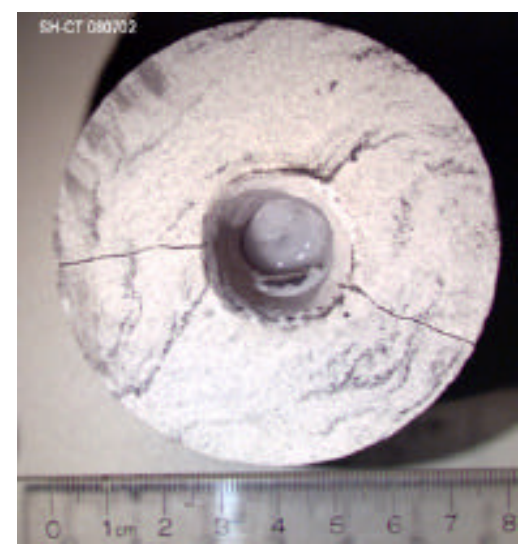

Figure 4-2 1 inch by 1.8 inch deep hole drilled by four bursts of 4 second duration 4 $\mathrm{kw} \mathrm{CO}_{2}$ laser beam on shale rock.

3. The existing purging system was not able to remove the melted material during the $4^{\text {th }}$ burst, probably due to the inability of the gas jet to reach such hole depths.

From points 1, 2, and 3, one concludes that a coaxial purging system, handling the current gas pressures would allow the $\mathrm{CO} 2$ laser to drill much deeper holes, keeping the lens from being exposed to the rock dust. 


\section{Method Two: Circular Motion Beam:}

In this method, the rock sample was moved circularly by the workstation under the fixed vertical beam and purge gas tube. This generated a relative circular motion of a defocused beam of 0.5 inch in diameter on the rock in a 0.5 inch diameter circle. A one inch diameter hole was formed by this circling beam after one revolution. A purging tube inside the hole circled together with the beam and was moved down after each revolution providing constant strong purging at the
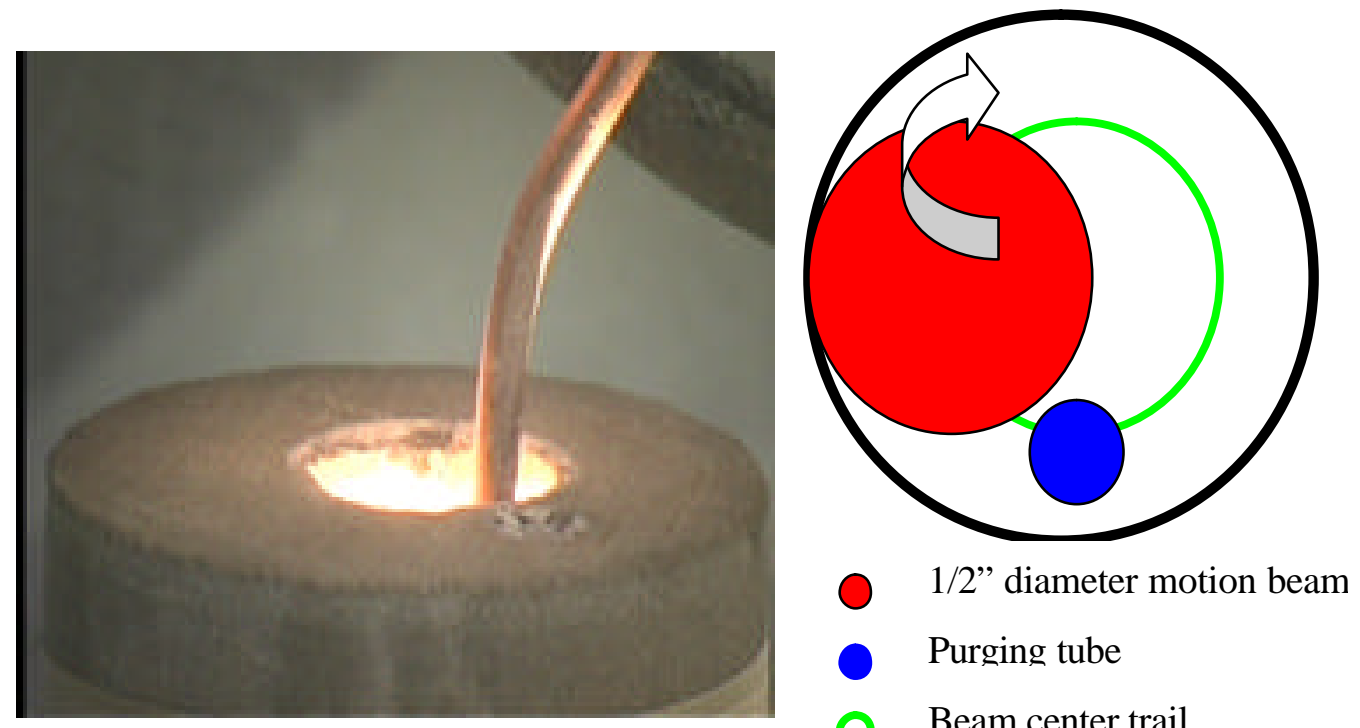

Beam center trail

- 1" diameter hole created

Figure 43 circular motion beam in action of drilling a one inch hole on shale sample (right) and relative positions of the beam, purging tube, and hole diameter created (left).

bottom of the hole as the hole got deeper. Figure 4-3 shows the circular motion beam in action of drilling a one inch hole on shale sample (right) and relative positions of the beam, purging tube, and hole diameter created (left). This method provides two major advantages over the fixed beam method: (1) the purging tube is placed inside the hole with vertical adjustment providing constant strong purging as the hole gets deeper, and (2) lased rock cools down before the beam makes a circle and comes back to the same spot so overheating or melting of rock could be avoided.

A 4" diameter by 6" thick limestone sample was lased by a circularly moved $\mathrm{CO}_{2}$ beam. The beam power was 4000 watts and the gas flow rate was $300 \mathrm{cfh}$. The laser head was moved down 0.5 " between bursts. One burst here is defined as one revolution that beam rotates. The beam moved at a 50 inches per minute. The 1" diameter by 5" deep hole made is shown in Figure 4-4. Because of the large aspect ratio 5:1, the hole cone-shaped with the bottom diameter reduced to $0.75^{\prime \prime}$. 


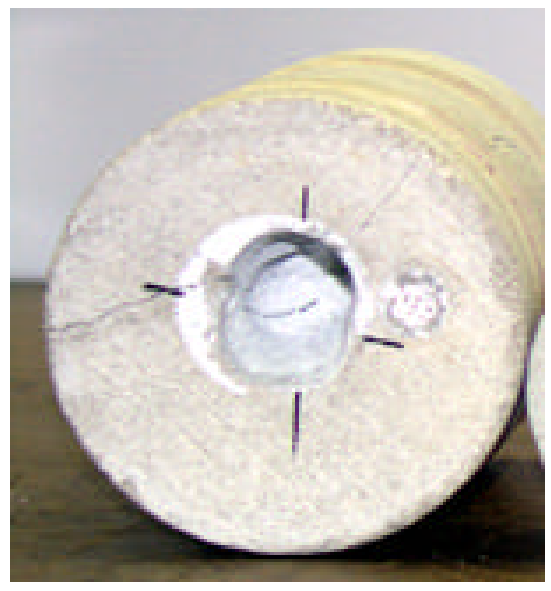

Fig. 4-3 one inch diameter, 5 inches deep hole drilled on limestone by $\mathrm{CO}_{2}$ laser at $4 \mathrm{~kW}$ power.

\section{Method Three: Rotary Rock Method}

In the circular motion beam method described above, the relative position of the beam and purging tube to the hole is changing all the time in a revolution, so is the gas flow inside of the hole. As a result, the formed hole becomes asymmetrical. To avoid this problem, a third method, rotary rock, was tested. As shown in Fig. 45, now the core rock sample is clamped by a rotary chuck and rotates around its own axis. The horizontal 0.5 " diameter beam and 1/8"purging tube are positioned about 1/4 inch away from the core axis and kept fixed for each lasing circle, then adjusted between the circles to keep the constant spot size and gas flow at the bottom of the hole as the hole goes deeper.

A continuous wave $\mathrm{CO}_{2}$ laser beam at $\mathrm{TEM}_{20}$ was used. The purging gas was nitrogen with flow rate $275 \mathrm{cfh}$. Two power levels, 4000 and 2500 watts and four rotary speeds, 10,000, 5,000, 3,000 , and 2,000 degree/min, were tested. At high power $(4000 \mathrm{~W})$ and low speed $(3,000$ degree/min), laser beam intensively melted the rock and formed glass phase that stayed in the hole (Fig. 4-6 left). Increasing rotary speed reduced the melting at fixed power. 


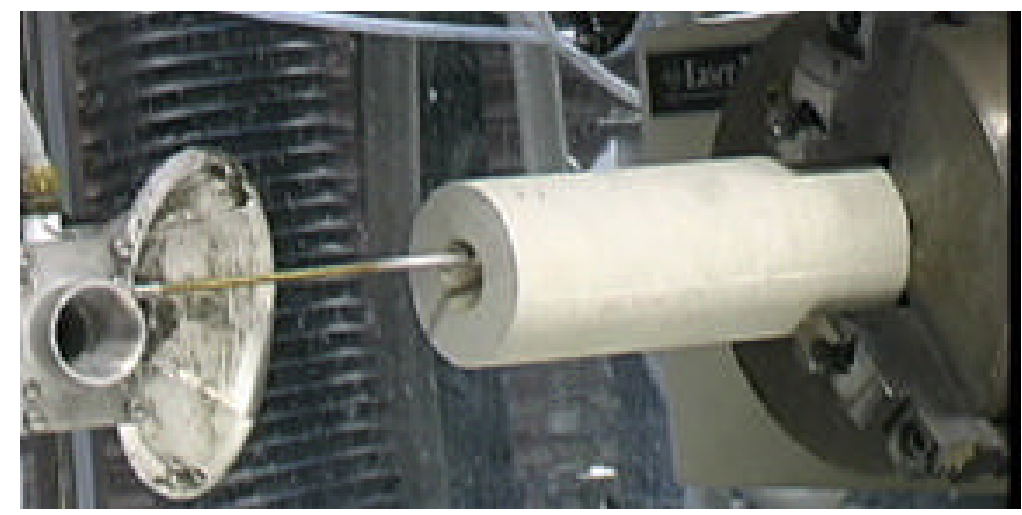

Fig. 4-5 Rotary rock method was used at $2500 \mathrm{~W}$ laser power and 10,000 degree/min rotary speed to drill a deep hole into 7 inch thick sandstone core sample.

Optimal conditions were found at 2,500 W and 10,000 degree/min. A clean hole without any melting deposition (Fig. 46 right) was created at the optimal conditions. The above optimal conditions were then applied to drill a deep hole in a 7 inch thick sandstone core sample as shown in Fig 45. The 1/2" diameter beam with 1/4" offset from the core center created one inch diameter hole. The depth of the hole reached 3.25 inches after about 45 second beam exposure but the hole diameter was tapered from 1" at the open into 0.25 " at 3.25 inch depth. This happened because the beam attenuation secondary effects increased as the hole became deeper. The hole was cone-shaped so quickly that rotary rock method did not work any more and test was stopped at 3.25" depth. Better purging system design and/or replacing the defocus beam with a collimated beam will be studied to drill deeper holes with this method.
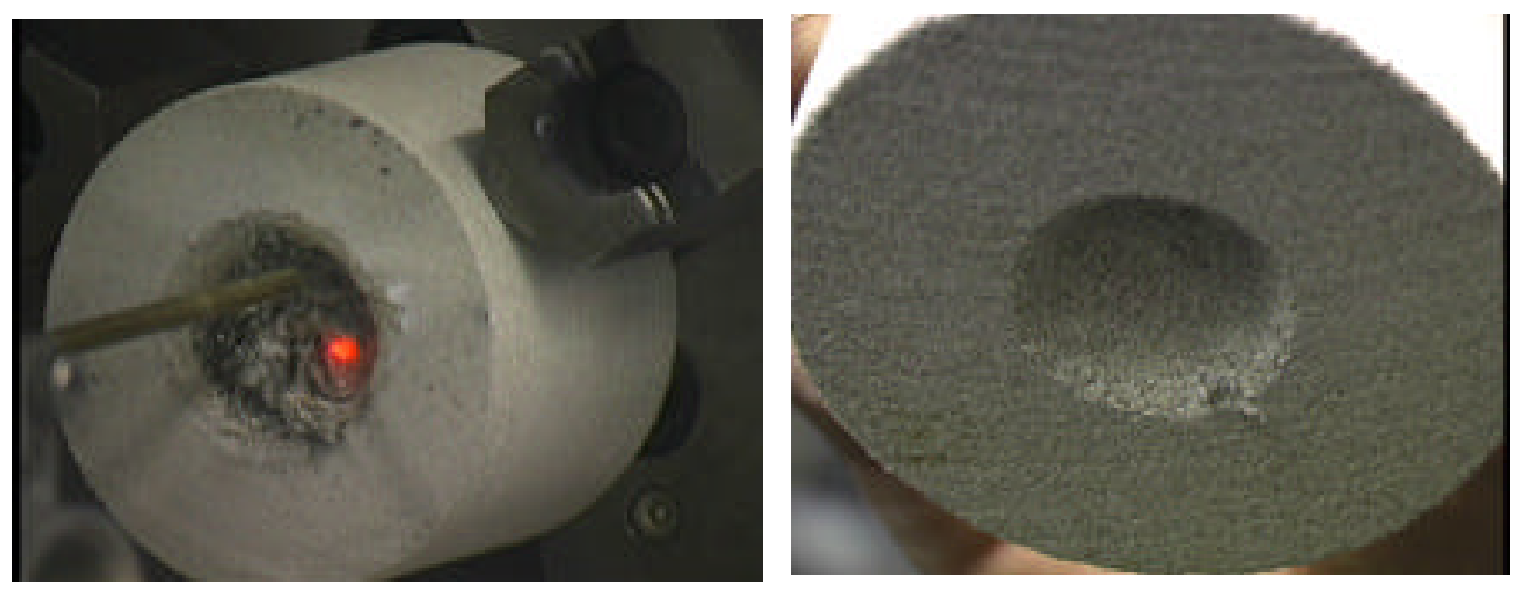

Fig. 4-6 Photographs showing a hole laser-drilled at $4000 \mathrm{~W}$ and 3000 degree/min rotary speed (Left) and a clean hole drilled at $2500 \mathrm{~W}$ and 10,000 degree/min. 


\section{Conclusions and Recommendations}

\section{Hole depth and associated problems}

To demonstrate the possibility of using high power laser beam for perforating, higher power $\mathrm{CO}_{2}$ laser beam was for the first time extensively used to drill deep holes into 3 " diameter by $3-6$ " long rock samples with three beam-purge-rock configurations. Good clean holes were drilled to a certain depth, about $2 / 3$ the length of the sample, at which point melting occurred and a layer of glassy phase formed. Additional laser energy either did little or created fractures due to the combined effects of reflection loss from the glassy surface, heat release from the bottom edge, and poor purging. Hole tapering was also observed in all configurations as the hole became deeper, which makes drilling deep holes difficult.

\section{Future tests}

We recommend that large rock samples as big as a foot cube be used for perforation testing in the future to avoid edge effect and fractures. Lased materials not only need to be quickly removed from hole by purging but also be blown away from the incoming beam path so that the drilling could be efficient and energy loss small. This requires better design of the beam/purge configuration. Use of a collimated beam instead of a defocused beam may also reduce the hole tapering. 


\section{WAVELENGTH DEPENDENCE OF SPECIFIC ENERGY RESULTS}

\section{Introduction}

One of the questions that has to be answered in order to develop a drilling system that is deployable in the field is what laser will be used. There are several aspects that need to be considered, including potential for coupling with an energy delivery system, inherent efficiency of converting electrical or other energy sources to laser energy, and the laser's efficiency in cutting rock. This comparison test series is meant to answer how much of the rock cutting efficiency is due to wavelength.

\section{Lasers Included in Comparison}

\section{Nd:YAG and CO2 Lasers}

Much of the work on this project has been done on the Nd:YAG laser because of its flexibility, pulse range, beam quality and availability. It is on the short end of the infrared spectrum, at 1.06 microns (the only laser used in this project with a shorter wavelength is the Nuvonyx diode laser, at 0.8 micrometers, below). At present, the $\mathrm{CO}_{2}$ laser is also being used extensively, at the other end of the infrared spectrum (10.6 microns).

The difficulty facing the team in trying to do a head-to-head comparison is in trying to match the laser parameters so that wavelength is the only variable. The Nd:YAG and the $\mathrm{CO}_{2}$ have very different pulse characteristics, with little overlap. Also, while it is not too difficult to match average power, their individual pulse peak powers can be very different, with the Nd:YAG capable of peak power up to 32 times the average power and the $\mathrm{CO}_{2}$ only 24. More detailed descriptions of the two lasers are in the Introduction section of this report.

\section{Diode Laser}

The 0.8 micrometer diode laser mentioned above was also used for tests in 2001 . The results for those tests are not used in this comparison because, even at the same laser schedule, E4R400L1, the average power is much higher $(\mathrm{ca} .1300 \mathrm{~W})$ due to the increased efficiency of the diode laser. This resulted in higher power densities, and the presence of melt in all samples. The onset of melting resulted in higher $\mathrm{SE}$ values.

\section{Wavelength Test Parameters}

A suitable parameter setting was found to be E4R400L1 for the Nd:YAG and $\mathrm{CO}_{2}$ lasers. The samples lased using the Nd:YAG had been done during the 2001 test program, where average powers ranging from 769-780 watts were measured. The average power for most lasers varies from day to day depending on factors such as humidity in the laboratory and the age of the flashlamps, as well as other maintenance-related items. The tests using the $\mathrm{CO}_{2}$ laser were performed during the 2002 test period, specifically for this comparison. The average power range was measured at 809-863 watts. The comparative laser parameters are shown in Table 51, placed at the end of this section.

\section{Equipment Setup}

The $\mathrm{CO}_{2}$ laser and it's stage was configured in order to match the spot size of the YAG beam for a given sample. The work on both the sandstone and the shale required a $0.5 \%(1.27 \mathrm{~cm})$ diameter, while the limestone had been tested at $0.125 "(0.32 \mathrm{~cm})$ hole diameter. The stage was kept 
stationary and the laser head was kept at a fixed distance from the surface of the sample. The laser was programmed to provide the parameters used with the YAG and the diode, i.e., peak height of $4 \mathrm{~kW}$, pulse width of 1 millisecond and a repetition rate of 400/second.

\section{Results}

The results of the head-to-head comparison are in Table 5-2.

\section{Sandstone}

The lithology with the most samples represented is the Berea Gray Sandstone. The BG comparison shown in Figure 5-1 indicates that the $\mathrm{CO}_{2}$ laser is at more efficient at lower energy levels, with the $S E$ values in the $4-10 \mathrm{~kJ} / \mathrm{cm}^{2}$ range, while the Nd:YAG SE values are $>10 \mathrm{~kJ} / \mathrm{cc}$. The higher energy input of the longer exposure tests show that the $\mathrm{CO}_{2}$ laser becomes less efficient, possibly due to the onset of melting.

\section{Limestone}

The limestone comparison was more difficult due to the smaller spot size that has to be used. This was not understood until after the multiple hole tests were performed on the $\mathrm{CO}_{2}$ laser, where it was found that limestone needs about $3 \mathrm{~kW} / \mathrm{cm}^{2}$ power density to cut efficiently. The $\mathrm{Nd}$ :YAG laser, using the $1.27 \mathrm{~cm}$ spot size, has a power density of about $1 \mathrm{~kW} / \mathrm{cm}^{2}$. The spot size has to be reduced in order to have the proper power density, but that creates problems related to the secondary effects seen when the project was using small, deep holes, such as beam absorption and inefficient purging.

The spot size used for the comparison was $0.08 \mathrm{~cm}^{2}$. The results, as seen in Figure 5-2 indicate the same relationship between the two lasers as seen in the sandstone samples.

\section{Shale}

The shale sample results showed less difference between the lasers than either of the other lithologies. Figure 5-3 shows that, at both the high and low energy inputs, there is no way to separate the two lasers.

\section{Conclusions and Recommendations}

The head-to-head wavelength comparison test data with sandstone, limestone and shale samples between the $\mathrm{CO}_{2}$ and $\mathrm{Nd}$ :YAG lasers showed that there is not a great difference in rock volume removed per total energy density between the lasers. The Nd:YAG laser is recommended for future tests due to its optical fiber deliverable capacity and smaller energy loss in water. The $\mathrm{CO}_{2}$ laser will continue to be used in tests in which laser average power greater than $2 \mathrm{~kW}$ is needed. 


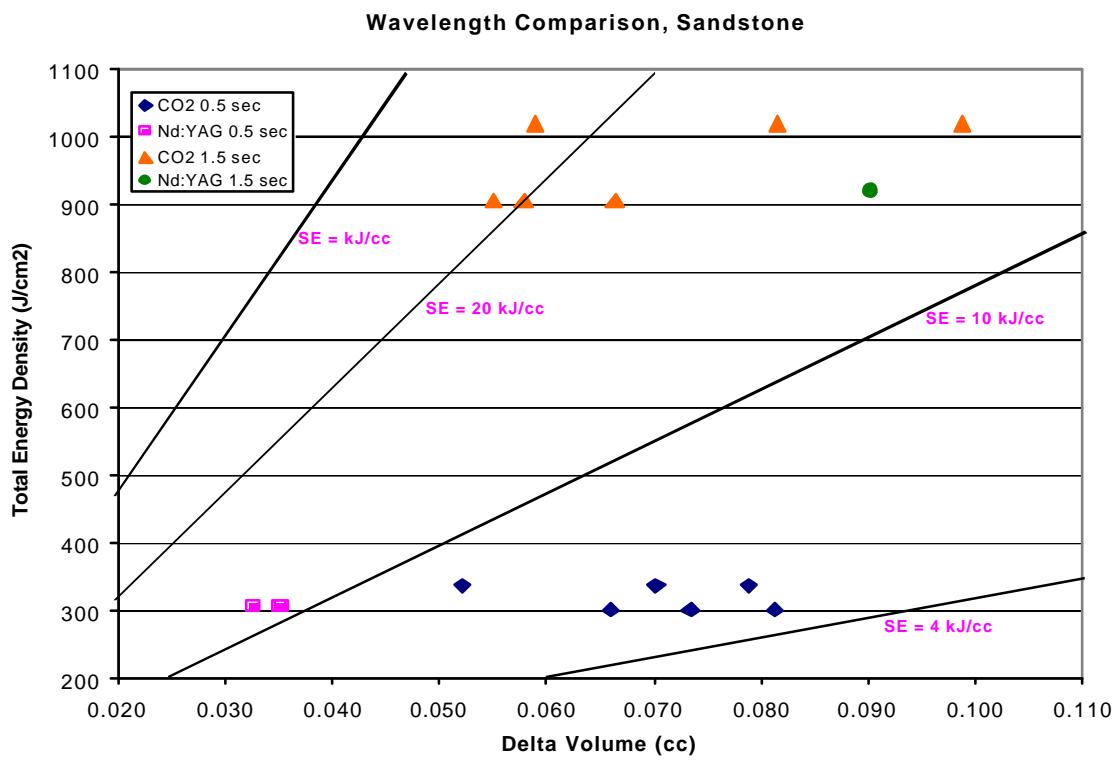

Figure 5-1. Wavelength comparison with sandstone samples between the $\mathrm{CO}_{2}$ and Nd:YAG lasers. The samples with lower energy input due to shorter exposure times show clear division between the lasers, with the Nd:YAG removing less material. The higher energy tests do not have clear advantage between the lasers, which is possibly due to the onset of melting. 


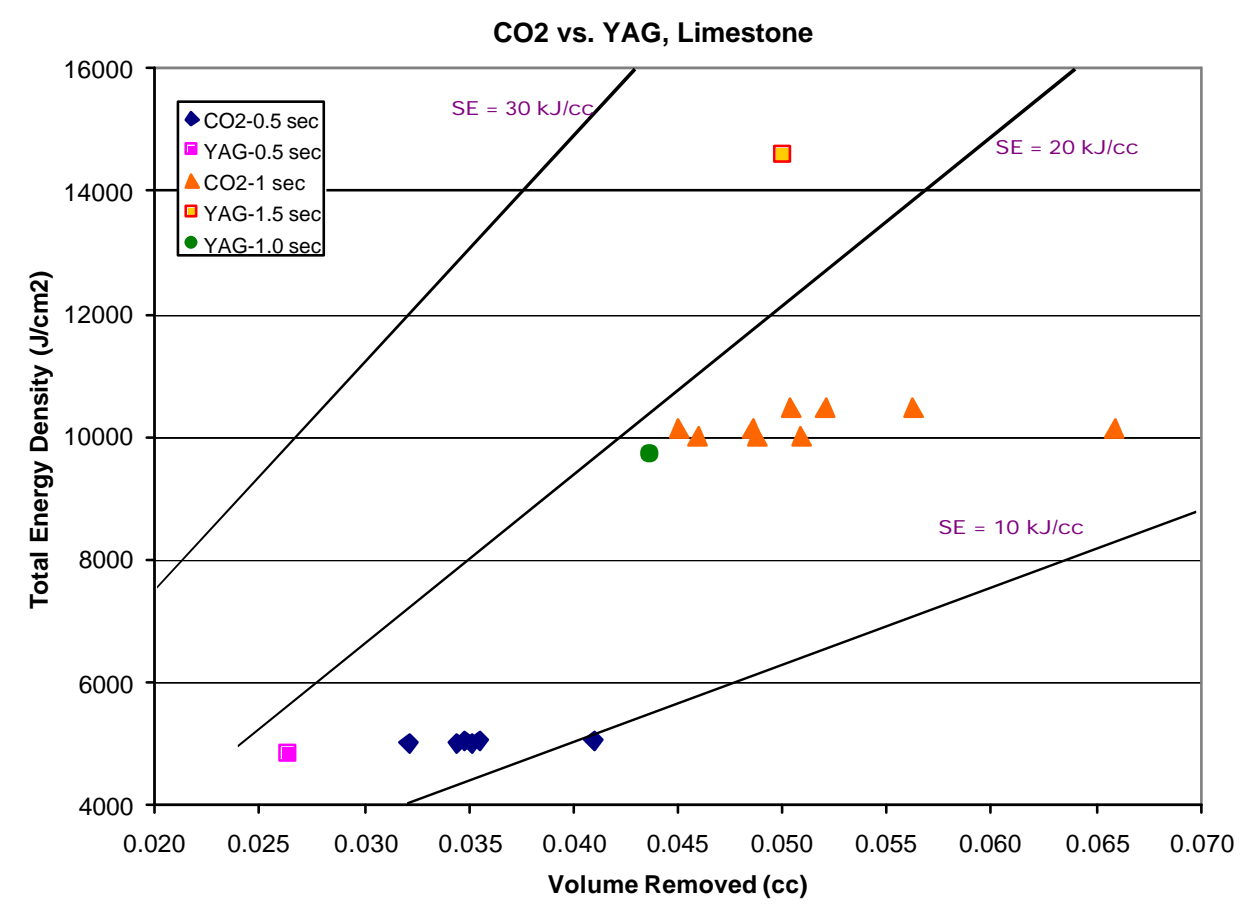

CO2 vs. YAG, Shale

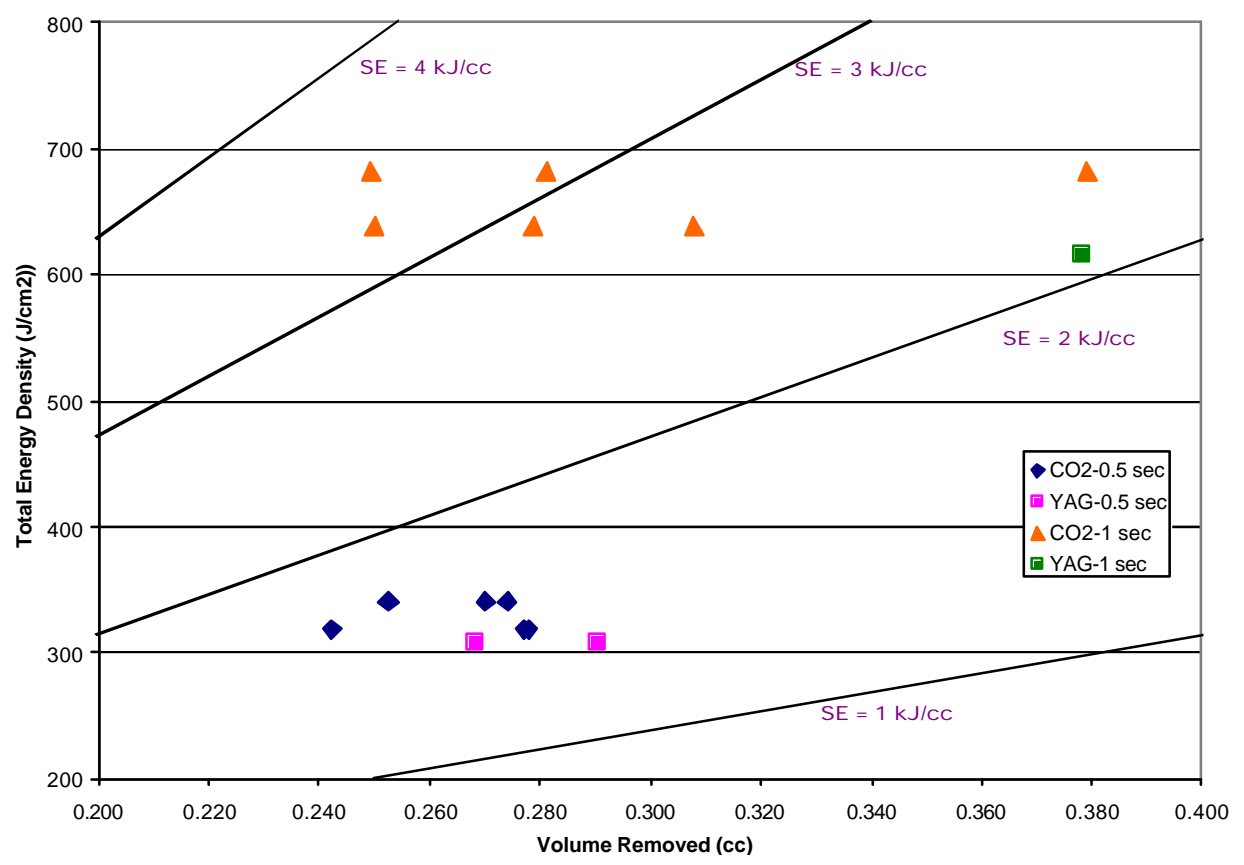




\begin{tabular}{|c|c|c|c|c|c|}
\hline \multicolumn{6}{|c|}{$\mathrm{CO}_{2}$} \\
\hline Sample & $\begin{array}{l}\text { Average Power } \\
(\mathbf{W})\end{array}$ & $\begin{array}{l}\text { Rep Rate } \\
(\mathrm{Hz})\end{array}$ & $\begin{array}{l}\text { Pulse Width } \\
(\mathrm{ms})\end{array}$ & $\begin{array}{l}\text { Spot Size } \\
(\mathrm{cm})\end{array}$ & \begin{tabular}{|l} 
Exposure \\
Time (sec)
\end{tabular} \\
\hline \multicolumn{6}{|c|}{ Limestone } \\
\hline 702LSC-1 & 802 & 400 & 1 & 0.32 & 0.5 \\
\hline 702LSC-2 & 802 & 400 & 1 & 0.32 & 0.5 \\
\hline 702LSC-3 & 802 & 400 & 1 & 0.32 & 0.5 \\
\hline 702LSC-4 & 794 & 400 & 1 & 0.32 & 0.5 \\
\hline 702LSC-5 & 794 & 400 & 1 & 0.32 & 0.5 \\
\hline 702LSC-6 & 794 & 400 & 1 & 0.32 & 0.5 \\
\hline 702LSC-7 & 802 & 400 & 1 & 0.32 & 1 \\
\hline 702LSC-8 & 802 & 400 & 1 & 0.32 & 1 \\
\hline 702LSC-9 & 802 & 400 & 1 & 0.32 & 1 \\
\hline 702LSB-1 & 830 & 400 & 1 & 0.32 & 1 \\
\hline 702LSB-2 & 830 & 400 & 1 & 0.32 & 1 \\
\hline 702LSB-3 & 830 & 400 & 1 & 0.32 & 1 \\
\hline 702LSB-4 & 794 & 400 & 1 & 0.32 & 1 \\
\hline 702LSB-5 & 794 & 400 & 1 & 0.32 & 1 \\
\hline 702LSB-6 & 794 & 400 & 1 & 0.32 & 1 \\
\hline \multicolumn{6}{|c|}{ Berea sandstone } \\
\hline 702BG52-1 & 856 & 400 & 1 & 1.27 & 0.5 \\
\hline 702BG52-2 & 856 & 400 & 1 & 1.27 & 0.5 \\
\hline 702BG52-3 & 856 & 400 & 1 & 1.27 & 0.5 \\
\hline 702BG54-1 & 766 & 400 & 1 & 1.27 & 0.5 \\
\hline 702BG54-2 & 766 & 400 & 1 & 1.27 & 0.5 \\
\hline 702BG54-3 & 766 & 400 & 1 & 1.27 & 0.5 \\
\hline 702BG53-1 & 766 & 400 & 1 & 1.27 & 1.5 \\
\hline 702BG53-2 & 766 & 400 & 1 & 1.27 & 1.5 \\
\hline 702BG53-3 & 766 & 400 & 1 & 1.27 & 1.5 \\
\hline 702BG55-1 & 863 & 400 & 1 & 1.27 & 1.5 \\
\hline 702BG55-2 & 863 & 400 & 1 & 1.27 & 1.5 \\
\hline 702BG55-3 & 863 & 400 & 1 & 1.27 & 1.5 \\
\hline \multicolumn{6}{|c|}{ Shale } \\
\hline 702SH8-C1 & 863 & 400 & 1 & 1.27 & 0.5 \\
\hline 702SH8-C2 & 863 & 400 & 1 & 1.27 & 0.5 \\
\hline 702SH8-C3 & 863 & 400 & 1 & 1.27 & 0.5 \\
\hline 702SH6-B1 & 809 & 400 & 1 & 1.27 & 0.5 \\
\hline 702SH6-B2 & 809 & 400 & 1 & 1.27 & 0.5 \\
\hline 702SH6-B3 & 809 & 400 & 1 & 1.27 & 0.5 \\
\hline 702SH13-B1 & 863 & 400 & 1 & 1.27 & 1 \\
\hline 702SH13-B2 & 863 & 400 & 1 & 1.27 & 1 \\
\hline 702SH13-B3 & 863 & 400 & 1 & 1.27 & 1 \\
\hline 702SH15-B1 & 809 & 400 & 1 & 1.27 & 1 \\
\hline 702SH15-B2 & 809 & 400 & 1 & 1.27 & 1 \\
\hline 702SH15-B3 & 809 & 400 & 1 & 1.27 & 1 \\
\hline
\end{tabular}




\begin{tabular}{|c|c|c|c|c|c|c|}
\hline \multicolumn{7}{|c|}{ NDYAG } \\
\hline Sample & \begin{tabular}{|l|} 
Average \\
Power (W)
\end{tabular} & Rep rate & \begin{tabular}{|l} 
Pulse \\
Width \\
(ms)
\end{tabular} & & \begin{tabular}{|l} 
Spot Size \\
$(\mathrm{cm})$
\end{tabular} & \begin{tabular}{|l|} 
Exposure \\
Time (sec)
\end{tabular} \\
\hline \multicolumn{7}{|c|}{ Limestone } \\
\hline LSA3-2 & 769 & 400 & & 1 & 0.32 & 0.5 \\
\hline LSA3-3 & 769 & 400 & & 1 & 0.32 & 1.5 \\
\hline \multicolumn{7}{|c|}{ Berea sandstone } \\
\hline $\operatorname{bg} 10(1)$ & 778 & 400 & & 1 & 1.27 & 0.5 \\
\hline $\operatorname{bg} 10(2)$ & 778 & 400 & & 1 & 1.27 & 0.5 \\
\hline $\operatorname{bg} 10(3)$ & 778 & 400 & & 1 & 1.27 & 0.5 \\
\hline $\operatorname{bg} 9(1)$ & 778 & 400 & & 1 & 1.27 & 1.5 \\
\hline $\operatorname{bg} 9(2)$ & 778 & $40 x$ & & 1 & 1.27 & 1.5 \\
\hline $\operatorname{bg} 9(3)$ & 778 & 400 & & 1 & 1.27 & 1.5 \\
\hline \multicolumn{7}{|c|}{ Shale } \\
\hline SH15 & 780 & 400 & & 1 & 1.27 & 0.5 \\
\hline SH16 & 780 & 400 & & 1 & 1.27 & \\
\hline
\end{tabular}


Table 5-2. Results of wavelength tests. The results indicate that there is some wavelength effect, but the degree is slight and the other considerations in the decision process for what laser will be used in the field may overwhelm the differences seen here.

\begin{tabular}{|c|c|c|c|c|c|c|c|c|c|c|c|c|}
\hline Lithology & Sample & Spot & Laser & $\begin{array}{c}\text { Wavelength } \\
\text { (Microns) }\end{array}$ & $\begin{array}{c}\text { Average } \\
\text { Power } \\
\text { (Measured, } \\
\text { W) }\end{array}$ & \begin{tabular}{c|} 
Spot \\
Diameter \\
$(\mathrm{cm})$
\end{tabular} & $\begin{array}{c}\text { Spot Area } \\
(\mathrm{cm} 2)\end{array}$ & \begin{tabular}{|l|} 
Exposure \\
Time (sec)
\end{tabular} & \begin{tabular}{|c|} 
Delta \\
Weight (g)
\end{tabular} & $\begin{array}{c}\text { Bulk } \\
\text { Density } \\
\text { (g/cc) }\end{array}$ & $\begin{array}{c}\text { Power } \\
\text { Density } \\
(W / c m 2)\end{array}$ & $\begin{array}{c}\text { Specific } \\
\text { Energy } \\
(J / c c)\end{array}$ \\
\hline BG & 52 & 1 & $\mathrm{CO} 2$ & 10.6 & 856 & 1.27 & 1.27 & 0.5 & 0.151 & 2.15 & 676 & 6,094 \\
\hline BG & 52 & 2 & $\mathrm{CO} 2$ & 10.6 & 856 & 1.27 & 1.27 & 0.5 & 0.1121 & 2.15 & 676 & 8,209 \\
\hline BG & 52 & 3 & $\mathrm{CO} 2$ & 10.6 & 856 & 1.27 & 1.27 & 0.5 & 0.1694 & 2.15 & 676 & 5,432 \\
\hline BG & 54 & 1 & $\mathrm{CO} 2$ & 10.6 & 766 & 1.27 & 1.27 & 0.5 & 0.1746 & 2.15 & 605 & 4,716 \\
\hline BG & 54 & 2 & $\mathrm{CO} 2$ & 10.6 & 766 & 1.27 & 1.27 & 0.5 & 0.1578 & 2.15 & 605 & 5,218 \\
\hline BG & 54 & 3 & $\mathrm{CO} 2$ & 10.6 & 766 & 1.27 & 1.27 & 0.5 & 0.1418 & 2.15 & 605 & 5,807 \\
\hline BG & 53 & 1 & $\mathrm{CO} 2$ & 10.6 & 766 & 1.27 & 1.27 & 1.5 & 0.1428 & 2.15 & 605 & 17,299 \\
\hline BG & 53 & 2 & $\mathrm{CO} 2$ & 10.6 & 766 & 1.27 & 1.27 & 1.5 & 0.1244 & 2.15 & 605 & 19,858 \\
\hline BG & 53 & 3 & $\mathrm{CO} 2$ & 10.6 & 766 & 1.27 & 1.27 & 1.5 & 0.1185 & 2.15 & 605 & 20,847 \\
\hline BG & 55 & 1 & $\mathrm{CO} 2$ & 10.6 & 863 & 1.27 & 1.27 & 1.5 & 0.1755 & 2.15 & 681 & 15,859 \\
\hline BG & 55 & 2 & $\mathrm{CO} 2$ & 10.6 & 863 & 1.27 & 1.27 & 1.5 & 0.2124 & 2.15 & 681 & 13,103 \\
\hline BG & 55 & 3 & $\mathrm{CO} 2$ & 10.6 & 863 & 1.27 & 1.27 & 1.5 & 0.1268 & 2.15 & 681 & 21,949 \\
\hline$B G$ & 10 & 1 & ND:YAG & 1.06 & 778 & 1.27 & 1.27 & 0.5 & 0.0756 & 2.15 & 614 & 11,063 \\
\hline BG & 10 & 2 & ND:YAG & 1.06 & 778 & 1.27 & 1.27 & 0.5 & 0.0761 & 2.15 & 614 & 10,990 \\
\hline$B G$ & 10 & 3 & ND:YAG & 1.06 & 778 & 1.27 & 1.27 & 0.5 & 0.0703 & 2.15 & 614 & 11,897 \\
\hline BG & 9 & 1 & ND:YAG & 1.06 & 778 & 1.27 & 1.27 & 1.5 & 0.1942 & 2.15 & 614 & 12,920 \\
\hline LS & C & 1 & $\mathrm{CO} 2$ & 10.6 & 802 & 0.32 & 0.08 & 0.5 & 0.0988 & 2.70 & 10130 & 9,781 \\
\hline LS & C & 2 & $\mathrm{CO} 2$ & 10.6 & 802 & 0.32 & 0.08 & 0.5 & 0.0839 & 2.70 & 10130 & 11,519 \\
\hline LS & C & 3 & $\mathrm{CO} 2$ & 10.6 & 802 & 0.32 & 0.08 & 0.5 & 0.0855 & 2.70 & 10130 & 11,303 \\
\hline LS & C & 4 & $\mathrm{CO} 2$ & 10.6 & 794 & 0.32 & 0.08 & 0.5 & 0.083 & 2.70 & 10029 & 11,527 \\
\hline LS & C & 5 & $\mathrm{CO} 2$ & 10.6 & 794 & 0.32 & 0.08 & 0.5 & 0.0774 & 2.70 & 10029 & 12,361 \\
\hline LS & C & 6 & $\mathrm{CO} 2$ & 10.6 & 794 & 0.32 & 0.08 & 0.5 & 0.0847 & 2.70 & 10029 & 11,296 \\
\hline LS & C & 7 & $\mathrm{CO} 2$ & 10.6 & 802 & 0.32 & 0.08 & 1 & 0.1171 & 2.70 & 10130 & 16,506 \\
\hline LS & C & 8 & $\mathrm{CO} 2$ & 10.6 & 802 & 0.32 & 0.08 & 1 & 0.1086 & 2.70 & 10130 & 17,798 \\
\hline LS & C & 9 & $\mathrm{CO} 2$ & 10.6 & 802 & 0.32 & 0.08 & 1 & 0.1588 & 2.70 & 10130 & 12,171 \\
\hline LS & B & 1 & $\mathrm{CO} 2$ & 10.6 & 830 & 0.32 & 0.08 & 1 & 0.1255 & 2.70 & 10483 & 15,939 \\
\hline
\end{tabular}




\begin{tabular}{|c|c|c|c|c|c|c|c|c|c|c|c|c|}
\hline LS & B & 2 & $\mathrm{CO} 2$ & 10.6 & 830 & 0.32 & 0.08 & 1 & 0.1214 & 2.70 & 10483 & 16,477 \\
\hline LS & B & 3 & $\mathrm{CO} 2$ & 10.6 & 830 & 0.32 & 0.08 & 1 & 0.1355 & 2.70 & 10483 & 14,762 \\
\hline LS & B & 4 & $\mathrm{CO} 2$ & 10.6 & 794 & 0.32 & 0.08 & 1 & 0.1226 & 2.70 & 10029 & 15,608 \\
\hline LS & B & 5 & $\mathrm{CO} 2$ & 10.6 & 794 & 0.32 & 0.08 & 1 & 0.1108 & 2.70 & 10029 & 17,270 \\
\hline LS & B & 6 & $\mathrm{CO} 2$ & 10.6 & 794 & 0.32 & 0.08 & 1 & 0.1175 & 2.70 & 10029 & 16,285 \\
\hline $\mathrm{LS}$ & A3 & 2 & ND:YAG & 1.06 & 769 & 0.32 & 0.08 & 0.5 & 0.0637 & 2.70 & 9,713 & 14,547 \\
\hline $\mathrm{LS}$ & A3 & 4 & ND:YAG & 1.06 & 769 & 0.32 & 0.08 & 1 & 0.1053 & 2.70 & 9,713 & 17,600 \\
\hline $\mathrm{LS}$ & A3 & 3 & ND:YAG & 1.06 & 769 & 0.32 & 0.08 & 1.5 & 0.1205 & 2.70 & 9,713 & 23,070 \\
\hline $\mathrm{SH}$ & 8 & $\mathrm{C} 1$ & $\mathrm{CO} 2$ & 10.6 & 863 & 1.27 & 1.27 & 0.5 & 0.6374 & 2.36 & 681 & 1,599 \\
\hline SH & 8 & $\mathrm{C} 2$ & $\mathrm{CO} 2$ & 10.6 & 863 & 1.27 & 1.27 & 0.5 & 0.5959 & 2.36 & 681 & 1,710 \\
\hline $\mathrm{SH}$ & 8 & $\mathrm{C} 3$ & $\mathrm{CO} 2$ & 10.6 & 863 & 1.27 & 1.27 & 0.5 & 0.647 & 2.36 & 681 & 1,575 \\
\hline $\mathrm{SH}$ & 6 & B1 & $\mathrm{CO} 2$ & 10.6 & 809 & 1.27 & 1.27 & 0.5 & 0.654 & 2.36 & 639 & 1,461 \\
\hline $\mathrm{SH}$ & 6 & B2 & $\mathrm{CO} 2$ & 10.6 & 809 & 1.27 & 1.27 & 0.5 & 0.6556 & 2.36 & 639 & 1,457 \\
\hline $\mathrm{SH}$ & 6 & B3 & $\mathrm{CO} 2$ & 10.6 & 809 & 1.27 & 1.27 & 0.5 & 0.5718 & 2.36 & 639 & 1,671 \\
\hline $\mathrm{SH}$ & 13 & B1 & $\mathrm{CO} 2$ & 10.6 & 863 & 1.27 & 1.27 & 1 & 0.6634 & 2.36 & 681 & 3,073 \\
\hline $\mathrm{SH}$ & 13 & $\mathrm{~B} 2$ & $\mathrm{CO} 2$ & 10.6 & 863 & 1.27 & 1.27 & 1 & 0.5886 & 2.36 & 681 & 3,463 \\
\hline $\mathrm{SH}$ & 13 & B3 & $\mathrm{CO} 2$ & 10.6 & 863 & 1.27 & 1.27 & 1 & 0.8948 & 2.36 & 681 & 2,278 \\
\hline SH & 15 & B1 & $\mathrm{CO} 2$ & 10.6 & 809 & 1.27 & 1.27 & 1 & 0.6582 & 2.36 & 639 & 2,903 \\
\hline $\mathrm{SH}$ & 15 & B2 & $\mathrm{CO} 2$ & 10.6 & 809 & 1.27 & 1.27 & 1 & 0.7267 & 2.36 & 639 & 2,629 \\
\hline $\mathrm{SH}$ & 15 & B3 & $\mathrm{CO} 2$ & 10.6 & 809 & 1.27 & 1.27 & 1 & 0.5905 & 2.36 & 639 & 3,236 \\
\hline $\mathrm{SH}$ & 15 & A2 & ND:YAG & 1.06 & 780 & 1.27 & 1.27 & 0.5 & 0.6333 & 2.36 & 616 & 1,455 \\
\hline $\mathrm{SH}$ & 15 & & ND:YAG & 1.06 & 780 & 1.27 & 1.27 & 0.5 & 0.6856 & 2.36 & 616 & 1,344 \\
\hline $\mathrm{SH}$ & 16 & & ND:YAG & 1.06 & 780 & 1.27 & 1.27 & 1 & 0.8925 & 2.36 & 616 & 2,064 \\
\hline
\end{tabular}




\section{CONVERTING FUNDAMENTAL DATA TO RATES OF PENETRATION}

\section{Introduction}

The work done to date on the Laser Well Drilling, Completion and Stimulation project has the goal of determining the minimum energy needed to cut the three most common lithologies that are encountered in the search for oil and gas, i.e., shale, sandstone and limestone. In order for the data that has been generated in this search to be meaningful, it has to be converted to terms with which the drilling community is familiar. The two most common are rate of penetration (ROP) and cost per foot.

The cost per foot is not calculable yet because capital investment and expendables costs have not yet been determined for this use of lasers. ROP is very important in getting to the point of calculating costs, because many costs are dependent on how many days a rig is sitting at a drilling location. This section of the Topical Report is intended to make estimates of possible ROPs using the repeated spot and multiple spot data generated in 2002 .

The method used here to calculate ROP is to take the Specific Energies calculated from the tests and determine a ROP consistent with the assumptions that had to be made. The assumptions fall into four categories corresponding to the rig, laser, optical fiber and rocks. In addition, three cases are calculated in an attempt to take into consideration the conditions to be found downhole.

\section{Basic assumptions}

Rig Design

While the exact appearance and constituents of a laser drilling rig has not been finalized, the configuration used for the purposes of these calculations is to have the laser(s) at the surface, with a lightweight, composite, coiled tubing reel conveying the laser energy to the bottomhole assembly by means of a bundle of optical fibers, each fiber carrying a portion of the total laser energy. The fibers terminate in a matrix head with lenses imbedded in the working surface in a pattern capable of removing material a measured thickness in a given time, keeping the working face nearly flat.

\section{Lasers}

No specific assumptions as to the particular laser are needed except that it is of sufficient power to do what is necessary and of a wavelength suitable for coupling to optical fibers.

\section{Optical Fibers}

It is assumed that the fiber core size will be about $1 \mathrm{~mm}$ in diameter and can carry average power up to $10 \mathrm{~kW}$, the maximum that has actually been injected into a fiber. In order to be conservative, calculations will use a maximum average power value per fiber of $6 \mathrm{~kW}$. The fibers used with the Nd:YAG at ANL routinely carry $2 \mathrm{~kW}$ average power, with peak powers up to 32 $\mathrm{kW}$.

Commercially available fibers, if carefully selected for low $\mathrm{OH}$ characteristics, may be able to carry these power levels with transmission loses of about 37\% per kilometer. For the purpose of these calculations, it will be assumed that the hole is 1000 meters deep. The available power at 
the fiber end, therefore, will be about $3.78 \mathrm{~kW}$. If this is then defocused to $1.27 \mathrm{~cm}^{2}$, the maximum power density available is $3 \mathrm{~kW} / \mathrm{cm}^{2}$.

The most recent tests indicate that $3.0 \mathrm{~kW} / \mathrm{cm}^{2}$ is actually too high for sandstone and shale, and often results in onset of melting early in the tests. On the other hand, the same series of tests indicate that $3.0 \mathrm{~kW} / \mathrm{cm}^{2}$ is a very good value for limestone, which does not have the effect of inappropriate melting.

\section{Rock Characteristics}

Natural rock is extremely variable in its characteristics. A short list of the variability includes mineralogy, grain size, porosity and permeability, cement type, compression strength, resistance to shearing, organic content, clay content (where clay is a term that implies grain size as well as mineralogy), whether the clays are in the matrix or in the pores, and many other factors. The studies that have resulted in this report have tried to both minimize and explore this variability.

The sandstone used for the majority of the tests is a quarry stone, Berea Gray, known for its homogeneity and constant characteristics. It is not a reservoir rock, which are usually less homogeneous. The other lithologies studied suffer from higher variability. Even within a single well, limestones and, particularly, shales can change foot by foot. Shales also are problematic in that it is hard to get a piece of core that is thick enough for the tests, as the shale splits easily along bedding planes. Many of the limestone tests performed in 2002 were done on another quarry stone, a Siluro-Ordovician limestone used on many of the buildings in Chicago.

The test samples are not representative of the hardest or the softest rocks encountered in oil and gas drilling, but it has been shown by the previous studies that lasers can cut all lithologies, and the variations in energy required are less than found in mechanical drilling.

\section{Shale Characteristics}

Several shales have been used in this study. Among the differences are mineralogy, mainly the amount of quartz, and how organically rich it is. The amount of energy needed to cut the shale is very small in all cases.

\section{Density}

The density of shale, like most rocks, changes from sample to sample. However, for the purpose of the calculations done here, the density is assumed to be $2.36 \mathrm{~g} / \mathrm{cm} 3$.

\section{Sandstone Characteristics}

As discussed above, most of the sandstone tests, and the majority of all the tests, were done on the Berea Gray quarry sandstone. This rock still has some variability, but is quite consistent.

\section{Density}

The density used in the calculations is $2.15 \mathrm{~g} / \mathrm{cm} 3$. 


\section{Limestone Characteristics}

As mentioned above, the quarry limestone for the 2002 study is much more homogeneous than the well core samples used previously.

\section{Density}

The density of this limestone is fairly constant at $2.7 \mathrm{~g} / \mathrm{cm}^{3}$.

\section{Geometry}

The calculations below assume a hexagonal pattern of lenses in the matrix head of the bottomhole assembly. This allows a hole outline that is close to circular and gives an efficient coverage of the working face with the degree of overlap controllable by the spacing of the lenses in the drilling head.
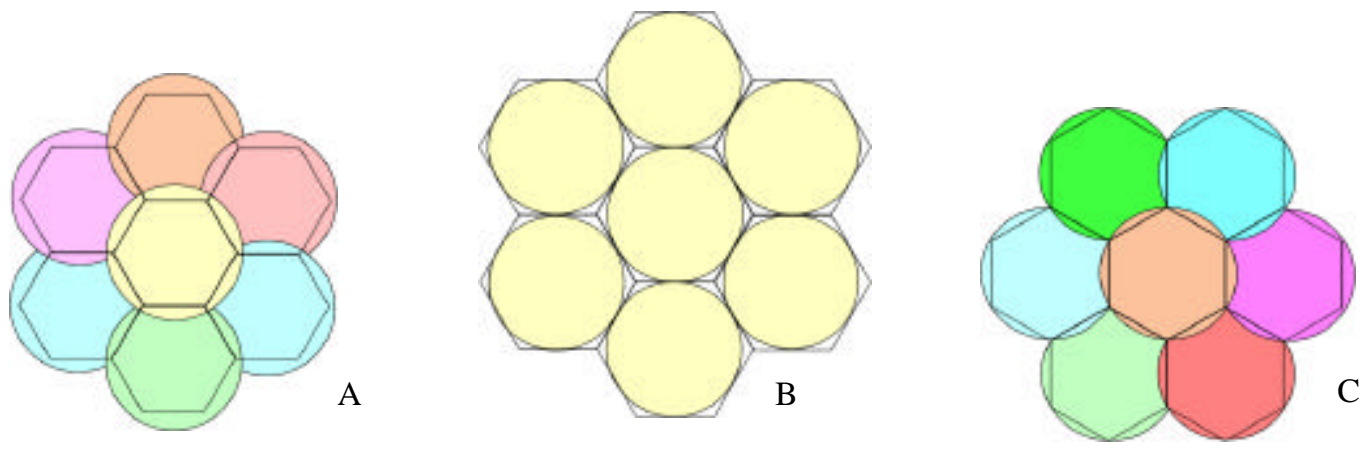

Figure 6-1. Hexagon groupings for the three overlap scenarios. A. Worst case, $1 \mathrm{~cm}$ center to ecenter spacing; B. Best Case, $1.27 \mathrm{~cm}$ spacing, note gap between circ les; C. Most likely, $1.1 \mathrm{~cm}$ spacing.

\begin{tabular}{|l|l|l|l|}
\hline Table 6-1: GEOMETRY ASSUMPTIONS \\
\hline Spot Size & Diameter & $1.27 \mathrm{~cm}$ & \\
\hline & Area & $1.27 \mathrm{~cm}^{2}$ & \\
\hline Spot Pattern & & Hexagonal & \\
\hline Hole Size & Diameter & $20 \mathrm{~cm}$ & $(7.9$ inches $)$ \\
\hline & Area & $314 \mathrm{~cm}^{2}$ & \\
\hline Burst Length & & $0.5 \mathrm{sec}$ & \\
\hline
\end{tabular}

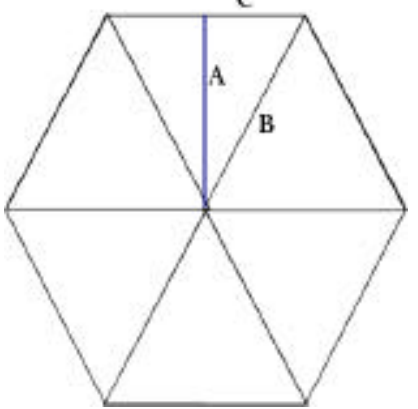

The hole size used in all the calculations is $20 \mathrm{~cm}$, which is close to a 8 inch hole (7.9 inches). The spot size is 0.5 inches, or $1.27 \mathrm{~cm}$, which is the hole size used most in the tests done for this study. These values give an area of the working face of $314 \mathrm{~cm}^{2}$. The number of spots required to cover the entire hole varies according to the amount of overlap required to make a flat enough surface to allow the laser head to move downward without hitting any ridges. Three overlaps have been calculated, or rather two overlaps and no overlap, and the number of spots from each will be used in the best, most likely and worst scenario calculations. The pattern of the three sets of hexagons are in Figure 6-1. 
The size of the hexagons tiling the hole is calculated according to the values given in Figure 6-2.

\begin{tabular}{|c|c|c|c|}
\hline $\begin{array}{l}\text { Table } 62 \text { Calculation } \mathrm{p} \\
\text { amounts. }\end{array}$ & ers for hexa & ons assur & ifferent $\mathrm{o}$ \\
\hline SPACINGS & BEST CASE & $\begin{array}{l}\text { MOST } \\
\text { LIKELY }\end{array}$ & $\begin{array}{l}\text { WORST } \\
\text { CASE }\end{array}$ \\
\hline $\mathrm{A}$ & 0.635 & 0.55 & 0.5 \\
\hline $\mathrm{B}$ & 0.73 & 0.635 & 0.58 \\
\hline $\bar{C}$ & 0.365 & 0.3175 & 0.29 \\
\hline Single Hexagon Area & 1.39 & 1.05 & 0.87 \\
\hline $\begin{array}{l}\text { Number of Hexagons } \\
\text { needed to cover } 314 \mathrm{~cm}^{2}\end{array}$ & 226 & 299 & 361 \\
\hline Percent Overlap & $0 \%$ & $6 \%$ & $10 \%$ \\
\hline
\end{tabular}

\section{Specific Energy Values}

The multispot tests indicate that it is going to require more energy to continually cut rock than just the minimum (absolute) SE determined with single spot, single shot tests. For example, the sandstone SE determined on the YAG laser increased from a single spot single burst level of 7.9 $\mathrm{kJ} / \mathrm{cc}$ to leveling off at about $12 \mathrm{~kJ} / \mathrm{cc}$ with multiple spots and repeats. Similarly, the shale increased from $0.52 \mathrm{~kJ} / \mathrm{cc}$ to $4.2 \mathrm{~kJ} / \mathrm{cc}$, almost an order of magnitude. The limestone behaves the same way, in that the SE increases with the number of repeats. However, the last set of tests using the higher power density available on the $\mathrm{CO}_{2}$ laser resulted in SE values much less than previous tests, which are used in these calculations.

Lower SE values are important because, with a given amount of power, a low SE means that the rock will cut faster than high SE rock. Three SE values will be used in these calculations, with the best case having the absolute best SE measured for the rock, the most likely using the same curves, but leveling them off close to where they are on the graph and the worst case using a extrapolation of the SE curves outward from the number of bursts actually tested.

\begin{tabular}{|l|l|l|l|}
\hline Table 6-3. Specific Energy values used in ROP calculations \\
\hline Specific Energy (kJ/cc) & Best Case & Most Likely & Worst Case \\
\hline Sandstone & 9.2 & 10 & 13 \\
\hline Shale & 0.518 & 5 & 10 \\
\hline Limestone & 10 & 14 & 20 \\
\hline
\end{tabular}

\section{Results}

\section{Best case scenario}

The best case assumptions are that the spacing can be expanded to 0\% overlap, and SE values are the best measured in any of the tests. Sandstone SE is $9.2 \mathrm{~kJ} / \mathrm{cc}$, shale SE is $0.518 \mathrm{~kJ} / \mathrm{cc}$ and limestone SE is $10 \mathrm{~kJ} / \mathrm{cc}$. The power density used is what gave the best SE result, as is the duration. No multiple burst effect is used, except for limestone, where the best SE came after many bursts. It is assumed that the entire hole is cut by two illuminations of the spots, which allows one duration relaxation period in between. 


\begin{tabular}{|c|c|c|c|c|c|c|c|c|c|c|c|c|}
\hline BEST CASE & SE & $\begin{array}{l}\text { Power } \\
\text { Density }\end{array}$ & $\begin{array}{l}\text { Number } \\
\text { of Spots }\end{array}$ & $\begin{array}{l}\text { Number } \\
\text { Illum. a } \\
\text { one time }\end{array}$ & Duration & $\begin{array}{l}\text { Spot } \\
\text { area }\end{array}$ & $\begin{array}{l}\text { Volume } \\
\text { per } \\
\text { (cc) }\end{array}$ & $\begin{array}{l}\text { Volume } \\
\text { per } \\
\text { IIllum. }\end{array}$ & $\begin{array}{l}\text { cm per } \\
\text { Illum. }\end{array}$ & $\begin{array}{l}\text { cm } \\
\text { Sec. }\end{array}$ & $\begin{array}{l}\text { percm per } \\
\text { Hour }\end{array}$ & \begin{tabular}{|l} 
Feet per \\
Hour
\end{tabular} \\
\hline Sandstone & 9.2 & 1.1 & 224 & 112 & 0.5 & 1.27 & 0.075 & 8.50 & 0.059 & 0.119 & 430 & 148 \\
\hline Shale & 0.518 & 1.0 & 224 & 112 & 0.5 & 1.27 & 0.612 & 68.64 & 0.482 & 0.965 & 3474 & 1146 \\
\hline Limestone & 10 & 3 & 224 & 112 & 0.5 & 1.27 & 0.10 & 8.57 & 0.08 & 0.15 & 540 & 18 \\
\hline
\end{tabular}

\section{Most likely case}

The most likely case parameters are the ones for which most data was taken in the multispot tests. The hexagon overlap is about $6 \%$, which is figured by nesting hexagons that are circumscribed by a $1.27 \mathrm{~cm}$ circles. The number of illuminations required to fill the hole is three, which allows a relaxation time of 1.0 second.

\begin{tabular}{|c|c|c|c|c|c|c|c|c|c|c|c|c|}
\hline \begin{tabular}{|l|} 
MOST \\
LIKELY \\
CASE
\end{tabular} & SE & \begin{tabular}{|l} 
Power \\
Density \\
$(\mathbf{k W /}$ \\
$\left.\mathrm{cm}^{2}\right)$
\end{tabular} & $\begin{array}{l}\text { Number } \\
\text { of Spots }\end{array}$ & \begin{tabular}{|l|} 
Number \\
Illum. \\
one time
\end{tabular} & Duration & $\begin{array}{l}\text { Spot } \\
\text { area } \\
\left.\text { cm }^{2}\right)\end{array}$ & $\begin{array}{|ll|}\text { Volume } \\
\text { per } & \text { Spot } \\
\text { (ce) } & \end{array}$ & $\begin{array}{l}\text { Volume } \\
\text { per Illum. } \\
\text { (cc) }\end{array}$ & $\begin{array}{l}\text { cm pe } \\
\text { Illum. }\end{array}$ & $\begin{array}{l}\mathrm{cm} \quad p \\
\text { Second }\end{array}$ & $\begin{array}{ll}\mathrm{cm} & \mathbf{1} \\
\text { Hour }\end{array}$ & \begin{tabular}{|l|l} 
per & Feet \\
per \\
Hour
\end{tabular} \\
\hline Sandstone & 10 & 1.1 & 300 & 100 & 0.5 & 1.27 & 0.07 & 6.99 & 0.06 & 0.11 & 396 & 13 \\
\hline Shale & 5 & 1.0 & 300 & 100 & 0.5 & 1.27 & 0.13 & 12.70 & 0.10 & 0.20 & 720 & 24 \\
\hline Limestone & 14 & 3.0 & 300 & 100 & 0.5 & 1.27 & 0.14 & 13.61 & 0.11 & 0.21 & 771 & 25 \\
\hline
\end{tabular}

\section{Worst case scenario}

The worst case assumes that spacing has to be closer, at $1 \mathrm{~cm}$, to remove the ridge between spots to allow the drilling head to move downward and continue the hole. The increased percentage of overlap dictates more fibers necessary to create a given hole size.

The factors used in the geometry calculations are shown in Table 6-2 and the calculations are in Table 6-6.

\begin{tabular}{|c|c|c|c|c|c|c|c|c|c|c|c|c|}
\hline $\begin{array}{l}\text { WORST } \\
\text { CASE }\end{array}$ & SE & \begin{tabular}{|l} 
Power \\
Density \\
$(\mathbf{k W /}$ \\
$\left.\mathrm{cm}^{2}\right)$
\end{tabular} & $\begin{array}{l}\text { Number } \\
\text { of Spots }\end{array}$ & $\begin{array}{l}\text { Number } \\
\text { Illum. At } \\
\text { one time }\end{array}$ & Duration & $\begin{array}{l}\text { Spot } \\
\text { area }\end{array}$ & $\begin{array}{l}\text { Volume } \\
\text { per Spot } \\
\text { (cc) }\end{array}$ & $\begin{array}{l}\text { Volume } \\
\text { per } \\
\text { Illum. }\end{array}$ & \begin{tabular}{|l|} 
cm \\
per \\
Illum.
\end{tabular} & \begin{tabular}{|lr} 
cm pe \\
Second
\end{tabular} & $\begin{array}{l}\text { cm } \\
\text { per } \\
\text { Hour }\end{array}$ & $\begin{array}{l}\text { Feet } \\
\text { per } \\
\text { Hour }\end{array}$ \\
\hline Sandstone & 13 & 1.1 & 360 & 90 & 0.5 & 1.27 & 0.05 & 4.84 & 0.04 & 0.08 & 305 & 10 \\
\hline Shale & 10 & 1.0 & 360 & 90 & 0.5 & 1.27 & 0.06 & 5.72 & 0.05 & 0.10 & 360 & 12 \\
\hline Limestone & 20 & 3.0 & 360 & 90 & 0.5 & 1.27 & 0.24 & 21.43 & 0.19 & 0.38 & 1,350 & 18 \\
\hline
\end{tabular}




\section{Conclusions and Recommendations}

The rates of penetration calculated for this section should be used as first approximations only. There are still many aspects of the laser drilling process that are just not known. The environment at the bottom of a hole has got to be much different than what has been done in the laboratory at room temperature and atmospheric pressure. It is easy to predict how the conditions downhole could be much more conducive for poorer performance, but the additive effect of the cutting process could also make the cutting more efficient. The results of these calculations are encouraging in that the fairly hard rocks of the ANL test series can be penetrated at rates the drilling industry deals with everyday.

\section{Future tests}

In order to make continuing improvements of accuracy while doing these calculations, it is necessary to create test situations more closely reflecting what is thought to be the way laser drilling will be done in real life. The test designs to be used in future tests have to be different in several ways to allow more realistic results.

- The test structure needs to be changed to allow the beam to be switched essentially instantaneously from fiber to fiber instead of mechanically moving the sample around.

- The amount of laser power available has to be increased sufficiently to allow two or three fibers to carry $3 \mathrm{~kW}$ or more at one time instead of one fiber with less than $2 \mathrm{~kW}$. When this happens, the idea of working a larger area in two or three illuminations can be tested.

- The gas purge system has to be made an integral part of the excavating process, just like it is today in mechanical drilling. It needs to be angled properly, have efficient nozzle designs and high enough gas velocities to purge material out of the way rapidly and efficiently. 


\section{APPENDIX A: DATA TABLES}

Table A-1: One Spot Repeated Bursts

Sandstone, Limestone and Shale samples.

Laser parameters are:

1. Wavelength $=1.06$ micrometers

2. Maximum average power 1.6 kilowatts

Laser schedule can be converted to pulse information:

1. $E=$ pulse peak power in kilowatts

2. $\mathrm{L}=$ pulse width at half peak height in milliseconds

3. $\mathrm{R}=$ pulse rate in $\mathrm{Hz}$ 


\begin{tabular}{|c|c|c|c|c|c|c|c|c|c|c|c|c|c|c|c|c|}
\hline Test Date & $\begin{array}{l}\text { Sample } \\
\text { Lithology }\end{array}$ & $\begin{array}{l}\text { Disk } \\
\text { Label }\end{array}$ & $\begin{array}{c}\text { Spot } \\
\#\end{array}$ & $\begin{array}{l}\text { Laser } \\
\text { Schedule }\end{array}$ & $\begin{array}{l}\text { Peak } \\
\text { Power } \\
(\mathrm{kW})\end{array}$ & $\begin{array}{l}\text { Pulse } \\
\text { Width } \\
\text { (ms) }\end{array}$ & $\begin{array}{c}\text { Repetitio } \\
\text { n Rate } \\
\text { (/sec) }\end{array}$ & $\begin{array}{c}\text { Measured } \\
\text { average } \\
\text { power } \\
\text { (watts) }\end{array}$ & $\begin{array}{c}\text { Spot } \\
\text { Size } \\
\text { (inches } \\
\text { ) }\end{array}$ & $\begin{array}{l}\text { Spot } \\
\text { Area } \\
(\mathrm{cm} 2)\end{array}$ & $\begin{array}{l}\text { Burst } \\
\text { Length } \\
\text { (sec) }\end{array}$ & $\begin{array}{l}\text { Number } \\
\text { of Bursts }\end{array}$ & $\begin{array}{l}\text { Time } \\
\text { Between } \\
\text { Bursts } \\
\text { (sec) }\end{array}$ & $\begin{array}{c}\text { Weight } \\
\text { Before } \\
\text { (gr) }\end{array}$ & $\begin{array}{c}\text { Weight } \\
\text { After (gr) }\end{array}$ & $\begin{array}{c}\text { Delta } \\
\text { Weight } \\
\text { (gr) }\end{array}$ \\
\hline $7 / 29 / 02$ & $B G$ & $\overline{\mathrm{A} 1}$ & 1 & E8L1R200 & 8 & 1 & 200 & 1172 & 0.5 & 1.27 & 0.5 & 2 & 0.5 & 440.730 & 440.400 & 0.330 \\
\hline 7/29/02 & $B G$ & $\mathrm{~A} 1$ & 2 & E8L1R200 & 8 & 1 & 200 & 1172 & 0.5 & 1.27 & 0.5 & 2 & 0.5 & 440.400 & 439.940 & 0.460 \\
\hline 7/29/02 & $B G$ & A1 & 3 & E8L1R200 & 8 & 1 & 200 & 1172 & 0.5 & 1.27 & 0.5 & 2 & 0.5 & 439.940 & 439.520 & 0.420 \\
\hline 7/29/02 & BG & A1 & 4 & E8L1R200 & 8 & 1 & 200 & 1172 & 0.5 & 1.27 & 0.5 & 3 & 0.5 & 439.520 & 438.890 & 0.630 \\
\hline 7/29/02 & $B G$ & A1 & 5 & E8L1R200 & 8 & 1 & 200 & 1172 & 0.5 & 1.27 & 0.5 & 3 & 0.5 & 438.890 & 438.310 & 0.580 \\
\hline 7/29/02 & $B G$ & A1 & 6 & E8L1R200 & 8 & 1 & 200 & 1172 & 0.5 & 1.27 & 0.5 & 3 & 0.5 & 438.310 & 437.730 & 0.580 \\
\hline 7/29/02 & $B G$ & A1 & 7 & E8L1R200 & 8 & 1 & 200 & 1172 & 0.5 & 1.27 & 0.5 & 1 & 0 & 437.730 & 437.480 & 0.250 \\
\hline 7/29/02 & $B G$ & A1 & 8 & E8L1R200 & 8 & 1 & 200 & 1172 & 0.5 & 1.27 & 0.5 & 5 & 0 & 437.480 & 436.940 & 0.540 \\
\hline 7/29/02 & BG & A2 & 1 & E8L1R200 & 8 & 1 & 200 & 1172 & 0.5 & 1.27 & 0.5 & 4 & 0.5 & 477.040 & 476.430 & 0.610 \\
\hline 7/29/02 & $B G$ & A2 & 2 & E8L1R200 & 8 & 1 & 200 & 1172 & 0.5 & 1.27 & 0.5 & 4 & 0.5 & 476.430 & 475.750 & 0.680 \\
\hline 7/29/02 & $B G$ & A2 & 3 & E8L1R200 & 8 & 1 & 200 & 1172 & 0.5 & 1.27 & 0.5 & 4 & 0.5 & 475.750 & 475.000 & 0.750 \\
\hline 7/29/02 & BG & A2 & 4 & E8L1R200 & 8 & 1 & 200 & 1172 & 0.5 & 1.27 & 0.5 & 5 & 0.5 & 475.000 & 474.310 & 0.690 \\
\hline 7/29/02 & $B G$ & A2 & 5 & E8L1R200 & 8 & 1 & 200 & 1172 & 0.5 & 1.27 & 0.5 & 5 & 0.5 & 474.310 & 473.580 & 0.730 \\
\hline 7/29/02 & BG & A2 & 6 & E8L1R200 & 8 & 1 & 200 & 1172 & 0.5 & 1.27 & 0.5 & 5 & 0.5 & 473.580 & 472.920 & 0.660 \\
\hline 7/30/02 & $B G$ & A3 & 9 & E8L1R200 & 8 & 1 & 200 & 1184 & 0.5 & 1.27 & 0.5 & 3 & 1.5 & 422.610 & 422.070 & 0.540 \\
\hline 7/30/02 & BG & A3 & 1 & E8L1R200 & 8 & 1 & 200 & 1184 & 0.5 & 1.27 & 0.5 & 2 & 0.5 & 425.840 & 425.440 & 0.400 \\
\hline 7/30/02 & $B G$ & A3 & 2 & E8L1R200 & 8 & 1 & 200 & 1184 & 0.5 & 1.27 & 0.5 & 2 & 1 & 425.440 & 425.040 & 0.400 \\
\hline 7/30/02 & $B G$ & A3 & 3 & E8L1R200 & 8 & 1 & 200 & 1184 & 0.5 & 1.27 & 0.5 & 2 & 1 & 425.040 & 424.650 & 0.390 \\
\hline 7/30/02 & $B G$ & A3 & 4 & E8L1R200 & 8 & 1 & 200 & 1184 & 0.5 & 1.27 & 0.5 & 2 & 1 & 424.650 & 424.220 & 0.430 \\
\hline 7/30/02 & BG & A3 & 5 & E8L1R200 & 8 & 1 & 200 & 1184 & 0.5 & 1.27 & 0.5 & 1 & 0 & 424.220 & 423.980 & 0.240 \\
\hline 7/30/02 & $B G$ & A3 & 6 & E8L1R200 & 8 & 1 & 200 & 1184 & 0.5 & 1.27 & 0.5 & 3 & 1 & 423.980 & 423.640 & 0.340 \\
\hline 7/30/02 & BG & A3 & 7 & E8L1R200 & 8 & 1 & 200 & 1184 & 0.5 & 1.27 & 0.5 & 3 & 1.5 & 423.640 & 423.160 & 0.480 \\
\hline 7/30/02 & $B G$ & A3 & 8 & E8L1R200 & 8 & 1 & 200 & 1184 & 0.5 & 1.27 & 0.5 & 3 & 1.5 & 423.160 & 422.610 & 0.550 \\
\hline 7/30/02 & $B G$ & A4 & 1 & E8L1R200 & 8 & 1 & 200 & 1184 & 0.5 & 1.27 & 0.5 & 4 & 1.5 & 452.820 & 452.240 & 0.580 \\
\hline 7/30/02 & $B G$ & A4 & 2 & E8L1R200 & 8 & 1 & 200 & 1184 & 0.5 & 1.27 & 0.5 & 4 & 1.5 & 452.240 & 451.670 & 0.570 \\
\hline 7/30/02 & $B G$ & A4 & 3 & E8L1R200 & 8 & 1 & 200 & 1184 & 0.5 & 1.27 & 0.5 & 4 & 1.5 & 451.670 & 451.310 & 0.360 \\
\hline 7/30/02 & $B G$ & A4 & 4 & E8L1R200 & 8 & 1 & 200 & 1184 & 0.5 & 1.27 & 0.5 & 5 & 1.5 & 451.310 & 450.570 & 0.740 \\
\hline 7/30/02 & $B G$ & A4 & 5 & E8L1R200 & 8 & 1 & 200 & 1184 & 0.5 & 1.27 & 0.5 & 5 & 1.5 & 450.570 & 450.060 & 0.510 \\
\hline 7/30/02 & $B G$ & A4 & 6 & E8L1R200 & 8 & 1 & 200 & 1184 & 0.5 & 1.27 & 0.5 & 5 & 1.5 & 450.060 & 449.400 & 0.660 \\
\hline 7/30/02 & $B G$ & A4 & 7 & E8L1R200 & 8 & 1 & 200 & 1184 & 0.5 & 1.27 & 0.5 & 3 & 1 & 449.400 & 449.010 & 0.390 \\
\hline 7/30/02 & $B G$ & A4 & 8 & E8L1R200 & 8 & 1 & 200 & 1184 & 0.5 & 1.27 & 0.5 & 3 & 1 & 449.010 & 448.660 & 0.350 \\
\hline 7/30/02 & $B G$ & A4 & 9 & E8L1R200 & 8 & 1 & 200 & 1184 & 0.5 & 1.27 & 0.5 & 3 & 1 & 448.660 & 448.180 & 0.480 \\
\hline 7/30/02 & LS & T1 & 3 & E8L1R200 & 8 & 1 & 200 & 1184 & 0.5 & 1.27 & 0.5 & 2 & 0.5 & 505.080 & 505.050 & 0.030 \\
\hline 7/30/02 & LS & T1 & 4 & E8L1R200 & 8 & 1 & 200 & 1184 & 0.5 & 1.27 & 2.5 & 1 & 0 & 505.050 & 505.010 & 0.040 \\
\hline 7/30/02 & LS & T1 & 1 & E8L1R200 & 8 & 1 & 200 & 1184 & 0.5 & 1.27 & 0.5 & 2 & 0.5 & 505.100 & 505.090 & 0.010 \\
\hline 7/30/02 & LS & T1 & 2 & E8L1R200 & 8 & 1 & 200 & 1184 & 0.5 & 1.27 & 1 & 2 & 0.5 & 505.090 & 505.080 & 0.010 \\
\hline 7/30/02 & $\mathrm{SH}$ & 1 & 1 & E8L1R100 & 8 & 1 & 100 & 694 & 0.5 & 1.27 & 0.5 & 2 & 0.5 & 280.660 & 280.200 & 0.460 \\
\hline 7/30/02 & $\mathrm{SH}$ & 1 & 2 & E8L1R100 & 8 & 1 & 100 & 694 & 0.5 & 1.27 & 0.5 & 2 & 0.5 & 280.200 & 279.740 & 0.460 \\
\hline 7/30/02 & $\mathrm{SH}$ & 1 & 3 & E8L1R100 & 8 & 1 & 100 & 694 & 0.5 & 1.27 & 0.5 & 2 & 0.5 & 279.740 & 279.370 & 0.370 \\
\hline 7/30/02 & $\mathrm{SH}$ & 1 & 4 & E8L1R100 & 8 & 1 & 100 & 694 & 0.5 & 1.27 & 0.5 & 3 & 0.5 & 279.370 & 278.860 & 0.510 \\
\hline 7/30/02 & $\mathrm{SH}$ & 1 & 5 & E8L1R100 & 8 & 1 & 100 & 694 & 0.5 & 1.27 & 0.5 & 3 & 0.5 & 278.860 & 278.170 & 0.690 \\
\hline 7/30/02 & $\mathrm{SH}$ & 1 & 6 & E8L1R100 & 8 & 1 & 100 & 694 & 0.5 & 1.27 & 0.5 & 3 & 0.5 & 278.170 & 277.600 & 0.570 \\
\hline $7 / 30 / 02$ & $\mathrm{SH}$ & 1 & & E8L1R100 & 8 & 1 & 100 & 694 & 0.5 & 1.27 & 2.5 & 1 & 0 & 460.140 & 459.380 & 0.760 \\
\hline
\end{tabular}

Appendix A 


\section{Table A-2: Multiple Spots, Repeated Bursts-Nd:YAG laser}

Limestone was not tested on the Nd:YAG laser.

Laser parameters are:

1. Wavelength $=1.06$ micrometers

2. Maximum average power 1.6 kilowatts

Laser schedule can be converted to pulse information:

1. $\mathrm{E}=$ pulse peak power in kilowatts

2. $\mathrm{L}=$ pulse width at half peak height in milliseconds

3. $\mathrm{R}=$ pulse rate in $\mathrm{Hz}$ 


\begin{tabular}{|c|c|c|c|c|c|c|c|c|c|c|c|c|c|c|c|c|c|c|c|c|}
\hline Test Date & \begin{tabular}{|c} 
Sample \\
Lithology
\end{tabular} & \begin{tabular}{|l|} 
Disk \\
Label
\end{tabular} & $\begin{array}{c}\text { Test } \\
\#\end{array}$ & $\begin{array}{c}\text { Laser } \\
\text { Schedule }\end{array}$ & $\begin{array}{c}\text { Measured } \\
\text { Average } \\
\text { Power } \\
\text { (W) }\end{array}$ & \begin{tabular}{|l|} 
Spot \\
Size \\
$(\mathrm{cm})$
\end{tabular} & $\begin{array}{l}\text { Spot } \\
\text { Area } \\
\left(\mathrm{cm}^{2}\right)\end{array}$ & \begin{tabular}{|c|} 
Power \\
Density \\
$\left(\mathrm{W} / \mathrm{cm}^{2}\right)$
\end{tabular} & \begin{tabular}{|l} 
Burst \\
Length \\
$(\mathrm{sec})$
\end{tabular} & $\begin{array}{l}\text { Number } \\
\text { of Spots }\end{array}$ & \begin{tabular}{|c|} 
Separation \\
Between \\
Spot \\
Centers \\
$(\mathrm{cm})$
\end{tabular} & $\begin{array}{l}\text { Number } \\
\text { of Bursts } \\
\text { per Spot }\end{array}$ & \begin{tabular}{|c|} 
Total \\
Number \\
of Burst
\end{tabular} & $\begin{array}{c}\text { Focusing } \\
\text { System } \\
\text { Drop } \\
(\mathrm{mm})\end{array}$ & \begin{tabular}{|c|} 
Positioner \\
Displacement \\
Time $(\mathrm{sec})$
\end{tabular} & $\begin{array}{c}\text { Weight } \\
\text { Before } \\
\text { Lasing }(\mathrm{g})\end{array}$ & \begin{tabular}{|c|} 
Weight \\
After \\
Lasing (g)
\end{tabular} & $\begin{array}{c}\text { Delta } \\
\text { Weight } \\
\text { (g) }\end{array}$ & \begin{tabular}{|c|} 
Bulk \\
Density \\
(g/cc)
\end{tabular} & comments \\
\hline $7 / 31 / 02$ & $\mathrm{BG}$ & A10 & 1 & \begin{tabular}{|l|l|} 
E8L1R200 \\
\end{tabular} & 1210 & 1.27 & 1.27 & 955 & 0.5 & 3 & 1.10 & 6 & 18 & 0 & 0.5 & 442.98 & 439.58 & 3.400 & 2.15 & \\
\hline $7 / 31 / 02$ & $\mathrm{BG}$ & A10 & 2 & \begin{tabular}{|l|} 
E8L1R200 \\
\end{tabular} & 1210 & \begin{tabular}{|l|}
1.27 \\
\end{tabular} & 1.27 & 955 & 0.5 & 3 & 1.10 & 6 & 18 & 1.6 & 0.5 & 439.58 & 436.53 & 3.050 & 2.15 & \\
\hline $8 / 1 / 02$ & $\mathrm{BG}$ & A11 & 1 & \begin{tabular}{|l|l} 
E8L1R200 \\
\end{tabular} & 1160 & 1.27 & 1.27 & 916 & 0.5 & 3 & 1.10 & 10 & 30 & 0 & 0.5 & 450.84 & 445.87 & 4.970 & 2.15 & \\
\hline $8 / 1 / 02$ & BG & A11 & 2 & E8L1R200 & 1160 & 1.27 & 1.27 & 916 & 0.5 & 3 & 1.10 & 15 & 45 & 0 & 0.5 & 445.87 & 440.25 & \begin{tabular}{|l|}
5.620 \\
\end{tabular} & 2.15 & \\
\hline $8 / 1 / 02$ & $\overline{B G}$ & A12 & 1 & \begin{tabular}{|l|} 
E8L1R200 \\
\end{tabular} & 1160 & 1.27 & 1.27 & 916 & 0.5 & 3 & 1.10 & 15 & 45 & 0 & 0.5 & 472.87 & 466.35 & 6.520 & 2.15 & $\begin{array}{l}\text { hole depth: } 0.62 \\
\text { inch }\end{array}$ \\
\hline $8 / 1 / 02$ & BG & A12 & 2 & \begin{tabular}{|l|} 
E8L1R200 \\
\end{tabular} & 1160 & 1.27 & 1.27 & 916 & 0.5 & 3 & 1.10 & 15 & 45 & 0.5 & 0.5 & 466.35 & 459.67 & 6.680 & 2.15 & $\begin{array}{l}\text { hole depth: } \\
0.57 \text { inch }\end{array}$ \\
\hline $8 / 1 / 02$ & BG & A13 & 1 & \begin{tabular}{|l|} 
E8L1R200 \\
\end{tabular} & 1160 & 1.27 & 1.27 & 916 & 0.5 & 3 & 1.10 & 30 & 90 & 0.25 & 0.5 & 450.65 & 439.34 & 11.310 & 2.15 & \\
\hline $8 / 1 / 02$ & $\overline{\mathrm{BG}}$ & A13 & 2 & \begin{tabular}{|l|} 
E8L1R200 \\
\end{tabular} & 1160 & 1.27 & 1.27 & 916 & 0.5 & 3 & 1.10 & 30 & 90 & 0.25 & 0.5 & 439.26 & 432.28 & \begin{tabular}{|l|}
6.980 \\
\end{tabular} & 2.15 & $\begin{array}{l}\text { the sample was } \\
\text { fixed to prevent } \\
\text { it from shifting } \\
\text { position }\end{array}$ \\
\hline $8 / 1 / 02$ & $\mathrm{BG}$ & A14 & 1 & \begin{tabular}{|l|l} 
E8L1R200 \\
\end{tabular} & 1160 & 1.27 & 1.27 & 916 & 0.5 & 4 & 1.10 & 10 & 40 & 0 & 0.5 & 480.7 & 473.92 & 6.780 & 2.15 & $\begin{array}{l}\text { parallelogram } \\
\text { shape }\end{array}$ \\
\hline $8 / 1 / 02$ & BG & A14 & 2 & \begin{tabular}{|l|l} 
E8L1R200 \\
\end{tabular} & 1160 & 1.27 & 1.27 & 916 & 0.5 & 4 & 1.10 & 10 & 40 & 0 & 0.25 & 473.88 & 467.72 & 6.160 & 2.15 & $\begin{array}{l}\text { same as } \\
\text { previous shot } \\
\text { but faster }\end{array}$ \\
\hline $7 / 30 / 02$ & $\overline{B G}$ & A5 & 1 & \begin{tabular}{|l|} 
E8L1R200 \\
\end{tabular} & 1184 & 1.27 & 1.27 & 935 & 0.5 & 2 & 1.10 & 2 & 4 & 0 & 0.5 & 460.14 & 459.38 & 0.760 & 2.15 & \\
\hline $7 / 30 / 02$ & $\mathrm{BG}$ & A5 & 2 & \begin{tabular}{|l|l} 
E8L1R200 \\
\end{tabular} & 1184 & 1.27 & 1.27 & 935 & 0.5 & 2 & 1.10 & 3 & 6 & 0 & 0.5 & 459.38 & 458.41 & 0.970 & 2.15 & \\
\hline $7 / 30 / 02$ & $\overline{B G}$ & A5 & 3 & \begin{tabular}{|l|} 
E8L1R200 \\
\end{tabular} & 1184 & 1.27 & 1.27 & 935 & 0.5 & 2 & 1.10 & 4 & 8 & 0 & 0.5 & 458.35 & 457.46 & 0.890 & 2.15 & melting \\
\hline $7 / 30 / 02$ & $\overline{\mathrm{BG}}$ & A5 & 4 & E8L1R200 & 1184 & 1.27 & 1.27 & 935 & 0.5 & 2 & 1.27 & 8 & 16 & 0 & 0.5 & 457.42 & 456.82 & 0.600 & 2.15 & \\
\hline $7 / 30 / 02$ & $\overline{\mathrm{BG}}$ & A5 & 5 & E8L1R200 & 1184 & 1.27 & 1.27 & 935 & 0.5 & 2 & 1.10 & 5 & 10 & 0 & 0.5 & 456.84 & 456.21 & 0.630 & 2.15 & \\
\hline $7 / 30 / 02$ & $\overline{B G}$ & A5 & 6 & E8L1R200 & 1184 & 1.27 & 1.27 & 935 & 0.5 & 2 & 1.10 & 5 & 10 & 0 & 0.5 & 456.21 & 455.52 & \begin{tabular}{|l|}
0.690 \\
\end{tabular} & 2.15 & \\
\hline $7 / 30 / 02$ & $\overline{\mathrm{BG}}$ & A5 & 7 & E8L1R200 & 1184 & 1.27 & 1.27 & 935 & 0.5 & 2 & 1.10 & 5 & 10 & 0 & 0.5 & 455.52 & 454.67 & 0.850 & 2.15 & \\
\hline $7 / 30 / 02$ & $\overline{B G}$ & A5 & 8 & \begin{tabular}{|l|} 
E8L1R200 \\
\end{tabular} & 1184 & 1.27 & 1.27 & 935 & 0.5 & 2 & 1.10 & 10 & 20 & 0 & 0.5 & 454.67 & 454.2 & 0.470 & 2.15 & \\
\hline $7 / 31 / 02$ & $\mathrm{BG}$ & A6 & 1 & E8L1R200 & 1210 & 1.27 & 1.27 & 955 & 0.5 & 2 & 1.00 & 2 & 4 & 0 & 0.5 & 451.37 & 450.66 & 0.710 & 2.15 & $\begin{array}{l}\text { ridge almost } \\
\text { gone }\end{array}$ \\
\hline $7 / 31 / 02$ & $\mathrm{BG}$ & A6 & 2 & \begin{tabular}{|l|l} 
E8L1R200 \\
\end{tabular} & 1210 & 1.27 & 1.27 & 955 & 0.5 & 2 & 1.00 & 3 & 6 & 0 & 0.5 & 450.66 & 449.45 & 1.210 & 2.15 & ridge gone \\
\hline $7 / 31 / 02$ & $\mathrm{BG}$ & A6 & 3 & \begin{tabular}{|l|l|} 
E8L1R200 \\
\end{tabular} & 1210 & \begin{tabular}{|l|}
1.27 \\
\end{tabular} & \begin{tabular}{|l|}
1.27 \\
\end{tabular} & 955 & 0.5 & 2 & 1.00 & 4 & 8 & 0 & 0.5 & 449.54 & 448.69 & 0.850 & 2.15 & \\
\hline $7 / 31 / 02$ & $\overline{\mathrm{BG}}$ & A6 & 4 & \begin{tabular}{|l|} 
E8L1R200 \\
\end{tabular} & 1210 & \begin{tabular}{|l|}
1.27 \\
\end{tabular} & \begin{tabular}{|l|}
1.27 \\
\end{tabular} & 955 & 0.5 & 2 & 1.00 & 5 & 10 & 0 & 0.5 & 448.69 & 447.54 & \begin{tabular}{|l|}
1.150 \\
\end{tabular} & 2.15 & \\
\hline \multirow[t]{2}{*}{$7 / 31 / 02$} & $\overline{B G}$ & A6 & 5 & \begin{tabular}{|l|} 
E8L1R200 \\
\end{tabular} & 1210 & 1.27 & \begin{tabular}{|l|}
1.27 \\
\end{tabular} & 955 & 0.5 & 2 & 1.10 & 3 & 6 & 1.6 & 0.5 & 447.54 & 446.71 & 0.830 & 2.15 & \\
\hline & $\mathrm{BG}$ & A6 & 6 & E8L1R200 & 1210 & 1.27 & \begin{tabular}{|l|}
1.27 \\
\end{tabular} & 955 & 0.5 & 3 & 1.10 & 2 & 6 & 0 & 0.5 & 446.71 & 445.58 & 1.130 & 2.15 & \\
\hline $7 / 31 / 02$ & $\overline{B G}$ & A6 & 7 & E8L1R200 & 1210 & 1.27 & 1.27 & 955 & 0.5 & 3 & 1.10 & 2 & 6 & 0 & 0.5 & 445.58 & 444.75 & 0.830 & 2.15 & near edge \\
\hline \begin{tabular}{|l|}
$7 / 31 / 02$ \\
\end{tabular} & $\mathrm{BG}$ & A6 & 8 & E8L1R200 & 1210 & 1.27 & 1.27 & 955 & 0.5 & 3 & 1.10 & 2 & 6 & 0 & 0.5 & 444.75 & 443.61 & 1.140 & 2.15 & near center \\
\hline \begin{tabular}{|l|}
$7 / 31 / 02$ \\
\end{tabular} & $\overline{B G}$ & A6 & 9 & E8L1R200 & 1210 & 1.27 & \begin{tabular}{|l|}
1.27 \\
\end{tabular} & 955 & 0.5 & 3 & 1.10 & 2 & 6 & 0 & 0.5 & 443.61 & 442.46 & 1.150 & 2.15 & near center \\
\hline \begin{tabular}{|l|}
$7 / 31 / 02$ \\
\end{tabular} & $\overline{B G}$ & A7 & 1 & E8L1R200 & 1210 & 1.27 & 1.27 & 955 & 0.5 & 3 & 1.10 & 3 & 9 & 0 & 0.5 & 445.17 & 443.09 & 2.080 & 2.15 & $\begin{array}{l}\text { triangle at the } \\
\text { center }\end{array}$ \\
\hline
\end{tabular}

Appendix A

A:4 


\begin{tabular}{|c|c|c|c|c|c|c|c|c|c|c|c|c|c|c|c|c|c|c|c|c|}
\hline $7 / 31 / 02$ & BG & A7 & 2 & E8L1R200 & 1210 & 1.27 & 1.27 & 955 & 0.5 & 3 & 1.10 & 3 & 9 & 0 & 0.5 & 443.09 & 441.27 & 1.820 & 2.15 & $\begin{array}{l}\text { triangle at } \\
\text { center of rock }\end{array}$ \\
\hline $7 / 31 / 02$ & BG & A8 & 1 & E8L1R200 & 1210 & 1.27 & 1.27 & 955 & 0.5 & 3 & 1.10 & 4 & 12 & 0 & 0.5 & 402.45 & 400.69 & 1.760 & 2.15 & $\begin{array}{l}\text { too close to } \\
\text { edge }\end{array}$ \\
\hline $7 / 31 / 02$ & BG & A8 & 2 & E8L1R200 & 1210 & 1.27 & \begin{tabular}{|l|}
1.27 \\
\end{tabular} & 955 & 0.5 & 3 & 1.10 & 4 & 12 & 0 & 0.5 & 400.69 & 398.39 & 2.300 & 2.15 & $\begin{array}{l}\text { near center, no } \\
\text { melt }\end{array}$ \\
\hline $7 / 31 / 02$ & BG & A8 & 3 & E8L1R200 & 1210 & 1.27 & \begin{tabular}{|l|}
1.27 \\
\end{tabular} & 955 & 0.5 & 3 & 1.10 & 4 & 12 & 0 & 0.5 & 398.39 & 396.17 & 2.220 & 2.15 & $\begin{array}{l}\text { near center, no } \\
\text { melt }\end{array}$ \\
\hline $7 / 31 / 02$ & BG & A8 & 4 & E8L1R200 & 1210 & 1.27 & 1.27 & 955 & 0.5 & 3 & 1.10 & 5 & 15 & 0 & 0.5 & 396.17 & 393.23 & 2.940 & 2.15 & $\begin{array}{l}\text { near center, no } \\
\text { melt }\end{array}$ \\
\hline $7 / 31 / 02$ & BG & A8 & 5 & E8L1R200 & 1210 & 1.27 & \begin{tabular}{|l|}
1.27 \\
\end{tabular} & 955 & 0.5 & 3 & 1.10 & 5 & 15 & 0 & 0.5 & 393.23 & 390.63 & 2.600 & 2.15 & \\
\hline $7 / 31 / 02$ & BG & A9 & 1 & E8L1R200 & 1210 & 1.27 & 1.27 & 955 & 0.5 & 3 & 1.10 & 6 & 18 & 0 & 0.5 & 482.5 & 480.51 & 1.990 & 2.15 & $\begin{array}{l}\text { spot size too } \\
\text { small by } \\
\text { mistake. } \\
\text { Melted material }\end{array}$ \\
\hline $7 / 31 / 02$ & BG & A9 & 2 & E8L1R200 & 1210 & 1.27 & \begin{tabular}{|l|}
1.27 \\
\end{tabular} & 955 & 0.5 & 3 & 1.10 & 6 & 18 & 0 & 0.5 & 480.51 & 477.35 & 3.160 & 2.15 & \\
\hline $8 / 1 / 02$ & $\mathrm{SH}$ & $1 \mathrm{D}$ & 1 & E8L1R200 & 1160 & 1.27 & 1.27 & 916 & 0.5 & 3 & 1.10 & 2 & 6 & 0 & 0.5 & 209.43 & 207.95 & 1.480 & 2.36 & melting \\
\hline $8 / 1 / 02$ & $\mathrm{SH}$ & $1 \mathrm{D}$ & 2 & E8L1R200 & 1160 & \begin{tabular}{|l|}
1.27 \\
\end{tabular} & \begin{tabular}{|l|}
1.27 \\
\end{tabular} & 916 & 0.5 & 3 & 1.10 & 3 & 9 & 0 & 0.5 & 207.95 & 205.05 & 2.900 & 2.36 & \\
\hline $8 / 1 / 02$ & $\mathrm{SH}$ & $3 \mathrm{D}$ & 1 & E8L1R200 & 1160 & 1.27 & 1.27 & 916 & 0.5 & 3 & 1.10 & 4 & 12 & 0 & 0.5 & 221.97 & 218.73 & 3.240 & 2.36 & $\begin{array}{l}\text { little melting, } \\
\text { hole depth: } \\
0.257 \text { inch }\end{array}$ \\
\hline $8 / 1 / 02$ & $\mathrm{SH}$ & $3 \mathrm{D}$ & 2 & E8L1R200 & 1160 & 1.27 & 1.27 & 916 & 0.5 & 3 & 1.10 & 6 & 18 & 0 & 0.5 & 218.73 & 213.97 & 4.760 & 2.36 & $\begin{array}{l}\text { no melt, hole } \\
\text { depth: } 0.429 \\
\text { inch }\end{array}$ \\
\hline $8 / 2 / 02$ & $\mathrm{SH}$ & $4 \mathrm{D}$ & 1 & E8L1R200 & 1130 & 1.27 & 1.27 & 892 & 0.5 & 3 & 1.10 & 10 & 30 & 0 & 0.5 & 252.7 & 250.89 & 1.810 & 2.36 & \begin{tabular}{|l|} 
experiment \\
stopped. \\
Problem with \\
purging system \\
\end{tabular} \\
\hline $8 / 2 / 02$ & $\mathrm{SH}$ & $4 \mathrm{D}$ & 2 & E8L1R200 & 1130 & 1.27 & 1.27 & 892 & 0.5 & 3 & 1.10 & 6 & 18 & 0 & 0.5 & 250.89 & 247.72 & 3.170 & 2.36 & holes at center \\
\hline $8 / 2 / 02$ & $\mathrm{SH}$ & $5 \mathrm{D}$ & 1 & E8L1R200 & 1130 & 1.27 & 1.27 & 892 & 0.5 & 3 & 1.10 & 10 & 30 & 0 & 0.5 & 245.1 & 237.87 & 7.230 & 2.36 & $\begin{array}{l}\text { hole depth: } \\
0.595\end{array}$ \\
\hline $8 / 2 / 02$ & $\mathrm{SH}$ & $6 \mathrm{D}$ & 1 & E8L1R200 & 1130 & 1.27 & 1.27 & 892 & 0.5 & 3 & 1.10 & 15 & 45 & 0 & 0.5 & 213.65 & 208.55 & 5.100 & 2.36 & $\begin{array}{l}\text { hole depth: } \\
\text { 0.53: sample } \\
\text { thickness: } 0.838\end{array}$ \\
\hline $8 / 2 / 02$ & $\mathrm{SH}$ & $7 \mathrm{D}$ & 1 & E8L1R200 & 1130 & 1.27 & 1.27 & 892 & 0.5 & 3 & 1.10 & 15 & 45 & 0 & 0.5 & 266.14 & 260.08 & 6.060 & 2.36 & $\begin{array}{l}\text { terribly } \\
\text { important } \\
\text { sample. Pieces } \\
\text { of iron were not } \\
\text { removed from } \\
\text { hole. Hole } \\
\text { depth: } 0.637 \\
\text { inch }\end{array}$ \\
\hline $8 / 2 / 02$ & $\mathrm{SH}$ & $\mathrm{D}$ & 5 & E8L1R200 & 1130 & 1.27 & 1.27 & 892 & 0.5 & 1 & 1.10 & 32 & 32 & 0 & 0.5 & 237.87 & & & 2.36 & $\begin{array}{l}\text { The purpose of } \\
\text { this shot is to } \\
\text { drill a hole } \\
\text { using a single } \\
\text { spot. }\end{array}$ \\
\hline
\end{tabular}




\section{Table A-3: CO2 Multiple Spot Tests}

Limestone and sandstone were tested on the $\mathrm{CO} 2$ laser

Laser Parameters are:

1. Wavelength

2. Maximum CW Power

3. Maximum Peak Power

4. Pulse Width Range

5. Pulse Frequency
$10.6 ? \mathrm{~m}$

$6.0 \mathrm{~kW}\left(\mathrm{TEM}_{20}\right)$

4 times $\mathrm{CW}$ output

$50-500 \mu \mathrm{s}$

$0-25 \mathrm{kHz}$
$1.8 \mathrm{~kW}\left(\mathrm{TEM}_{00}\right)$ 


\begin{tabular}{|c|c|c|c|c|c|c|c|c|c|c|c|c|c|c|}
\hline Lithology & $\begin{array}{c}\text { Disk } \\
\text { Number }\end{array}$ & Prep Date & Test \# & \begin{tabular}{|l|} 
spot \\
size \\
$(\mathrm{cm})$
\end{tabular} & $\begin{array}{l}\text { average } \\
\text { power } \\
\text { (w) }\end{array}$ & $\begin{array}{l}\text { number } \\
\text { of spots }\end{array}$ & \begin{tabular}{|c|} 
distance \\
between \\
spots $(\mathrm{cm})$
\end{tabular} & $\begin{array}{c}\text { number } \\
\text { of bursts } \\
\text { per spot }\end{array}$ & \begin{tabular}{|c|} 
total \\
number of \\
bursts
\end{tabular} & $\begin{array}{c}\text { burst } \\
\text { length } \\
(\mathrm{sec})\end{array}$ & $\begin{array}{l}\text { Movement } \\
\text { Time (sec) }\end{array}$ & $\begin{array}{c}\text { weight } \\
\text { before }(\mathrm{g})\end{array}$ & $\begin{array}{c}\text { weight } \\
\text { after }(\mathrm{g})\end{array}$ & $\begin{array}{c}\text { delta } \\
\text { weight } \\
(\mathrm{g})\end{array}$ \\
\hline $\mathrm{LS}$ & $\mathrm{T} 4$ & 72902 & 1 & 1.27 & 4500 & 3 & 1.1 & 1 & 3 & 0.5 & 0.5 & 482.45 & 480.73 & 1.72 \\
\hline LS & $\mathrm{T} 4$ & 72902 & 2 & 1.27 & 4500 & 3 & 1.1 & 1 & 3 & 0.5 & 0.5 & 480.73 & 479.06 & 1.67 \\
\hline LS & $\mathrm{T} 4$ & 72902 & 3 & 1.27 & 4500 & 3 & 1.1 & 1 & 3 & 0.5 & 0.5 & 479.06 & 477.42 & 1.64 \\
\hline LS & $\mathrm{T} 4$ & 72902 & 4 & 1.27 & 4500 & 3 & 1.1 & 2 & 6 & 0.5 & 0.5 & 477.34 & 474.68 & 2.66 \\
\hline LS & $\mathrm{T} 4$ & 72902 & 5 & 1.27 & 4500 & 3 & 1.1 & 2 & 6 & 0.5 & 0.5 & 474.68 & 471.88 & 2.8 \\
\hline LS & $\mathrm{T} 4$ & 72902 & 6 & 1.27 & 4500 & 3 & 1.1 & 2 & 6 & 0.5 & 0.5 & 471.88 & 469.13 & 2.75 \\
\hline LS & T5 & 72902 & 1 & 1.27 & 4500 & 3 & 1.1 & 3 & 9 & 0.5 & 0.5 & 504.69 & 500.36 & 4.33 \\
\hline LS & T5 & 72902 & 2 & 1.27 & 4500 & 3 & 1.1 & 4 & 12 & 0.5 & 0.5 & 500.36 & 495.25 & 5.11 \\
\hline LS & T5 & 72902 & 3 & 1.27 & 3000 & 3 & 1.1 & 1 & 3 & 0.5 & 0.5 & 495.25 & 494.41 & 0.84 \\
\hline LS & T5 & 72902 & 4 & 1.27 & 3000 & 3 & 1.1 & 1 & 3 & 0.5 & 0.5 & 494.31 & 493.3 & 1.01 \\
\hline LS & T5 & 72902 & 5 & 1.27 & 3000 & 3 & 1.1 & 1 & 3 & 0.5 & 0.5 & 493.3 & 492.39 & 0.91 \\
\hline LS & T5 & 72902 & 6 & \begin{tabular}{|l|}
1.27 \\
\end{tabular} & 3000 & 3 & 1.1 & 2 & 6 & 0.5 & 0.5 & 492.39 & 491 & 1.39 \\
\hline LS & T6 & 72902 & 1 & 1.27 & 3000 & 3 & 1.1 & 2 & 6 & 0.5 & 0.5 & 504.26 & 503.08 & 1.18 \\
\hline LS & T6 & 72902 & 2 & 1.27 & 3000 & 3 & 1.1 & 2 & 6 & 0.5 & 0.5 & 503.08 & 501.85 & 1.23 \\
\hline LS & T6 & 72902 & 3 & 1.27 & 3000 & 3 & 1.1 & 3 & 9 & 0.5 & 0.5 & 501.84 & 500.58 & 1.26 \\
\hline LS & T6 & 72902 & 4 & 1.27 & 3000 & 3 & 1.1 & 4 & 12 & 0.5 & 0.5 & 500.58 & 498.75 & 1.83 \\
\hline LS & T6 & 72902 & 5 & 1.27 & 2160 & 3 & 1.1 & 1 & 3 & 0.5 & 0.5 & 498.75 & 498.42 & 0.33 \\
\hline LS & T6 & 72902 & 6 & 1.27 & 2160 & 3 & 1.1 & 1 & 3 & 0.5 & 0.5 & 498.42 & 498.11 & 0.31 \\
\hline LS & T9 & 72902 & 1 & 1.27 & 2160 & 3 & 1.1 & 1 & 3 & 0.5 & 0.5 & 502.45 & 502.05 & 0.4 \\
\hline LS & T9 & 72902 & 2 & 1.27 & 2160 & 3 & 1.1 & 2 & 6 & 0.5 & 0.5 & 502.05 & 501.45 & 0.6 \\
\hline LS & T9 & 72902 & 3 & 1.27 & 2160 & 3 & 1.1 & 2 & 6 & 0.5 & 0.5 & 501.45 & 500.9 & 0.55 \\
\hline LS & T9 & 72902 & 4 & 1.27 & 2160 & 3 & 1.1 & 2 & 6 & 0.5 & 0.5 & 500.86 & 500.23 & 0.63 \\
\hline LS & T9 & 72902 & 5 & 1.27 & 2210 & 3 & 1.1 & 3 & 9 & 0.5 & 0.5 & 500.23 & 499.4 & 0.83 \\
\hline LS & T9 & 72902 & 6 & 1.27 & 2210 & 3 & 1.1 & 4 & 12 & 0.5 & 0.5 & 499.4 & 498.33 & 1.07 \\
\hline LS & $\mathrm{T} 7$ & $\begin{array}{c}072902, \\
\text { saturated in } \\
\text { water for } 1 \mathrm{hr} \text {. }\end{array}$ & 1 & 1.27 & 2160 & 3 & 1.1 & 2 & 6 & 0.5 & 0.5 & 506.41 & 505.78 & 0.63 \\
\hline BG & 12 & S & 1 & 1.27 & 2210 & 3 & 1.1 & 1 & 3 & 0.5 & 0.5 & 421.89 & 419.83 & 2.06 \\
\hline BG & 12 & S & 2 & 1.27 & 2210 & 3 & 1.1 & 2 & 6 & 0.5 & 0.5 & 419.83 & 416.07 & 3.76 \\
\hline BG & 12 & $S$ & 3 & 1.27 & 2210 & 3 & 1.1 & 3 & 9 & 0.5 & 0.5 & 416.07 & 411.37 & 4.7 \\
\hline
\end{tabular}

Appendix A 


\begin{tabular}{|l|l|l|l|l|l|l|l|l|l|l|l|l|l|l|}
\hline BG & 11 & S (Saturated) & 1 & 1.27 & 2210 & 3 & 1.1 & 1 & 3 & 0.5 & 0.5 & 578.21 & 576.04 & 2.17 \\
\hline BG & 11 & S (Saturated) & 2 & 1.27 & 2210 & 3 & 1.1 & 2 & 6 & 0.5 & 0.5 & 576.04 & 573.22 & 2.82 \\
\hline BG & 11 & S (Saturated) & 3 & 1.27 & 2210 & 3 & 1.1 & 3 & 9 & 0.5 & 0.5 & 573.22 & 568.41 & 4.81 \\
\hline BG & 11 & S (Saturated) & 4 & 1.27 & 2210 & 3 & 1.1 & 1 & 3 & 0.5 & 0.5 & 568.33 & 566.77 & 1.56 \\
\hline BG & 11 & S (Saturated) & 5 & 1.27 & 2210 & 3 & 1.1 & 2 & 6 & 0.5 & 0.5 & 566.6 & 563.08 & 3.52 \\
\hline
\end{tabular}




\section{Table A-4: Perforation Simulation Tests}

Laser: $\mathrm{CO}_{2}$ laser at $10.6 \mu \mathrm{m}$ wavelength

Continuous wavelength at $\mathrm{TEM}_{20}$ mode

Purge gas: $99.99 \%$ nitrogen at 200 - 400 PSI

Purging method: I: Two 60 degree side tubes

II: Tube moved with the beam circularly and adjustable vertically between the bursts

III: Tube stationary inside the hole and adjustable between bursts

Perforation method: I: Fixed beam

II: Circular motion beam

III: Rotary rock

\begin{tabular}{|l|l|l|l|l|l|l|l|l|l|}
\hline $\begin{array}{l}\text { Sample } \\
\#\end{array}$ & $\begin{array}{l}\text { Prep } \\
\text { date }\end{array}$ & $\begin{array}{l}\text { Perforation } \\
\text { method }\end{array}$ & $\begin{array}{l}\text { Purge } \\
\text { method } \\
\text { size } \\
\text { (in) }\end{array}$ & $\begin{array}{l}\text { Beam } \\
\text { size } \\
\text { (in) }\end{array}$ & $\begin{array}{l}\text { Average } \\
\text { power } \\
\text { (W) }\end{array}$ & $\begin{array}{l}\text { Hole } \\
\text { depth } \\
\text { (in) }\end{array}$ & $\begin{array}{l}\text { Laser } \\
\text { on } \\
\text { time } \\
\text { (Sec) }\end{array}$ & Note \\
\hline SHCT & $8 / 2 / 03$ & I & I & 1 & 1 & 4000 & 1 & 14 & $\begin{array}{l}\text { Bottom } \\
\text { melted }\end{array}$ \\
\hline SH10d & $8 / 2 / 03$ & I & I & 1 & 1 & 4000 & 0.915 & 10 & \\
\hline Sh8d & $8 / 14 / 02$ & I & I & 1 & 1 & 4630 & 1 & 5 & \\
\hline BGB3 & $8 / 14 / 02$ & I & I & 1 & 1 & 4630 & 1.8 & 11 & \\
\hline LST2 & $8 / 14 / 02$ & I & I & 0.75 & 0.75 & 4630 & 0.15 & 7.5 & $\begin{array}{l}\text { Shallow } \\
\text { hole }\end{array}$ \\
\hline LST2 & $8 / 14 / 02$ & I & I & 0.25 & 0.25 & 4630 & 0.5 & 4.5 & $\begin{array}{l}\text { Through } \\
\text { hole }\end{array}$ \\
\hline LSt & $10 / 29 / 02$ & II & II & 0.5 & 1 & 3960 & 5 & $\begin{array}{l}> \\
\text { Cracks and } \\
\text { cone- } \\
\text { shaped }\end{array}$ \\
\hline $\begin{array}{l}\text { 020503 } \\
\text { Rotary }\end{array}$ & $2 / 4 / 03$ & III & III & 0.5 & 1 & 2500 & 3.25 & 45 & $\begin{array}{l}10,000 \\
\text { degree/min }\end{array}$ \\
\hline
\end{tabular}




\section{Table A-5: Wavelength Tests}

It was difficult to find matching laser parameters for the $\mathrm{CO} 2$ and $\mathrm{Nd}$ :YAG lasers. While both are pulse capable, the methods of creating the pulses are different and the nature of the pulses are different. This test intended to use existing Nd:YAG test results, to save time, and match new $\mathrm{CO} 2$ tests where possible. The closest match available was the $\mathrm{Nd}$ :YAG results taken at E4L1R400, where the measured average power was 768-789 watts. The $\mathrm{CO} 2$ parameters used were also E4L1R400, with the measured average power at 766-802 watts. The results are shown in the following table. 


\begin{tabular}{|c|c|c|c|c|c|c|c|}
\hline \multicolumn{7}{|c|}{ Wavelength Comparison Test of CO2 and Nd:Yag laser for rock drilling } & \\
\hline \multicolumn{8}{|c|}{ Both lasers were pulsed at pulse width $1 \mathrm{~ms}$, rep rate $400 \mathrm{~Hz}$ and measured average power around $800 \mathrm{~W}$} \\
\hline $\begin{array}{l}\text { Spot size } \\
(\mathrm{cm})\end{array}$ & $\begin{array}{c}\text { exposure time } \\
(\mathrm{sec})\end{array}$ & sample \# & \begin{tabular}{|l} 
average \\
power $(W)$
\end{tabular} & $\begin{array}{l}\text { specific energy } \\
\left(\mathrm{J} / \mathrm{cm}^{3}\right.\end{array}$ & $\begin{array}{l}\text { specific energy } \\
\left(\mathrm{J} / \mathrm{cm}^{3}\right)\end{array}$ & $\begin{array}{l}\text { average power } \\
\text { (W) }\end{array}$ & sample \# \\
\hline & & \multicolumn{3}{|c|}{ CO2 Results } & \multicolumn{3}{|c|}{ Nd:YAG Results } \\
\hline \multicolumn{8}{|c|}{ Limestone } \\
\hline 0.32 & 0.5 & 702-LS-C1 & 802 & 9,586 & 14,547 & 769 & LS-A3-2 \\
\hline 0.32 & 0.5 & 702-LS-C2 & 802 & 11,288 & & & \\
\hline 0.32 & 0.5 & 702-LS-C3 & 802 & 11,077 & & & \\
\hline 0.32 & 0.5 & 702-LS-C4 & 794 & 11,297 & & & \\
\hline 0.32 & 0.5 & 702-LS-C5 & 794 & 12,114 & & & \\
\hline 0.32 & 0.5 & 702-LS-C6 & 794 & 11,070 & & & \\
\hline 0.32 & 1 & 702-LS-C7 & 802 & 16,176 & 17,600 & 769 & LS-A3-4 \\
\hline 0.32 & 1 & 702-LS-C8 & 802 & 17,442 & & & \\
\hline 0.32 & 1 & 702-LS-C9 & 802 & 11,928 & & & \\
\hline 0.32 & 1 & 702-LS-B1 & 830 & 15,620 & & & \\
\hline 0.32 & 1 & 702-LS-B2 & 830 & 16,148 & & & \\
\hline 0.32 & 1 & 702-LS-B3 & 830 & 14,467 & & & \\
\hline 0.32 & 1 & 702-LS-B4 & 794 & 15,296 & & & \\
\hline 0.32 & 1 & 702-LS-B5 & 794 & 16,925 & & & \\
\hline 0.32 & 1 & 702-LS-B6 & 794 & 15,960 & & & \\
\hline \multicolumn{8}{|c|}{ Berea sandstone } \\
\hline 1.27 & 0.5 & 702-BG-52-1 & 856 & 6,694 & 11,062 & 778 & BG-10(1) \\
\hline 1.27 & 0.5 & 702-BG-52-2 & 856 & 9,017 & 10,990 & 778 & BG-10(2) \\
\hline 1.27 & 0.5 & 702-BG-52-3 & 856 & 5,967 & 11,896 & 778 & BG-10(3) \\
\hline 1.27 & 0.5 & 702-BG-54-1 & 766 & 5,181 & & & \\
\hline 1.27 & 0.5 & 702-BG-54-2 & 766 & 5,732 & & & \\
\hline 1.27 & 0.5 & 702-BG-54-3 & 766 & 6,379 & & & \\
\hline
\end{tabular}




\begin{tabular}{|c|c|c|c|c|c|c|c|}
\hline 1.27 & 1.5 & 702-BG-53-1 & 766 & 19,004 & 12,919 & 778 & $\operatorname{bg} 9(1)$ \\
\hline 1.27 & 1.5 & 702-BG-53-2 & 766 & 21,815 & 17,220 & 778 & $\operatorname{bg} 9(2)$ \\
\hline 1.27 & 1.5 & 702-BG-53-3 & 766 & 22,901 & 41,335 & 778 & $\operatorname{bg} 9(3)$ \\
\hline 1.27 & 1.5 & 702-BG-55-1 & 863 & 17,421 & & & \\
\hline 1.27 & 1.5 & 702-BG-55-2 & 863 & 14,394 & & & \\
\hline 1.27 & 1.5 & 702-BG-55-3 & 863 & 24,112 & & & \\
\hline \multicolumn{8}{|c|}{ Shale } \\
\hline 1.27 & 0.5 & 702-SH-8-C1 & 863 & 1,598 & 1,343 & 780 & SH15A1 \\
\hline 1.27 & 0.5 & 702-SH-8-C2 & 863 & 1,710 & 1,454 & 780 & SH15A2 \\
\hline 1.27 & 0.5 & 702-SH-8-C3 & 863 & 1,575 & & & \\
\hline 1.27 & 0.5 & 702-SH-6-B1 & 809 & 1,460 & & & \\
\hline 1.27 & 0.5 & 702-SH-6-B2 & 809 & 1,457 & & & \\
\hline 1.27 & 0.5 & 702-SH-6-B3 & 809 & 1,670 & & & \\
\hline 1.27 & 1 & 702-SH-13-B1 & 863 & 3,072 & 2,064 & 780 & SH16 \\
\hline 1.27 & 1 & 702-SH-13-B2 & 863 & 3,463 & & & \\
\hline 1.27 & 1 & 702-SH-13-B3 & 863 & 2,278 & & & \\
\hline 1.27 & 1 & 702-SH-15-B1 & 809 & 2,903 & & & \\
\hline 1.27 & 1 & 702-SH-15-B2 & 809 & 2,629 & & & \\
\hline 1.27 & 1 & 702-SH-15-B3 & 809 & 3,235 & & & \\
\hline
\end{tabular}




\section{Appendix B: ANALYZING THE DATA}

One of the chief obstacles of this work is analyzing the data. There are so many factors that contribute a given result that it is extremely difficult to identify what one or two contribute to the activity occurring at any given time. The key data points can be broken into the laser parameters, the rock characteristics, the experiment design and the experiment environment.

\section{Laser Parameters}

The primary laser input parameters include:

1. average power,

2. pulse height, width and repetition rate,

3. spot area, which contributes to

4. energy density

5. duration

\section{Rock Characteristics}

The three lithologies that are the focus of the test series reported here are sandstone, limestone and shale. The differences between them can be generalized to mineralogy and grain size. There are differences within each lithology as well. The sandstone that the bulk of the tests were done on is the Berea Gray, a quarry stone known for it's homogeneity. Two shales were used, one was the same as used in the 2001 tests, and is a organic rich, dark colored claystone, while the other is quite different, much lighter in color and with more granular minerals rather than clays. The limestone also is different from the 2001 series, being also a quarry stone that seems more uniform and porous.

The characteristics of color, mineralogy, porosity, permeability, grain size distribution and other physical properties all affect the rock/laser interaction behavior.

\section{Experiment Design}

In the series of tests reported on in this report, the number of bursts, their length and the amount of time between bursts are added. In the multiple spot tests of this report, parameters added include the amount of overlap between spots and the judgment of whether the ridge in between will be removed enough to continue deeper.

\section{Experiment Environment}

In the tests performed under water, the absorption of energy by the water and the variation of the beam spot size with water thickness contribute to the difficulty.

\section{Non-quantitative Observations}

Some of the results obtained in these test series have to be reported as visual observations, there are no quantifiable results. This does not diminish their importance, as the tests are providing a basis for the engineering designs that are the next phase of this work. 
In addition to the quantifiable variables, there are the more qualitative ones, such as the presence of melting (how much and how tightly attached) and the presence of cracking after the experiment is finished. Both of these parameters affect cutting efficiency profoundly.

\section{Quantitative Observations}

The measure of efficiency used to compare effectiveness of the rock/laser interaction is called the Specific Energy $(\mathrm{SE}, \mathrm{J} / \mathrm{cc}$ ), the amount of energy required to remove a unit volume of rock. SE is calculated by Equation 1:

$$
\mathrm{SE}(\mathrm{J} / \mathrm{cc})=\mathrm{Pav} * \mathrm{t} /(\mathrm{Wd} / ?)
$$

Where SE is Specific Energy, Pav is average power, Wd is the change in weight in grams and ?

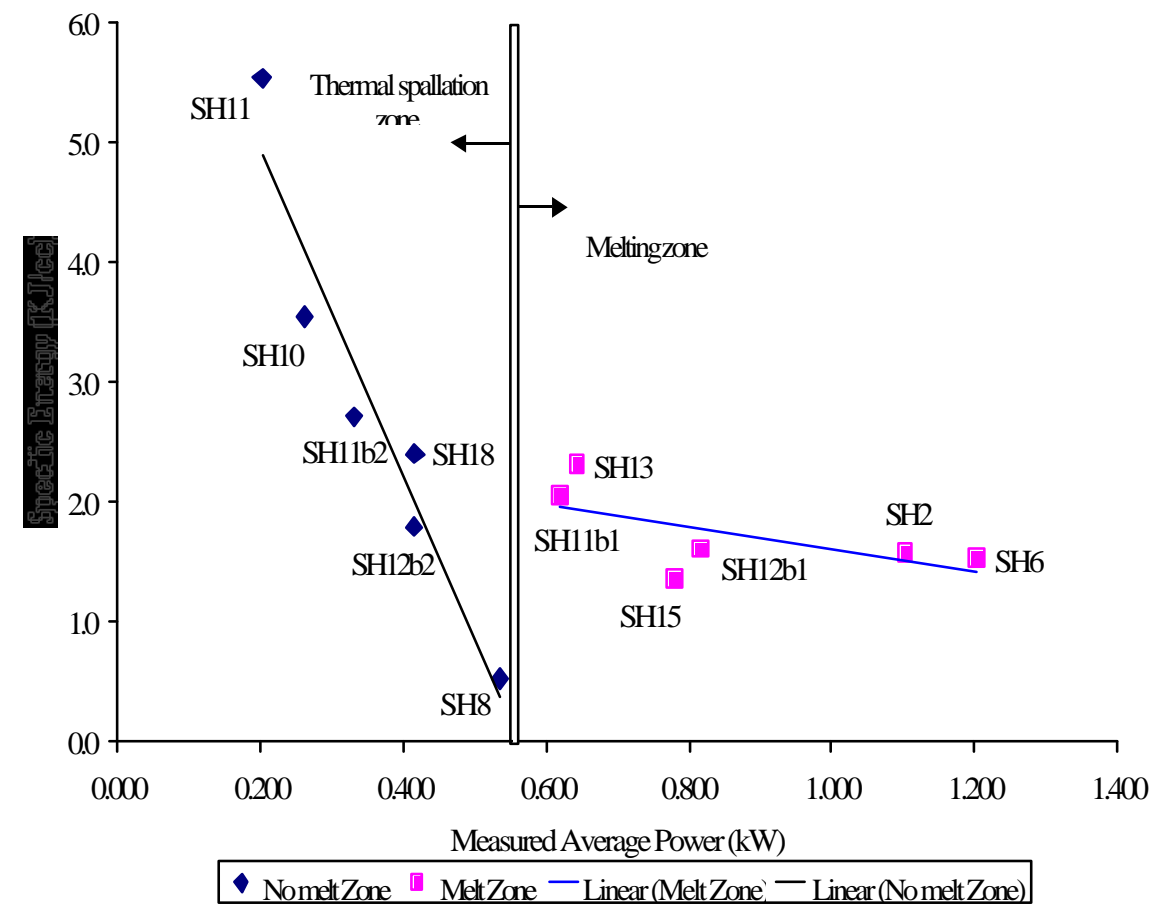

Figure B-1. Shale Specific Energy drops at a high rate with increasing average power until the onset of melting, when it increases quickly and significantly, then begins to decrease at a slower rate. All samples $\mathrm{t}=0.5$ sec, $\mathrm{A}_{\text {spot }}=1.27 \mathrm{~cm}^{2}$. From Gahan et al., 2001.

is the density of the rock $(\mathrm{g} / \mathrm{cc})$. Average power is the product of the laser pulse parameters, peak power (Pp, kilowatts), Pulse width ( $\mathrm{L}, \mathrm{msec}$ ) and repetition rate $\mathrm{R}$, per sec). In the laser programming terminology, $\mathrm{Pp}$ is $\mathrm{E}$, so a laser program will look like E8L1R200, which gives a nominal Pav of 1,600 watts $\left(8 \times 10^{3} * 1 \times 10^{-3} * 200=1,600\right.$ watts $)$. In practice, Pav is a measured value and is different from the nominal value because of differing efficiencies within the laser at different settings. $\mathrm{R}$ and $\mathrm{L}$ are accurate settings, so Pp varies with varying Pav, and is calculated from it. It is tempting to plot Specific Energy against other parameters to develop relationships. 
Some valuable insights have been revealed in this way, such as the decrease of SE with increasing average power up to the onset of melting in shale (Figure 2-1). This is also a good

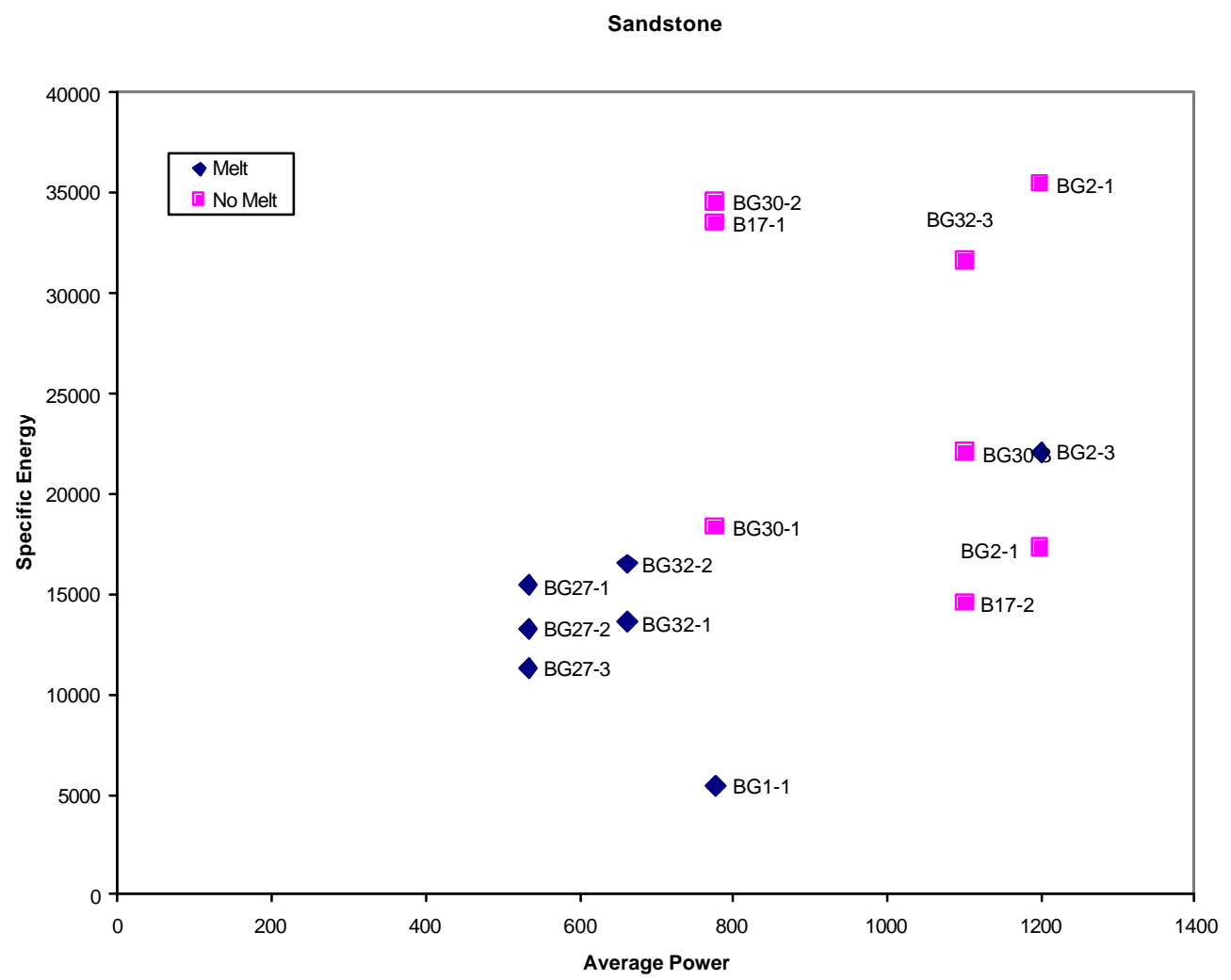

Fig. B-2: Berea Gray Sandstone tests on ND:YAG laser. Axes are the same as figure 1-3 above. Laser parameters are different, but are all the same. Spot size $=0.5$ ", duration=1.0 sec.

The separation between spalled and melted samples is not as clear as with the shale

example of the lithologic dependence of results, as such a relationship cannot be as simply demonstrated for either sandstone (Figure 2-2) and limestone. Also, since SE contains many of the input parameters, dependent relationships can be more visually obvious than they are important.

A valuable way to analyze the data is to plot the input parameters against the results. For example, the values of Total Energy (average power times duration, TE) or Total Energy Density (Total Energy/Spot Area, TED) can be plotted against the weight of rock removed (Delta Weight, Wd) and several important conclusions drawn. Constant SE lines can be drawn on the graph to show those relationships. In Excel spreadsheets, the source of the plots in this paper, various other parameters can be identified by differing colors and data point shapes in the graph. Several of these plots are shown in the Results sections of the test series chapters.

\section{Exploring an Important Dataset}

The test series for 2002 added a tremendous amount of complexity. Not only were the laser parameters varied, but the number of spots, how close they were center to center, whether the lens was held stationary or if it was moved downward while lasing, the number of bursts and how long 
the time interval between repeats were all added to the list discussed above. Trying to determine which parameter has the most effect is extremely difficult, especially since there has not been enough time to do statistically significant amounts of tests on any one set of parameters.

The following sets of charts all show the same data set, using the same variables and axes, which are the total number of bursts on the $\mathrm{x}$ axis and the Specific Energy on the $\mathrm{y}$ axis. Each chart highlights a different set of parameters. The goal of plotting the data in this way is to detect families of parameters and trends that may be extrapolated to simulate what is expected downhole.

The first chart (Figure B-3) shows immediately that the points at the low end of the $\mathrm{x}$ axis are

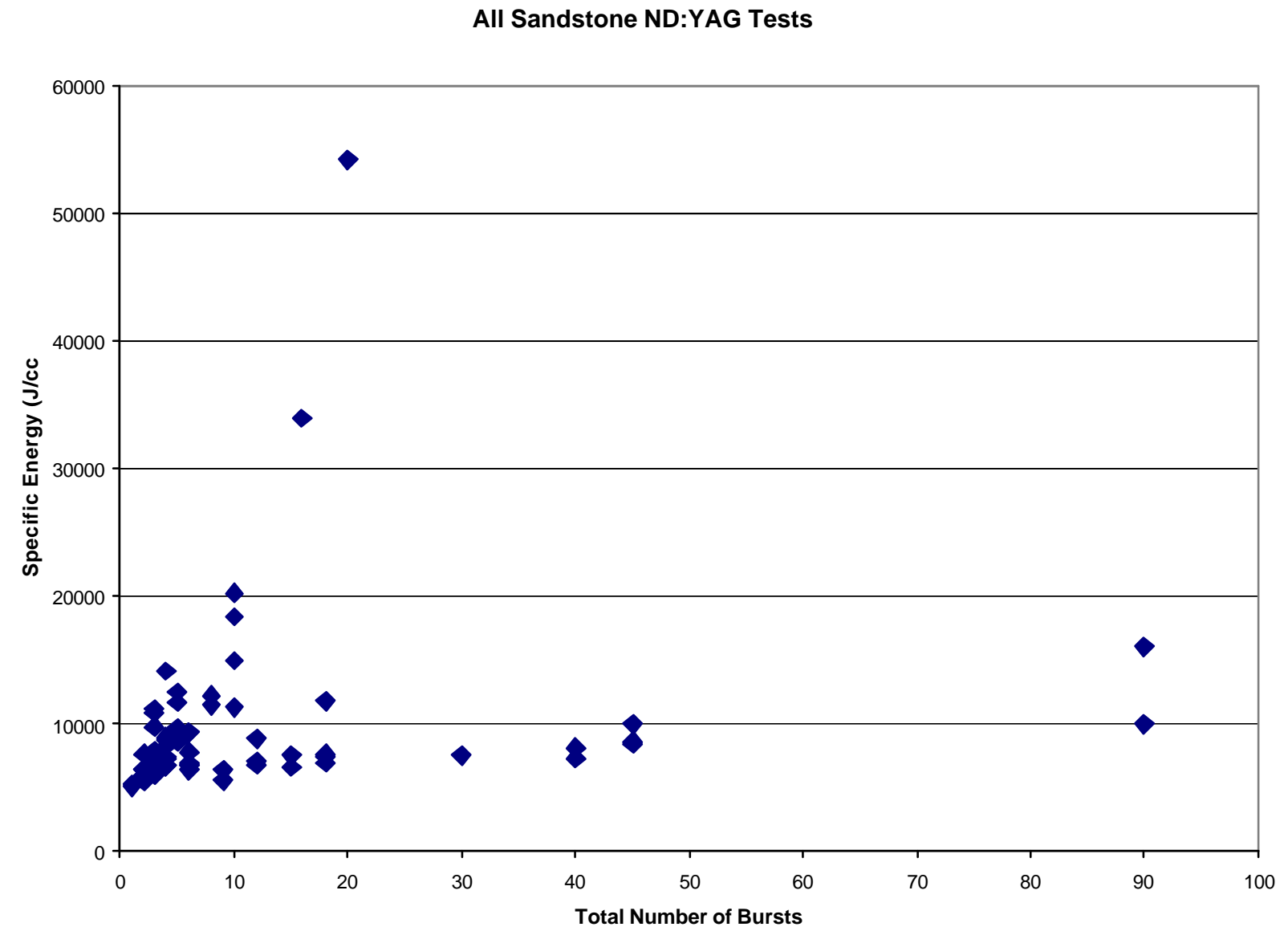

Figure B-3. All of the dry sandstone tests done on the ND:YAG are plotted in this graph. The points include one spot repeated tests, two spot tests with varying relaxation times, three and four spot tests, some with varying lens distances.

generally lower in SE and are tightly grouped, but quickly separate into two families of points as the number of bursts increase. In order to determine why this happens, it is necessary to highlight the different classes of data, such as the number of spots, the relaxation time (time before the laser hits the same spot again) or the power density (average power divided by the area of the beam). 
How Number of Spots Effect SE

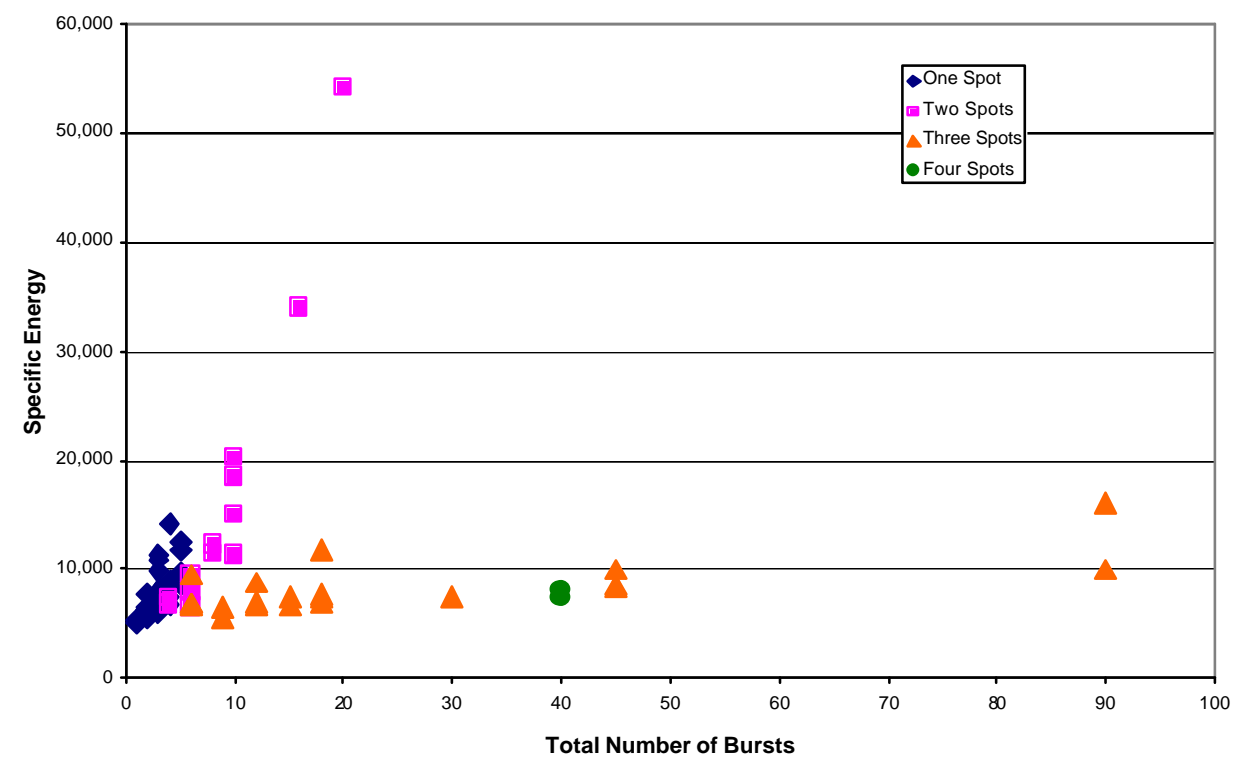

Figure B-4. The same data points as Fig. B-3 have been highlighted by the number of spots lased in each test. The two spot tests are concentrated in the spur that increases SE most rapidly with increasing bursts.

How Spot Spacing Effects SE

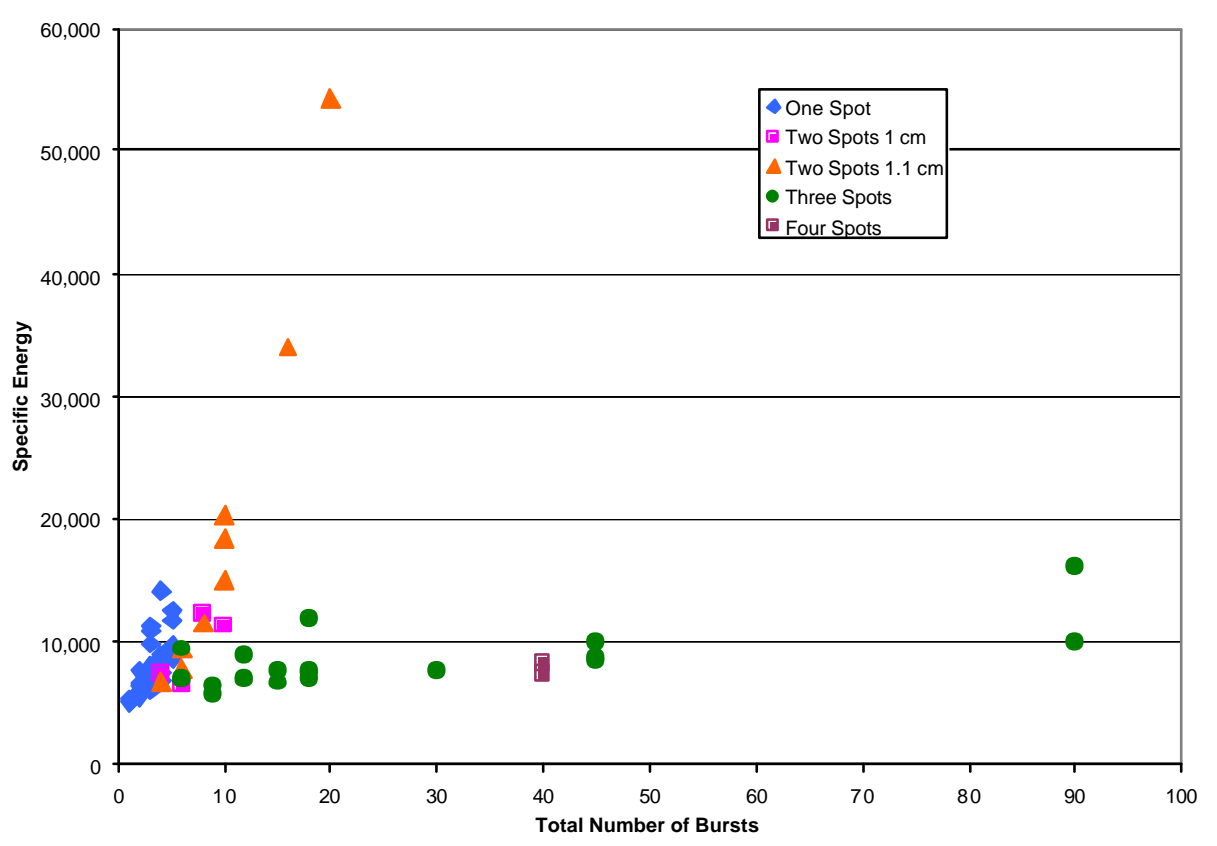

Figure B-5. The distance between spot centers, along with the spot diameter, determines the amount of overlap between shots. Some overlap is thought to be necessary to remove the ridge between spots. The spacings tested do not seem to affect SE significantly. 
When the data is separated into the number of spots lased in each test, it becomes clear that the number of spots has a large affect on the results (Figure B-4).

It is not clear from Figure B-4 why the number of holes would make a difference. Is it the overlap, two holes overlapping $6 \%$, three holes adding another $12 \%$ and four adding $6 \%$, for $24 \%$ total? This may have some significance, but before exploring this further, it is necessary to determine the importance of changing the amount of overlap in the two hole test. Figure B-5 breaks the two hole data points into the $1 \mathrm{~cm}$ and $1.1 \mathrm{~cm}$ spacing. It is clear that, at least at low numbers of repeats, that the spacing change tested was not significant.

It is also necessary to determine the importance of moving the lens downward as the test

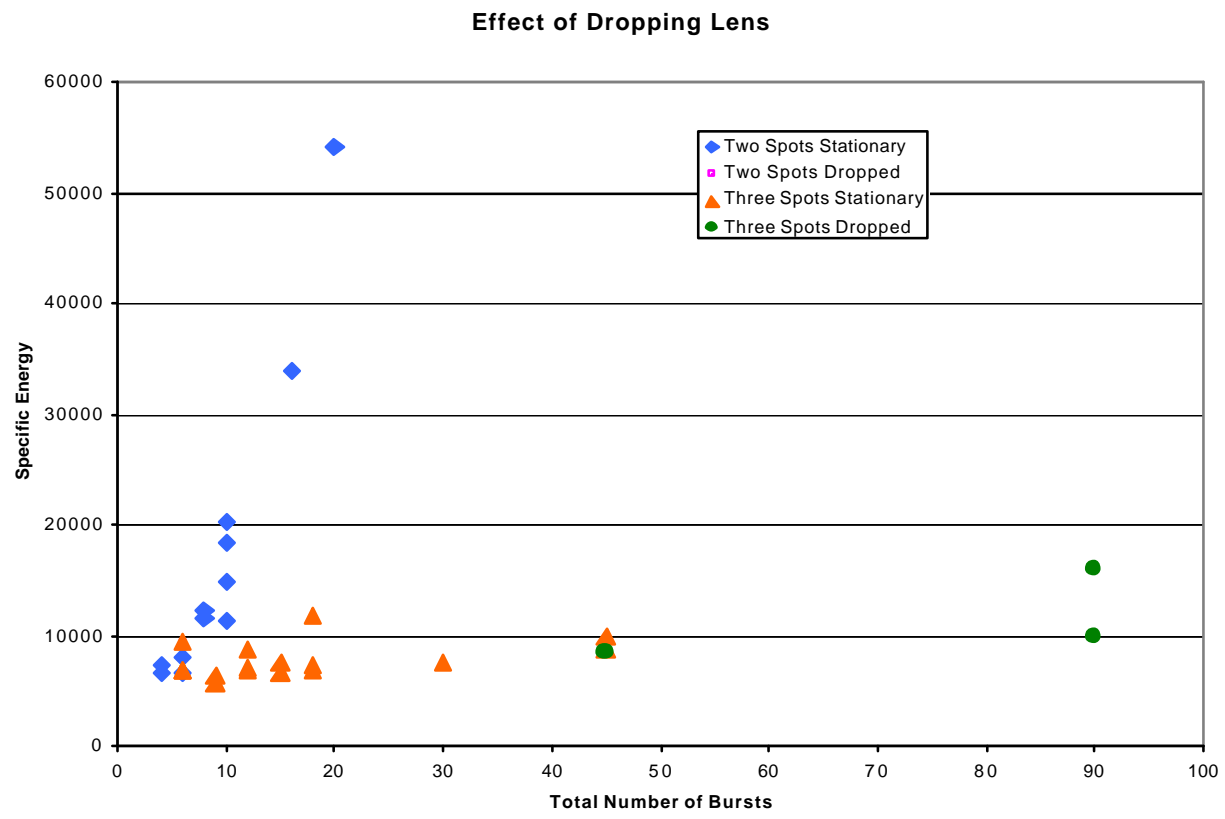

Figure B-6. The two and three spot tests included moving the lens downward as the hole deepened in an attempt to maintain a constant distance between the laser lens and the bottom of the hole. Changing the focus point did not affect the SE significantly, indicating the beam was well collimated.

proceeds, simulating the way a drilling head would be used in a hole, to keep the working face at the same distance from the optics. In Figure B-6, looking only at the two and three hole tests (the only ones where the optics were moved), there does not seem to be any difference in the two sets of data. The two hole data point is hidden behind stationary optics data point.

This analysis leaves the possibility that the relaxation time is the important factor. Relaxation time is the amount of time before the beam returns to a given spot. The one and two hole tests used multiple relaxation times between 0.5 and 1.5 seconds. The three and four hole tests did not try any times longer than the minimum imposed by the experimental design. The amount of time alloted for the stage to move the sample was kept at no less than 0.5 seconds because of the possibility of the sample shifting due to the acceleration and deceleration of the stage. In fact the sample did shift in two of the three hole tests before it was realized what was happening, but that shift was controllable. Therefore, the three hole tests had a relocation time of 2.5 seconds and the 


\section{Relaxation Time}

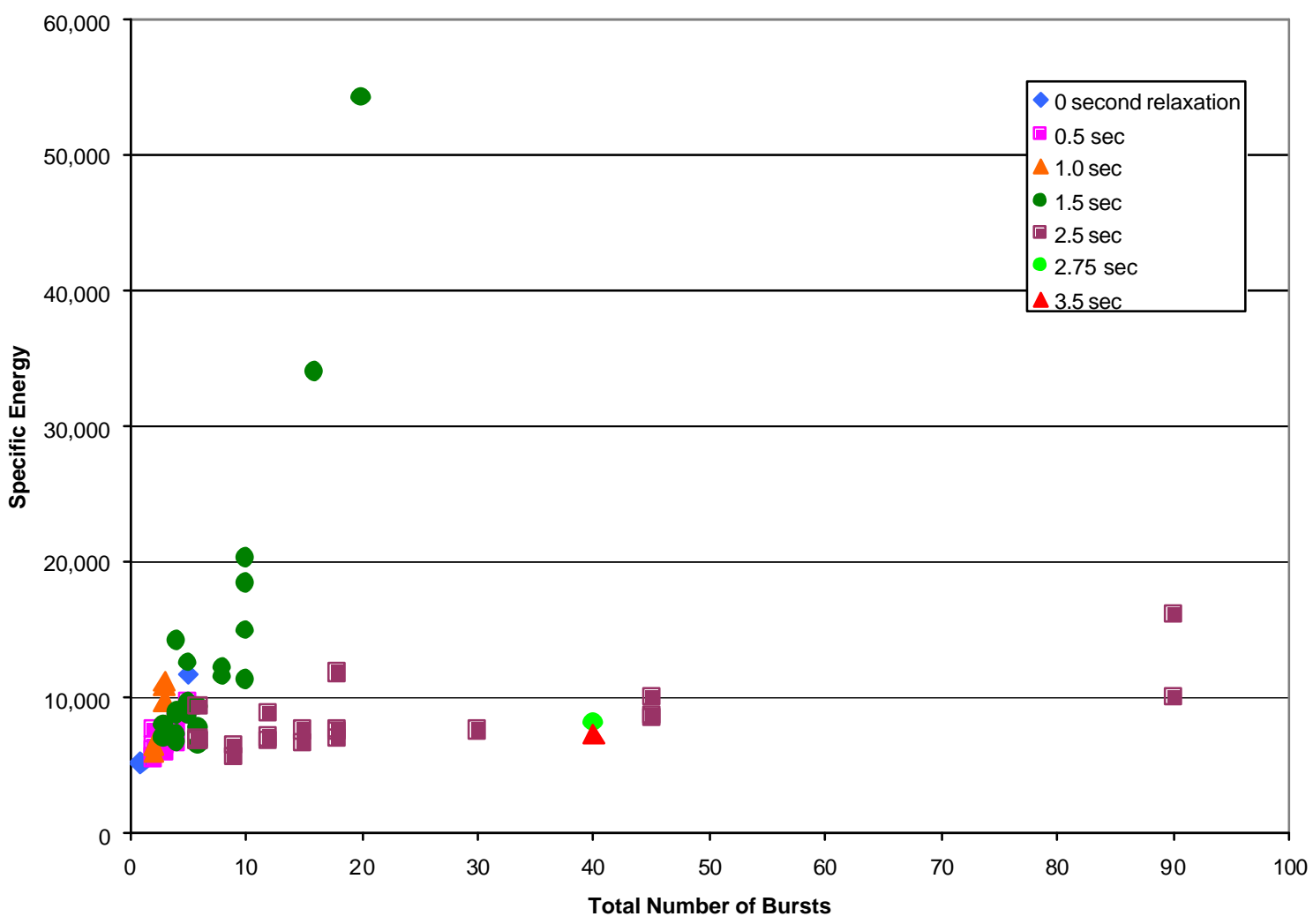

Figure B-7. To test the idea that the difference between the two spot tests and the three and four spot tests is due more to relaxation time than anything else, this plot was made disregarding the number of spots and focussing on the relaxation time. 2.5, 2.75 and 3.5 seconds all are in the same population. Between 2.5 and 1.5 seconds a significant change occurs, where relaxation time becomes very important above 10 bursts.

four hole tests of 3.5 seconds. This jump, between 1.5 seconds for the longest two hole test and the shortest three hole test, proved to be significant, as shown by Figure B-7. There does not seem to be any difference between the three hole and the four hole relaxation times. The interval between 1.5 and 2.5 seconds will have to be investigated further to set a minimum. Also, adding additional holes to make a true 7 hole pattern, as shown in the chapter on Rate of Penetration, will have to be tested to see how that changes the results.

\section{Summary}

The preceding is an attempt to show a procedure to discover the important factors that determine how rock behaves under certain lasing conditions. In the example, it can be seen that relaxation time is very important when multiple spots are lased repeatedly to create a deeper hole. This result affects strongly the rate of penetration and other expectations when assembling many fibers and lenses to make a large hole. This is just a beginning, but will help to guide future tests and the design work planned for the next year and beyond. 